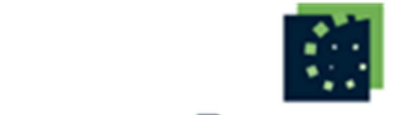

BROCKMANN Consult GMBH

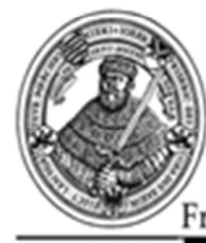

Friedrich-Schiller-Universität Jena
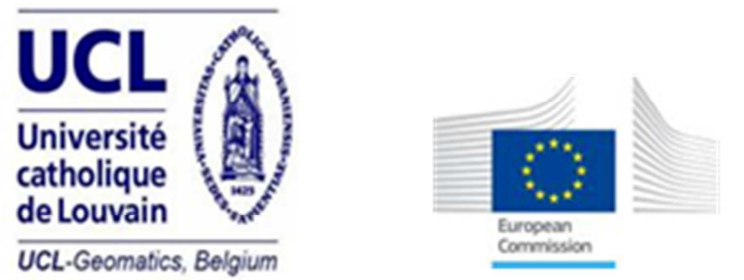

WAGENINGEN UNIVERSITY
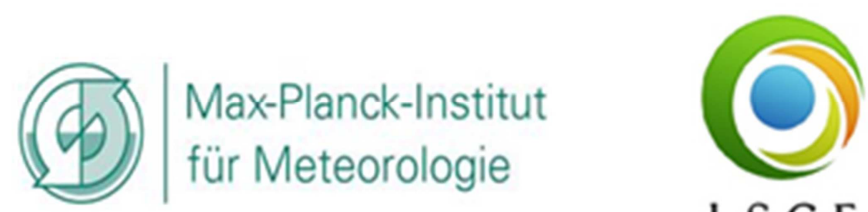

LSCE

\title{
Met Office
}

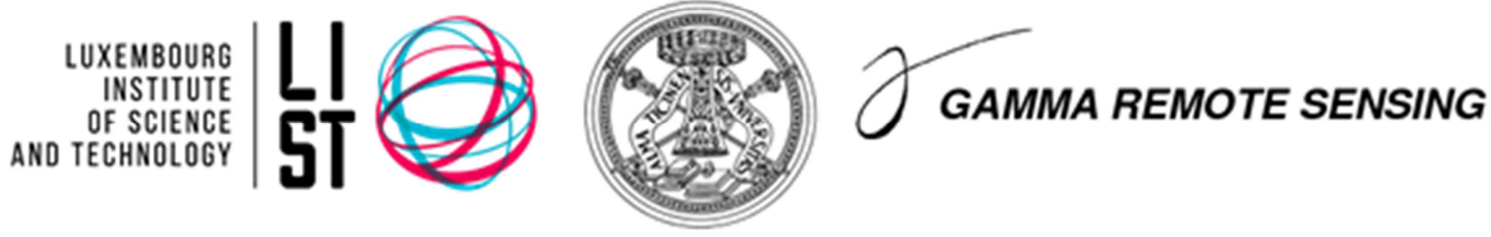

Land Cover CCI

\section{Product User GuIDE}

\section{VERSION 2.0}

DOCUMENT REF:

DELIVERABLE REF:

VERSION:

CREation Date:

LAST MODIFIED:
CCI-LC-PUGV2

D3.3

2015-09-14

2017-04-10 
This page is intentionally blank. 


\begin{tabular}{|c|c|c|c|c|}
\hline \multirow{2}{*}{ Cesa } & Ref & \multicolumn{3}{|c|}{ CCI LC PUG v2 } \\
\cline { 2 - 5 } & Issue & Page & Date & Iand couer \\
\cline { 2 - 5 } & 2.0 & 3 & $2017-04-10$ & cci \\
\hline
\end{tabular}

Document Signature Table

\begin{tabular}{|c|l|l|l|l|l|}
\hline & \multicolumn{1}{|c|}{ NAME } & FUNCTION & COMPANY & SIGNATURE & DATE \\
\hline VERIFIED & Defourny P. & Science leader & UCL & & \\
\hline PREPARED & Lamarche C. & & UCL & & \\
\hline PREPARED & Bontemps S. & & UCL & & \\
\hline PREPARED & De Maet T. & & UCL & & \\
\hline PREPARED & Van Bogaert E. & & UCL & & \\
\hline PREPARED & Moreau I. & & UCL & & \\
\hline PREPARED & Brockmann C. & & BC & & \\
\hline PREPARED & Boettcher M. & & BC & & \\
\hline PREPARED & Kirches G. & & BC & & \\
\hline PREPARED & Wevers J. & & BC & & \\
\hline PREPARED & Santoro M. & & Gamma RS & & \\
\hline
\end{tabular}

Document Versions Record

\begin{tabular}{|l|c|l|}
\hline VERSION & DATE & \multicolumn{1}{c|}{ DESCRIPTION } \\
\hline 0.1 & $2015-10-22$ & First draft version, based on Year 1 document (version 1.2) \\
\hline 1.0 & $2016-05-02$ & First version based on Phase II Year 2 \\
\hline 1.1 & $2016-06-15$ & Updated to answer CCI-LC_Ph2_M4-Deliverables_RIDs \\
\hline 2.0 & $2017-04-10$ & Version of the document representative of the CCI-LC Phase 2 products (v20.7) \\
\hline
\end{tabular}

Document Change Record (to version 2.0)

\begin{tabular}{|l|l|l|}
\hline \multicolumn{1}{|c|}{ RID } & \multicolumn{1}{|c|}{ SECTION } & \multicolumn{1}{c|}{ COMMENTS } \\
\hline- & Acronyms List & Links are waived due to their maintenance costs. \\
\hline- & Reference Document list & Links are waived due to their maintenance costs. \\
\hline & 2.0 & Updated section to be in line with Phase II products \\
\hline & 2.2 & Updated to be in line with URDv2-1.2 \\
\hline- & 2.3 & $\begin{array}{l}\text { Update related the processing chain implemented to generate the products } \\
\text { of Phase II }\end{array}$ \\
\hline & 3.1 & Updated sections to reflect the global annual LC maps from Phase II \\
\hline & N/A & A new section was created for the new WB seasonality product \\
\hline & N/A & This section was updated to reflect the product evolution in Phase II \\
\hline- & 6.0 & Update related the products of Phase II \\
\hline- & 7.3 & Update related the user tool v3.12 \\
\hline- & Appendix 4 & Update related the products of Phase II \\
\hline- & Appendix 6 & Update related the user tool v3.12 \\
\hline
\end{tabular}

Document Diffusion List

\begin{tabular}{|l|l|l|}
\hline \multicolumn{1}{|c|}{ ORGANIZATION } & \multicolumn{1}{|c|}{ NAME } & QUANTITY \\
\hline ESA & O. Arino, F. Ramoino & \\
\hline
\end{tabular}




\begin{tabular}{|c|c|c|c|c|}
\hline \multirow{2}{*}{ CeSa } & Ref & \multicolumn{2}{|c|}{ CCI LC PUG v2 } \\
\cline { 2 - 5 } & Issue & Page & Date & Iand couer \\
\cline { 2 - 5 } & 2.0 & 4 & $2017-04-10$ & Iai \\
\hline
\end{tabular}

\section{SYMBOLS AND ACRONYMS}

\begin{tabular}{|c|c|}
\hline (A)ATSR & : (Advanced) Along Track Scanning Radiometer \\
\hline API & : Application Programming Interface \\
\hline ASAR & : Advanced Synthetic Aperture Radar \\
\hline ATBD & : Algorithm Theoretical Basis Document \\
\hline AVHRR & : Advanced Very High Resolution Radiometer \\
\hline $\mathrm{BC}$ & : Brockmann-Consult \\
\hline $\mathrm{CCl}$ & : Climate Change Initiative \\
\hline $\mathrm{CCl}-\mathrm{LC}$ & : Climate Change Initiative Land Cover \\
\hline CEOS & : Committee on Earth Observation Satellites \\
\hline CEOS-WGCV & : CEOS Working Group on Calibration and Validation \\
\hline $\mathrm{CMC}$ & : Climate Modelling Community \\
\hline CMIP & : Coupled Model Intercomparison Project \\
\hline CMUG & : Climate Modelling User Group \\
\hline CRS & : Coordinate Reference System \\
\hline ECV & : Essential Climate Variable \\
\hline ERS & : European Remote Sensing Satellite \\
\hline Envisat & : Environmental Satellite \\
\hline EO & : Earth Observation \\
\hline ESA & : European Space Agency \\
\hline ET & : Evapotranspiration \\
\hline fAPAR & : Fraction-Absorbed Photosynthetically Active Radiation \\
\hline $\mathrm{FR}$ & : Full Resolution \\
\hline Gamma-RS & : Gamma Remote Sensing \\
\hline GCOS & : Global Climate Observing System \\
\hline GCS & : Global Coordinate System \\
\hline GDAL & : Geospatial Data Abstraction Library \\
\hline GFED & : Global Fire Emissions Database \\
\hline GIMMS & : Global Inventory Monitoring and Modelling System \\
\hline GIS & : Geographic Information System \\
\hline GMM & : Global Monitoring Mode \\
\hline GRASS & : Geographic Resources Analysis Support System \\
\hline IMM & : Image Mode Medium \\
\hline IPCC & : Intergovernmental Panel on Climate Change \\
\hline ISSI & : International Space Science Institute \\
\hline LAI & : Leaf Area Index \\
\hline Landsat & : Land remote sensing Satellite \\
\hline LC & : Land Cover \\
\hline LCCS & : Land Cover Classification System \\
\hline LS & : Land Surface \\
\hline MERIS & : Medium Resolution Imaging Spectrometer \\
\hline MODIS & : Moderate Resolution Imaging Spectroradiometer \\
\hline NDVI & : Normalized Difference Vegetation Index \\
\hline NIR & : Near InfraRed \\
\hline NLCD & : National Land Cover Database \\
\hline $\mathrm{OLCl}$ & : Ocean and Land Colour Instrument \\
\hline
\end{tabular}




\begin{tabular}{|c|c|c|c|c|}
\hline \multirow{2}{*}{ C CSa } & Ref & \multicolumn{3}{|c|}{ CCI LC PUG v2 } \\
\cline { 2 - 5 } & Issue & Page & Date & land couer \\
\cline { 2 - 5 } & 2.0 & 5 & $2017-04-10$ & cci \\
\hline
\end{tabular}

PFT

PROBA-V

PUG

RR

SAR

SLSTR

SPOT

SPOT-VGT

SR

SRTM

SWBD

$U C L$

UN

UNFCCC

WB

WBP

WGS84

WSM
: Plant Functional Types

: Project for On-Board Autonomy, with the $\mathrm{V}$ standing for Vegetation

: Product User Guide

: Reduced Resolution

: Synthetic Aperture Radar

: Sea and Land Surface Temperature Radiometer

: Satellite Pour l'Observation de la Terre

: SPOT- Vegetation

: Surface Reflectance

: Shuttle Radar Topography Mission

: SRTM Water Body Database

: Université catholique de Louvain

: United Nations

: United Nations Framework Convention on Climate Change

: Water Body

: Water Body Product

: World Geodetic System 84

: Wide Swath Mode 


\begin{tabular}{|c|c|c|c|c|}
\hline \multirow{2}{*}{ CeSa } & Ref & \multicolumn{2}{|c|}{ CCI LC PUG v2 } \\
\cline { 2 - 5 } & Issue & Page & Date & Iand couer \\
\cline { 2 - 5 } & 2.0 & 6 & $2017-04-10$ & Iai \\
\hline
\end{tabular}

\section{REFERENCE DOCUMENTS}

\section{Applicable documents}

\begin{tabular}{|c|c|c|c|}
\hline ID & TITLE & ISSUE & DATE \\
\hline AD.1 & $\begin{array}{l}\text { Statement of Work for ESA Climate Change Initiative Phase II - CCI-PRGM- } \\
\text { EOPS-SW-12-0012 }\end{array}$ & 1.2 & 07.06 .2013 \\
\hline AD. 2 & $\begin{array}{l}\text { ESA Climate Change Initiative Phase II - Land Cover ECV } \\
\text { Technical baseline for the project (update of the technical proposal with } \\
\text { clarification and negotiation items) }\end{array}$ & 1.0 & 13.03 .2014 \\
\hline AD. 3 & $\begin{array}{l}\text { CCI System Requirements v1, CCI-PRGM-EOPS-TN-12-0031 } \\
\text { Available on line at: http://46.137.76.174/?q=webfm_send/72. }\end{array}$ & 1.0 & 13.06 .2013 \\
\hline AD. 4 & $\begin{array}{l}\text { CCI-LC URD Phase II. Land Cover Climate Change Initiative - User } \\
\text { Requirements Document }\end{array}$ & 1.1 & 30.11 .2014 \\
\hline AD.5 & $\begin{array}{l}\text { CCI-LC PSD Phase II. Land Cover Climate Change Initiative - Product } \\
\text { Specification Document }\end{array}$ & 1.1 & 01.12 .2014 \\
\hline AD. 6 & $\begin{array}{l}\text { CCI-LC DARD Phase II. Land Cover Climate Change Initiative - Data Access } \\
\text { Requirement Document }\end{array}$ & 1.1 & 30.11 .2014 \\
\hline AD.7 & $\begin{array}{l}\text { CCI-LC ATBD Phase II. Land Cover Climate Change Initiative - Algorithm } \\
\text { Specification Document - Part I: Overview }\end{array}$ & 1.1 & 03.12 .2014 \\
\hline AD. 8 & $\begin{array}{l}\text { CCI-LC ATBD Phase II. Land Cover Climate Change Initiative - Algorithm } \\
\text { Specification Document - Part II: Pre-processing }\end{array}$ & 1.1 & 03.12 .2014 \\
\hline AD.9 & $\begin{array}{l}\text { CCI-LC ATBD Phase II v2. Land Cover Climate Change Initiative - Algorithm } \\
\text { Specification Document - Part III: LC classification }\end{array}$ & 1.2 & 13.01 .2016 \\
\hline AD.10 & $\begin{array}{l}\text { CCI-LC ATBD Phase II. Land Cover Climate Change Initiative - Algorithm } \\
\text { Specification Document - Part IV: LS seasonality }\end{array}$ & 1.1 & 03.12 .2014 \\
\hline AD.11 & $\begin{array}{l}\text { CCI-LC ATBD Phase II v2. Land Cover Climate Change Initiative - Algorithm } \\
\text { Specification Document - Part V: WB classification }\end{array}$ & 1.1 & 03.12 .2014 \\
\hline
\end{tabular}

Reference documents

ID

RD.1

RD.2

RD.3

RD.4

RD.5

RD.6

TITLE

CCI-LC URD Phase I. Land Cover Climate Change Initiative - User Requirements Document. Issue 2.2. Date 23.02.2011.

CCI-LC PSD Phase I. Land Cover Climate Change Initiative - Product Specification Document. Issue 1.11. Date 03.07.2014.

CCI-LC PVP Phase I. Land Cover Climate Change Initiative - Product Validation Plan. Issue 1.3. Date 04.07.2011.

CCI-LC ATBD Phase I. Land Cover Climate Change Initiative - Algorithm Theoretical Basis Document. Issue 2.3. Date 28.11.2013.

CCI-LC PVASR Phase I. Land Cover Climate Change Initiative - Product Validation and Algorithms Selection Report. Issue 2.2. Date 03.07.2012.

CCI-LC PUG Phase I. Land Cover Climate Change Initiative - Product User Guide. Issue 2.4. Date 02.09.2014. transmitted without the express prior written authorization of UCL-Geomatics (Belgium). 


\begin{tabular}{|c|c|c|c|c|}
\hline \multirow{2}{*}{ e ESa } & Ref & \multicolumn{3}{|c|}{ CCI LC PUG v2 } \\
\cline { 2 - 5 } & Issue & Page & Date & land couer \\
& 2.0 & 7 & $2017-04-10$ & cci \\
\hline
\end{tabular}

CCI-LC project Phase I - Production of a reference dataset for the validation of the Water body product (D3 of CCN4). Issue 1.0. Date 07.08.2013.

Di Gregorio A., 2005, UN Land Cover Classification System (LCCS) - Classification concepts and user

RD.8 manual for Software version 2. Available at: http://www.fao.org/docrep/008/y7220e/y7220e00.htm. Date 1.06.2016

Bicheron, P., Defourny, P., Brockmann, C., Schouten, L., Vancutsem, C., Huc, M., Bontemps, S., Leroy, M., Achard, F., Herold, M., Ranera, F., Arino, O. GlobCover: products description and validation report, ESA GlobCover project. Available at: http://due.esrin.esa.int/page_globcover.php. Issue 2.0. Date 05.09.2008.

Bontemps, S., Herold, M., Kooistra, L., van Groenestijn, A., Hartley, A., Arino, O., Moreau, I., and

RD.10 Defourny, P. (2012). Revisiting land cover observations to address the needs of the climate modelling community. Biogeosciences, 9, 2145-2157, doi:10.5194/bgd-9-2145-2012

RD.11 Global Mangrove Atlas. Available at: http://geodata.grid.unep.ch/results.php

RD.12 Randolph Inventory Glaciers. Available at: http://www.glims.org/RGI/

RD.13 Bontemps, S., Defourny, P., Van Bogaert, E., Kalogirou, V. and Arino, O., GlobCover 2009 - Products Description and Validation Report (2010). Available at: http://due.esrin.esa.int/page_globcover.php Committee on Earth Observation Satellites, 2008, Working Group on Information Systems and

RD.14 Services - Interoperability Handbook, February 2008 Issue 1.1. Available at: http://www.eohandbook.com/

Verhegghen A., Bontemps S. and Defourny, P., 2014. Global land-surface phenology reference dataset from 13 years NDVI and EVI SPOT VEGETATION time series analysis. International Journal of Remote Sensing, 35, 7, 2440-2471.

RD.16 NetCDF Climate and Forecast (CF) Metadata Conventions. Issue 1.5. Date 25.10.2010.

RD.17 Bennett, V, Guidelines for Data Producers - Climate Change Initiative Phase I, CCI-PRGM-EOPS-TN-110003. Issue 2.1. Date 20.03.2012.

RD.18 The Geospatial Data Abstraction Library website : http://www.gdal.org/

RD.19 The Geographic Resources Analysis Support System (GRASS GIS) website : http://grass.osgeo.org/ Kottek, M., J. Grieser, C. Beck, B. Rudolf, and F. Rubel, 2006: World Map of the Köppen-Geiger climate classification updated. Meteorol. Z., 15, 259-263. DOI: 10.1127/0941-2948/2006/0130

Farr, T. G.; Rosen, P. A.; Caro, E.; Crippen, R.; Duren, R.; Hensley, S.; Kobrick, M.; Paller, M.; Rodriguez,

RD.21 E.; Roth, L.; Seal, D.; Shaffer, S.; Shimada, J.; Umland, J.; Werner, M.; Oskin, M.; Burbank, D.; Alsdorf, D. The Shuttle Radar Topography Mission. Reviews of Geophysics 2007, 45, RG2004.

RD.22 Wessel, P.; Smith, W. A global, self-consistent, hierarchical, high-resolution shoreline database. Journal of Geophysical Research: Solid ... 1996, 101, 8741-8743.

RD.23 SCAR Antarctic Digital Database Version 6.0 http://www.add.scar.org/ (accessed Dec 21, 2015). Lamarche, C.; Santoro M.; Bontemps S.; d'Andrimont, R.; Radoux J.; Giustarini, L.; Brockmann, C.; Militzer, J.; Defourny, P.; Arino, O. (2016). Compilation and Validation of SAR and Optical Data Products for a Complete and Global Map of Inland/Ocean Water Tailored to the Climate Modeling Community. Remote Sensing.

RD.25 Defourny, P.; Mayaux, P.; Herold, M.; Bontemps, S. Global Land-Cover Map Validation Experiences : Toward the Characterization of Quantitative Uncertainty 2012.

RD.26 Carroll, M. L.; Townshend, J. R.; DiMiceli, C. M.; Noojipady, P.; Sohlberg, R. a. A new global raster water mask at 250 m resolution. International Journal of Digital Earth 2009, 2, 291-308. Hansen, M. C.; Potapov, P. V; Moore, R.; Hancher, M.; Turubanova, S. A.; Tyukavina, A.; Thau, D.; Stehman, S. V; Goetz, S. J.; Loveland, T. R.; Kommareddy, A.; Egorov, A.; Chini, L.; Justice, C. O.; Townshend, J. R. G. High-resolution global maps of 21st-century forest cover change. Science (New York, N.Y.) 2013, 342, 850-3. transmitted without the express prior written authorization of UCL-Geomatics (Belgium). 


\begin{tabular}{|c|c|c|c|c|}
\hline \multirow{2}{*}{ e ESa } & Ref & \multicolumn{2}{|c|}{ CCI LC PUG v2 } \\
\cline { 2 - 5 } & Issue & Page & Date & land couer \\
& 2.0 & 8 & $2017-04-10$ & cci \\
\hline
\end{tabular}

RD.28 body dataset for 2000: first results of a topographic-spectral classification algorithm. International Journal of Digital Earth 2015, 1-21.

RD.29 http://proba-v.vgt.vito.be/sites/default/files/PROBAV-Products_User_Manual_v1.3.pdf. Issue 1.3. Date 31.08.2015.

Pesaresi M., Ehrlich D., Ferri S., Florczyk A.J., Freire S., Halkia S., Julea A.M., Kemper T., Soille P. and V. Syrris. Operating procedure for the production of the Global Human Settlement Layer from Landsat data of the epochs 1975, 1990, 2000, and 2014. Publications Office of the European Union, EUR 27741 EN, 2016. doi: 10.2788/253582.

Sulla-Menashe, D.; Friedl, M. a.; Krankina, O. N.; Baccini, A.; Woodcock, C. E.; Sibley, A.; Sun, G.;

RD.31 Kharuk, V.; Elsakov, V. Hierarchical mapping of Northern Eurasian land cover using MODIS data. Remote Sensing of Environment 2011, 115, 392-403.

RD.32

Bartholome, E. and Belward, A., 2005, "GLC2000: a new approach to ' global land cover mapping from Earth Observation data", International Journal of Remote Sensing, 26, 1959-1977

RD.33 Timelapse Google Earth Engine website: http://world.time.com/timelapse2/

RD.34 SERVIR website. https://www.nasa.gov/mission_pages/servir/africa.html

RD.35 Global Urban Footprint, GUF; DLR 2016

Esch, T., Taubenböck, H., Roth, A., Heldens, W., Felbier, A., Thiel, M., Schmidt, M., Müller, A., Dech, S. (2012): TanDEM-X mission-new perspectives for the inventory and monitoring of global settlement patterns. Journal of Applied Remote Sensing, vol. 6, issue 1, 061702 (October 04, 2012); 21 pp., doi: 10.1117/1.JRS.6.061702

Esch, T., Marconcini, M., Felbier, A., Roth, A., Heldens, W., Huber, M., Schwinger, M., Taubenböck, H., Müller, A., Dech, S. (2013) Urban Footprint Processor - Fully Automated Processing Chain Generating

RD.37 Settlement Masks from Global Data of the TanDEM-X Mission. IEEE Geoscience and Remote Sensing Letters, Vol. 10, No. 6, November 2013. Pp. 1617-1621. ISSN 1545-598X, DOI 10.1109/LGRS.2013.2272953 Brown, L.R. Outgrowing the Earth: The Food Security Challenge in an Age of Falling Water Tables and Rising Temperatures; Earth Policy Institute: Washington, DC, USA, 2005.

Developing a Strategy for Global Agricultural Monitoring in the Framework of Group on Earth

RD.39 Observations (GEO) Workshop Report, 2007. Available online: http://www.fao.org/gtos/igol/docs/ meeting-reports/07-geo-ag0703-workshop-report-nov07.pdf (accessed on 21 August 2015). Soares, J.; Williams, M.; Jarvis, I.; Bingfang, W.; Leo, O.; Fabre, P.; Huynh, F.; Kosuth, P.; Lepoutre, D.; Parihar, J.S.; et al. Strengthening global agriculture monitoring-Improving Sustainable Data for Worldwide Food Security \& Commodity Market Transparency Proposal. The G20 Global Agricultural Monitoring Initiative, 2011. Available online:

http://www.earthobservations.org/documents/cop/ag_gams/201106_g20_global_agricultural_monit oring_initiative.pdf (accessed on 21 August 2015).

Waldner F., Fritz S., di Gregorio A., Defourny P., 2015, “Mapping Priorities to Focus Cropland Mapping

RD.41 Activities: Fitness Assessment of Existing Global, Regional and National Cropland Maps", Remote Sensing, 7, 7959-7986

RD.42

Pekel J-F., Cottam A., Gorelick N., Belward AS. High-resolution mapping of global surface water and its long-term changes. Nature. 540, 418-422 (15 December 2016). doi:10.1038/nature20584 


\begin{tabular}{|c|c|c|c|c|}
\hline \multirow{2}{*}{ CeSa } & Ref & \multicolumn{2}{|c|}{ CCI LC PUG v2 } \\
\cline { 2 - 5 } & Issue & Page & Date & 2017-04-10 \\
\cline { 2 - 5 } & 2.0 & 9 & Iand couer \\
cci
\end{tabular}

\section{TABLE OF CONTENTS}

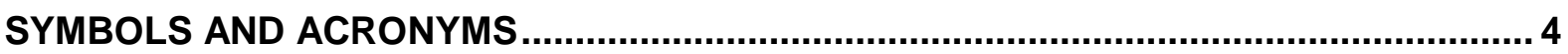

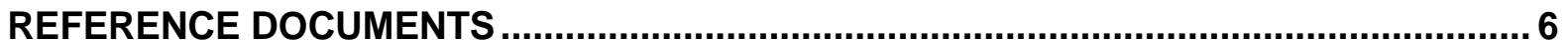

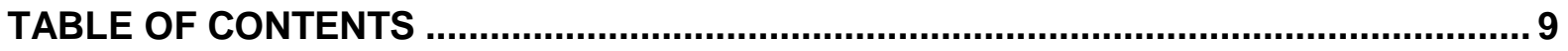

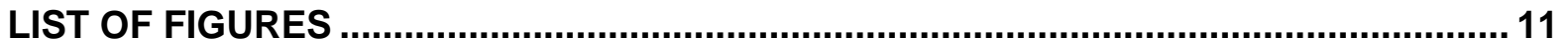

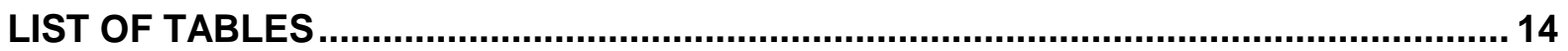

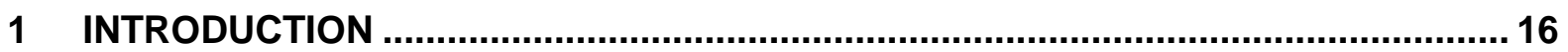

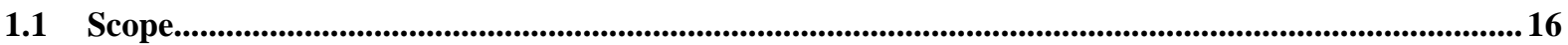

1.2 Background of the project................................................................................................................................. 16

$1.3 \quad$ Structure of the document .......................................................................................................................................... 17

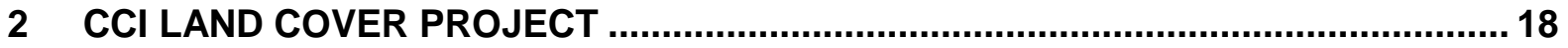

2.1 Revisited land cover concept ........................................................................................................................18

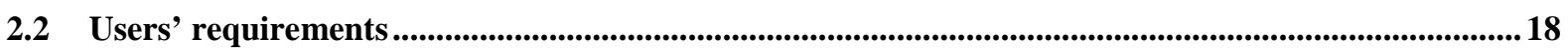

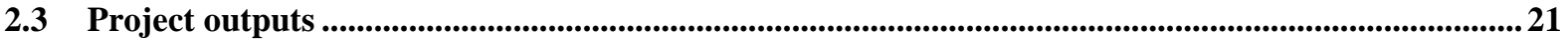

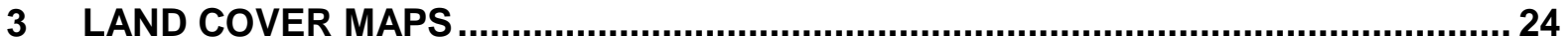

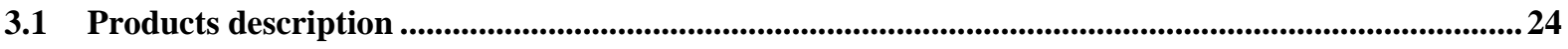

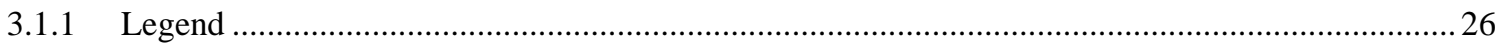

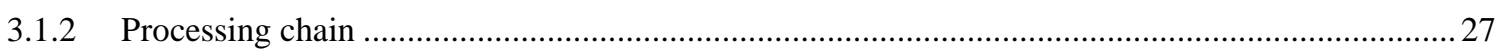

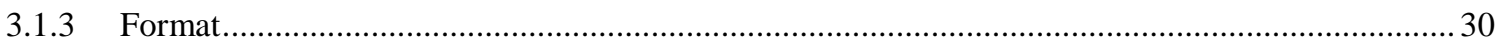

3.2 Qualitative assessment ......................................................................................................................................33

$3.3 \quad$ Validation..................................................................................................................................................................38

3.4 Limitations.................................................................................................................................................. 42

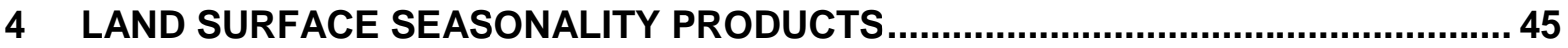

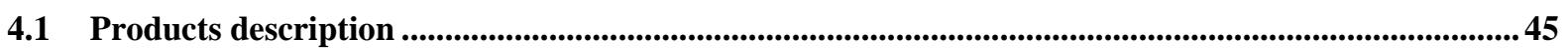

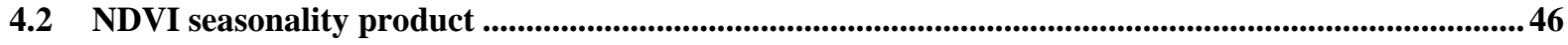

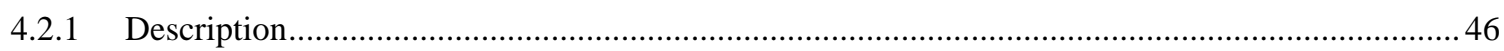

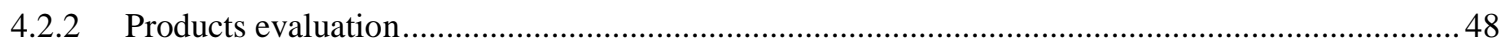




\begin{tabular}{|c|c|c|c|c|}
\hline \multirow{2}{*}{ CeSa } & Ref & \multicolumn{3}{|c|}{ CCI LC PUG v2 } \\
\cline { 2 - 5 } & Issue & Page & Date & Iand couer \\
\cline { 2 - 5 } & 2.0 & 10 & $2017-04-10$ & cci \\
\hline
\end{tabular}

4.2.3 Format 48

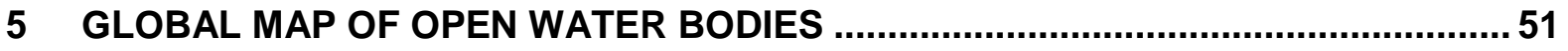

5.1 Product description ............................................................................................................................................51

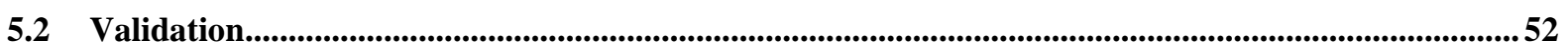

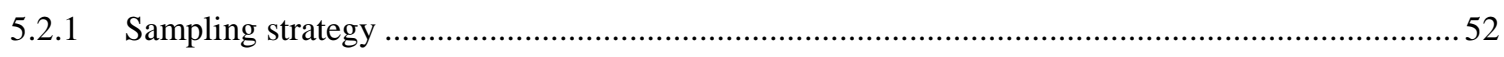

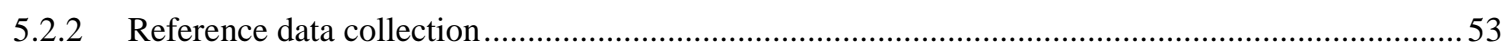

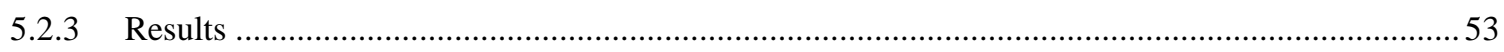

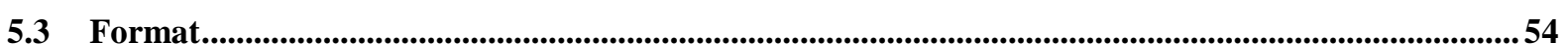

6 SURFACE REFLECTANCE PRODUCTS ......................................................... 57

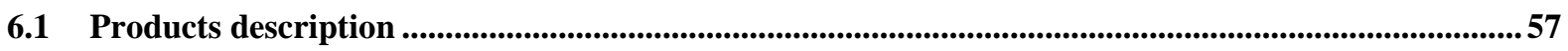

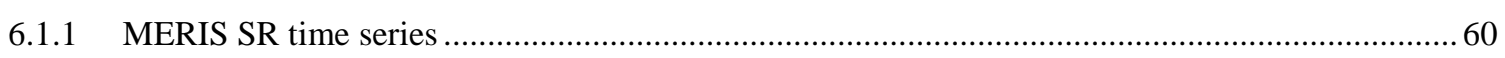

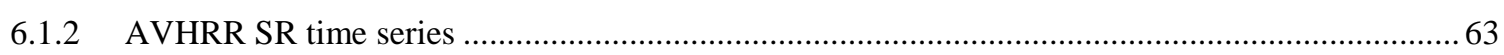

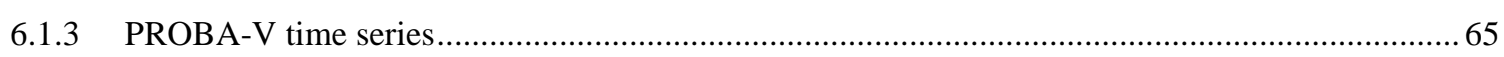

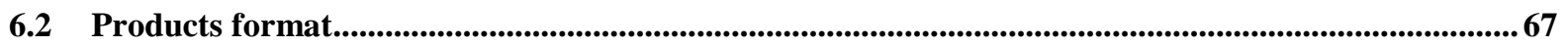

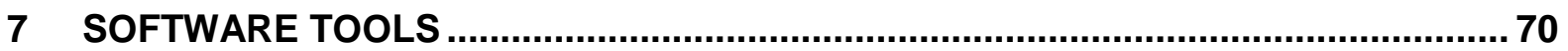

7.1 Software tools for viewing and using the CCI-LC SR 7-day composite products.................................70

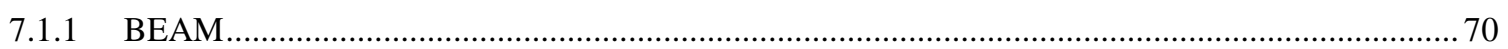

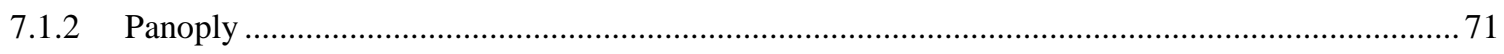

7.2 Software tools for the CCI-LC maps and seasonality products ...................................................................72

7.3 CCI-LC user tool.................................................................................................................................................... 72

7.4 Software tools for CCI-LC dataset visualization.................................................................................78

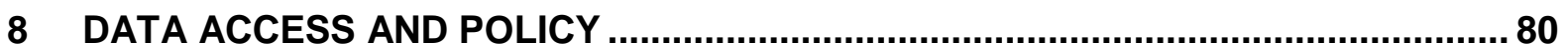

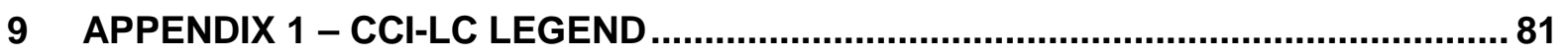

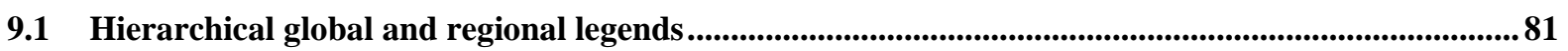

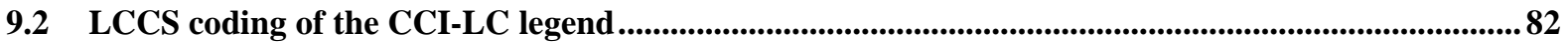

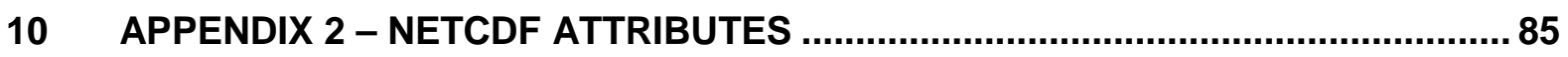

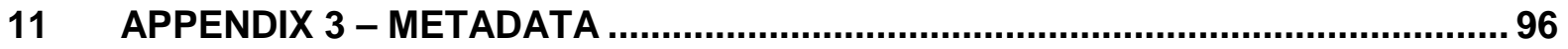

12 APPENDIX 4 - INSTRUCTION MANUAL OF THE AGGREGATION TOOL ............ 99 


\begin{tabular}{|c|c|c|c|c|}
\hline \multirow{2}{*}{ CeSa } & Ref & \multicolumn{2}{|c|}{ CCI LC PUG v2 } \\
\cline { 2 - 5 } & Issue & Page & Date & Iand couer \\
\cline { 2 - 5 } & 2.0 & 11 & $2017-04-10$ & Ici \\
\hline
\end{tabular}

\section{LIST OF FIGURES}

Figure 2-1: Threshold (minimum) and target (optimal) requirements identified for LC products in the User Requirements Survey carried out in the CCI - LC project Phases I and II. Check-marks indicate fulfilled requirements (from [AD.4]).

Figure 2-2: Planning of datasets to be produced in the CCI-LC Phase II (updated from [AD.5])

Figure 3-1: The most recent map from the LC map series from the year 2015, at $300 \mathrm{~m}$ spatial resolution.

Figure 3-2: Illustration of a sequence of the CCl global annual land cover maps for years 1992, 2000, 2004, 2007, 2011 and 2015 for an area of the Salta Province in Argentina.

Figure 3-3: Schematic representation of the CCI-LC classification chain that generates global annual LC maps. The chain is made of 2 main processes and makes use of the entire archives of Envisat MERIS (2003 -2012), AVHRR (1992 - 1999), SPOT-VGT (1999 - 2013) and PROBA-V data for 2013, 2014 and 2015.

Figure 3-4: Change detection on a pixel basis from a time series of 24 annual 1-km global classifications (1992 to 2015: AVHRR, SPOT-VGT and PROBA-V). Red arrows indicate years of change detected along the time series.

Figure 3-5: Description of the coordinate reference system defining the global LC products.

Figure 3-6: Comparison, over Russia, between the 2015 LC map (a), the CCI LC v1.6.1 from the 2010 epoch (b), the Northern Eurasia Land Cover database [RD.31] (c) and the ESRI high resolution base map layer (d).

Figure 3-7: Comparison, over Zambia, between the 2015 LC map (a), the CCI-LC v1.6.1 from the 2010 epoch (b), the SERVIR land cover of Zambia (c) and the ESRI high resolution base map layer (d).

Figure 3-8: Comparison, over Angola, between the 2015 LC map (a), the CCl-LC v1.6.1 from the 2010 epoch (b), the regional GLC2000 for Africa [RD.32] (c) and the ESRI high resolution base map layer (d).

Figure 3-9: Comparison of deforestation patterns in Brazil between annual LC maps for years 1992, 1997, 2000, 2005, 2010 and 2015 (a) and the corresponding Landsat imagery from Timelapse Google Earth Engine (b). 36

Figure 3-10: Dynamics of the Aral Sea illustrated by the CCI global annual land cover maps for years 1992, 1996, 1999, 2003, 2009 and 2015.

Figure 4-1: Average (left) and standard deviation (right) components of the NDVI Seasonality Product at 4 weeks of the year. The dates indicated in Figure A, B, C and D correspond to starting day of the 7-day composite period. White colour situated in high latitudes corresponds to NaN values [RD.15]

Figure 4-2: Detailed spatial example of NDVI seasonality profiles - average (plain line) and standard deviation (dotted line) - extracted in the region of Central Africa. The profiles are extracted from 3 pixels belonging to 3 classes of the 2010 LC state map product. The variety of the dynamic of vegetation is clearly captured. 48 


\begin{tabular}{|c|c|c|c|c|}
\hline \multirow{2}{*}{ CeSa } & Ref & \multicolumn{2}{|c|}{ CCI LC PUG v2 } & Date \\
\cline { 2 - 5 } & Issue & Page & $2017-04-10$ & $\begin{array}{l}\text { land couer } \\
\text { cci }\end{array}$ \\
\cline { 2 - 5 } & 2.0 & 12 &
\end{tabular}

Figure 5-1: River network continuity has drastically improved in the CCI-LC WBP V4.0 (left, compared to the WBP v3.0 on the right), adding high resolution WB dataset as inputs.

Figure 5-2: Illustration of the CCI-LC WBP v4.0 with distinction of the inland water from oceans.

Figure 5-3: Location of the samples of $150 \mathrm{~m} \times 150 \mathrm{~m}$ of the validation reference database and distribution in the stratification (agreement land, agreement water and discrepancies) based on the three other independent WB sources.

Figure 6-1: Description of the tiling system used for the SR products (from [RD.9] and [RD.13])

Figure 6-2: Example of CCI-LC MERIS FR SR 7-day composite, at 300m spatial resolution and tile h37v12 ESACCI-LC-L3-SR-MERIS-300m-P7D-h37v12-20050702-v1.0.nc (RGB with channels 7, 5, 2).

Figure 6-3: The CCI-LC Global Surface reflectance MERIS FR 7-day composite from the 2009-04-02 through 2009-04-08 at 300m spatial resolution (RGB with channels 7, 5, 3).

Figure 6-4: The CCI-LC Global Surface reflectance MERIS FR 7-day composite from the 2003-01-15 through 2003-01-21 at 300m spatial resolution (RGB with channels 7, 5, 3).

Figure 6-5: The CCI-LC Global Surface reflectance composite from all MERIS FR SR 7-day composites from the 2010 epoch (2008-2012), at 300m spatial resolution (RGB with channels 14, 7, 5).

Figure 6-6: Example of CCI-LC AVHRR SR 7-day composite, at 1000m spatial resolution and tile h26v18-ESACCILC-L3-SR-AVHRR-1000m-P7D-h26v18-19930521-v2.2.nc

Figure 6-7: The CCI-LC Global Surface reflectance composite from all AVHRR SR 7-day composites from 1996-0521, at 1000m spatial resolution (ESACCI-LC-L3-SR-AVHRR-1000m-P7D-h00-71v00-35-19960521-v2.2.nc) 65

Figure 6-8: Example of CCI-LC PROBA-V SR 7-day composite, at 300m spatial resolution and tile h36v13ESACCI-LC-L3-SR-VEGETATION-300m-P7D-h36V13-20150319-v2.0.nc

Figure 6-9: The CCI-LC Global Surface reflectance AVHRR composite from all SR 7-day composites from 2014-0716 to2014-09-02, at 300m spatial resolution (ESACCI-LC-L3-SR-Vegetation-300m-P7D-h00-71v00-3520140716-201400902-v2.1.nc)

Figure 7-1: Screenshot of VISAT.

Figure 7-2: Screenshot of Panoply.

Figure 7-3: Visualization of the pixel aggregation from the spatial resolution of original LC-CCI Map product into the user defined spatial resolution of the aggregated LC-CCI Map product.

Figure 7-4: Köppen-Geiger climate classification [RD.20].

Figure 7-5: Example of the aggregated global land cover map V1 obtained with the user tool. Its pixel size is 9.8 km, the majority class is 1 and the pixel value represents the LC class according to Table 7-2.

Figure 7-6: Example of an aggregated CCI Global Land Cover Map V1 obtained with the aggregation tool. Its pixel size is $9.8 \mathrm{~km}$, area of CCl-LC class - 130 - grassland. 


\begin{tabular}{|c|c|c|c|l|}
\hline \multirow{2}{*}{ Cesa } & Ref & \multicolumn{3}{|c|}{ CCI LC PUG v2 } \\
\cline { 2 - 5 } & Issue & Page & Date & Iand couer \\
\cline { 2 - 5 } & 2.0 & 13 & $2017-04-10$ & cci \\
\hline
\end{tabular}

Figure 7-7: Example of an aggregated CCI Global Land Cover Map V1 obtained with the aggregation tool. Its pixel size is $9.8 \mathrm{~km}$, area of CCI-LCPFT - natural grass.

Figure 7-8: Main page of the CCI-LC products visualization tool, with the following functionalities: top-left) LCMaps legend description; bottom-left) download of documents describing the CCI-LC products; top-left) tools box to control the zooms ( + and -), to set the view to the global extent (O) and to reach particular coordinates; top) products available for visualization; centre) visualization panel. A right click on the map activates the apparition of the LS seasonality profiles (NDVI) and highlights the LC-Map label on the left panel; top right) redirection to data download web page. Please note that a right click also shows additional profiles of the dynamics of land cover regarding the snow and burned areas occurrence. 


\begin{tabular}{|c|c|c|c|c|}
\hline \multirow{2}{*}{ C CSa } & Ref & & CCI LC PUG v2 & Date \\
\cline { 2 - 5 } & Issue & Page & $2017-04-10$ & land couer \\
\cline { 2 - 5 } & 2.0 & 14 & cci
\end{tabular}

\section{LIST OF TABLES}

Table 2-1: Summary of the CCI-LC products

Table 3-1: Level 1 (or global) legend of the CCI-LC maps, based on the UN-LCCS. ........................................26

Table 3-2: Satellite data sources used to generate the global LC maps.

Table 3-3: Correspondence between the IPCC land categories used for the change detection and the LCCS legend used in the CCI-LC classes.

Table 3-4. Components that make the name of the LC maps delivered by the CCI-LC project.

Table 3-5: Quality flags of the LC maps.

Table 3-6: Adjusted contingency matrix that considers the CCI-LC 2015 map and the "certain" ("homogeneous" and "heterogeneous") points of the GlobCover 2009 validation dataset. Green cells mark diagonal cells while yellow cells represent other samples that also mark a clear agreement between the product and the reference.

Table 3-7: Adjusted contingency matrix that considers the CCI-LC 2015 map and the "certain" and "homogeneous" points of the GlobCover 2009 validation dataset. Green cells mark diagonal cells while yellow cells represent other samples that also mark a clear agreement between the product and the reference.........40

Table 4-1: Main characteristics of the LS seasonality products.............................................................. 46

Table 4-2: The description of the 4 series layers included in the global NDVI seasonality product....................49

Table 4-3: Naming convention in the NDVI seasonality filenames........................................................5 50

Table 5-1: Spatial completeness, coverage and accuracy results of the WBP v4.0.....................................54

Table 5-2: The description of the layers included in the CCI-LC WB v4.0 product..........................................5

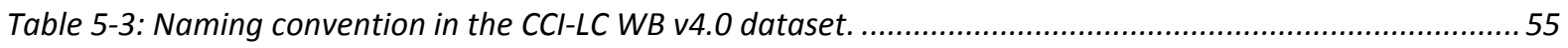

Table 6-1: Satellite data that are planned to be used to generate the CCI-LC SR time series...........................57

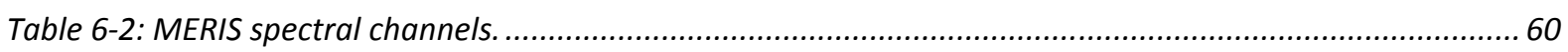

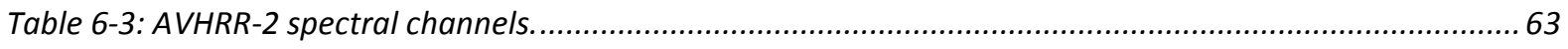

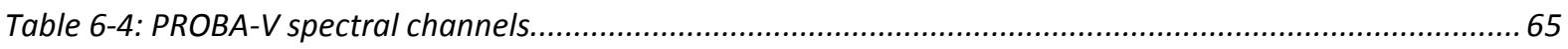

Table 6-5: Components that make the name of the SR products delivered by the CCI-LC project......................67

Table 7-1: Minimum set of projections and spatial resolutions that need to be included in the re-projection, aggregation and subset tool developed by the CCI-LC project. .... 


\begin{tabular}{|c|c|c|c|c|}
\hline \multirow{2}{*}{ CeSa } & Ref & \multicolumn{3}{|c|}{ CCI LC PUG v2 } \\
\cline { 2 - 5 } & Issue & Page & Date & Iand couer \\
\cline { 2 - 5 } & 2.0 & 15 & $2017-04-10$ & cci \\
\hline
\end{tabular}

Table 7-2: Look-up table - conversion of CCI-LC classes to PFT......

Table 10-1: Global attributes of the global 7-day SR products delivered by the CCI-LC project, according to the structure of the NetCDF files.

Table 10-2: Information related to the spatial dimension of the global SR products delivered by the CCI-LC project.

Table 10-3: Variables and variables' attributes of the global 7-day SR products delivered by the CCl-LC project, according to the structure of the NetCDF files.

Table 10-4 : Global attributes of the global LC maps delivered by the CCI-LC project, according to the structure of the NetCDF files.

Table 10-5: Variables and variables' attributes of the global LC maps delivered by the CCI-LC project, according to the structure of the NetCDF files..... 


\begin{tabular}{|c|c|c|c|c|}
\hline \multirow{2}{*}{ CeSa } & Ref & & CCI LC PUG v2 & Date \\
\cline { 2 - 5 } & Issue & Page & $2017-04-10$ & Iand couer \\
& 2.0 & 16 & cci \\
\hline
\end{tabular}

\section{INTRODUCTION}

\subsection{Scope}

The Product User Guide (PUG) is the reference product description, which describes data format, filenames, metadata and thematic content with the aim to familiarize users with the products.

The $1^{\text {st }}$ phase of the Climate Change Initiative $(\mathrm{CCI})$ generated a suite of products consisting of 3 consistent global Land Cover (LC) products corresponding to the 1998-2002, 2003-2007 and 20082012 periods, climatological 7-day time series representing seasonal dynamics of the land surface, Medium Resolution Imaging Spectrometer (MERIS) Surface Reflectance (SR) time series which served as input for generating the global land cover maps. In addition, a global Water Body (WB) product was derived from the Envisat Advanced Synthetic Aperture Radar (ASAR) archives. These products were described in a PUG [RD.6].

The $2^{\text {nd }}$ phase of project, started in March 2014, led to a set of new and improved products: SR time series of Advanced Very High Resolution Radiometer (AVHRR) and PROBA-V, global annual and consistent LC maps from 1992 to 2015 and new versions of the global map of open water bodies and of the user tool.

This PUGv2 describes the available land cover products at the end of the second year of the CCI-LC project Phase II.

\subsection{Background of the project}

The European Space Agency (ESA) CCI projects will deliver the next generation of satellite derived geophysical parameters, with quantified uncertainties that will allow each parameter to be assessed against requirements from the Global Climate Observing System (GCOS) for Essential Climate Variables (ECV) and the Climate Modelling Community (CMC), represented within the CCI program by the Climate Modelling User Group (CMUG).

The objective of the CCI is to realize the full potential of the long-term global Earth Observation (EO) archives that ESA together with its Member states have established over the last thirty years, as a significant and timely contribution to the ECV databases required by United Nations Framework Convention on Climate Change (UNFCCC). The programme is organized in 2 phases.

The CCI Phase I provided a unique opportunity for the European EO science community to define and validate innovative approaches for continuously generating and updating a comprehensive and consistent set of ECV global satellite based data products in the long term - i.e. decades hence. The focus was on a major sustained, and coordinated scientific effort to review and improve underlying processing, retrieval and validation methods. 


\begin{tabular}{|c|c|c|c|c|}
\hline \multirow{2}{*}{ e ESa } & Ref & \multicolumn{2}{|c|}{ CCI LC PUG v2 } \\
\cline { 2 - 5 } & Issue & Page & Date & land couer \\
\cline { 2 - 5 } & 2.0 & 17 & $2017-04-10$ & cci \\
\hline
\end{tabular}

The CCI Phase II focuses on the generation of long-term, consistent, global data records for each ECV, exploiting the full range of available data sets from ESA and relevant European missions with the aim to issue extended and improved globally consistent ECV data sets from all CCI projects. Each project must make significant, further progress towards meeting the GCOS and related user requirements, exceeding the achievements of the Phase I CCI projects with quantifiable validated measure of performance.

This means the prototype ECV production systems implemented in CCI Phase I must be developed to a sustainable level, based on complete requirements specified and thoroughly validated by the competent science communities during Phase I [AD.3]. These system requirements must be updated to take account of the availability of new and upcoming missions (e.g. Landsat-8, Sentinels and PROBA-V) and evolution to meet industry level standards for operations, maintenance, evolution and configuration control. Phase II projects should follow an iterative life-cycle, of concurrent development and operations. Project activities must continue to be driven by climate science, traceable to documented user needs and CCI projects must engage the relevant science communities, working side-by-side with industry and data centers in Europe.

\subsection{Structure of the document}

After this introduction, the document is divided into 7 sections that are shortly described below:

- Section 2 briefly presents the CCI Land Cover (CCI-LC) project;

- Sections 3 to 6 describe the various products: land cover maps, land surface seasonality product, open water body product and surface reflectance time series;

- Section 7 presents the various tools that can be used to visualize and aggregate the products;

- Section 8 explains how to access the CCI-LC products and give their terms of use.

This document contains various appendices (sections 9 to 12) with additional detailed information. 


\begin{tabular}{|c|c|c|c|c|}
\hline \multirow{2}{*}{ CeSa } & Ref & \multicolumn{2}{|c|}{ CCI LC PUG v2 } \\
\cline { 2 - 5 } & Issue & Page & Date & Iand couer \\
\cline { 2 - 5 } & 2.0 & 18 & $2017-04-10$ & Iai \\
\hline
\end{tabular}

\section{CCI LAND COVER PROJECT}

\subsection{Revisited land cover concept}

Considering the importance of land cover as an input in climate modelling, the development of a new global LC database was initiated during the $1^{\text {st }}$ phase of the project. The specifications of this new database relied on an in-depth user requirement analysis conducted during the 6 first months of the Phase I project [RD.1].

This analysis revealed first the need to consider LC data under 2 aspects: stable in the form of land cover map and dynamic in the form of time series. In addition, the LC products should provide flexibility to serve different scales and purposes in terms of spatial and temporal resolutions. Their quality should also be transparent by using quality flags and controls.

From a remote sensing point of view, these requirements - and the first one in particular - led in rethinking the whole LC concept into $\boldsymbol{L C}$ state and $\boldsymbol{L S}$ seasonality components [RD.2]. The $\boldsymbol{L C}$ state concept refers to the set of LC features remaining stable over time which define the LC independently of any sources of temporary or natural variability. It is agreed that the LC state is well described using the United Nations (UN) Land Cover Classification System (LCCS) [RD.8], which is also quite compatible with the Plant Function Types (PFT) concept of many models [RD.1]. The $\boldsymbol{L S}$ seasonality concept relates directly to the temporary or natural variability of LC features that can induce some variation in land surface over time without changing the LC in its essence. This LS seasonality is typically driven by biogeophysical processes. It encompasses different observable variables such as the green vegetation phenology, snow coverage, open water presence, and burned areas occurrence, etc.

Furthermore, the need to generate successive LC state products consistent over time resulted in the development of a new original classification approach. Most often, LC maps were generated from few instantaneous observations of the land cover state. As a result, classification outputs are sensitive to the date(s) of observation and can reflect temporary conditions (e.g. map savannahs as burnt scars, boreal forest as snow, croplands as bare soils, etc.). The developed alternative consisted in describing the LC state from multi-year observation dataset. In this case, assuming that no LC change - even temporary - has occurred over this multi-year period, the LC is expected to be mapped in a consistent way over time. This approach was successfully implemented in the $1^{\text {st }}$ phase and continued in the $2^{\text {nd }}$ phase.

\subsection{Users' requirements}

At the beginning of the $2^{\text {nd }}$ phase of the project, a new user survey was conducted among the climate modelling partners of the CCI-LC project to analyze the fulfilment of the requirements defined in 


\begin{tabular}{|c|c|c|c|c|}
\hline \multirow{2}{*}{ CeSa } & Ref & \multicolumn{2}{|c|}{ CCI LC PUG v2 } \\
\cline { 2 - 5 } & Issue & Page & Date & land couer \\
& 2.0 & 19 & $2017-04-10$ & cci \\
\hline
\end{tabular}

Phase I and to identify target requirements for future LC products. The comprehensive user survey results of Phase I were reanalysed (excepted future modelling requirements) and consolidated through synthesizing new user needs from the scientific community from initiatives such as Terrabytes and International Space Science Institute (ISSI) special group, from Coupled Model Intercomparison Project (CMIP) 6 process and from the outcomes of the fifth assessment report of the Intergovernmental Panel on Climate Change (IPCC). The GCOS process has started to specify new ambitions for ECVs to meet the needs of the climate mitigation community - this also posed new requirements for the CCI-LC project. This activity is documented in details in [AD.4].

It resulted in a series of new requirements, which were organized into higher or lower priority categories:

\section{1) Higher priority}

a. Better description of LC characteristics in the context of PFT model requirements. As a follow-up of the Phase I work, the new requirement is to formulate LC - PFT conversion tables separately for different climatic regions. These regions are to be defined by the climate modeller users of the consortium, with PFT fractions per region identified using the land cover validation dataset.

b. In particular, the percentage ranges for LC - PFT conversion in the case of mixed classes, for example the class 'mosaic tree and shrub $(>50 \%) /$ herbaceous $(<50 \%)$ ', should be better defined in order to provide the proportion (\%) of tree, shrub, and herbaceous.

c. Longer temporal extent for LC maps (30 years and more) including datasets for the 1990's and the 1980's.

d. Higher temporal resolution: annual time steps in LC change.

e. More specific information of land cover/use change is required, at least in the context of the IPCC land categories (forests, agriculture, grassland, settlement, wetland, other land).

f. Additional attributes of the LC classes are required including vegetation height, minimum and maximum Leaf Area Index (LAI), clumping index and the distinction between $\mathrm{C} 3$ and $\mathrm{C} 4$ plants.

g. Move to $30 \mathrm{~m}$ (or better) scale LC and change assessments, at least for selected regions.

h. Provide the full time series for the Normalized Difference Vegetation Index (NDVI) LS seasonality.

i. Provide additional LS seasonality such as water and surface albedo for vegetation and soil LC classes.

j. Provide an improved water body product with at least a distinction inland water/ocean included. 


\begin{tabular}{|c|c|c|c|c|}
\hline \multirow{2}{*}{ C ESa } & Ref & & CCI LC PUG v2 & Date \\
\cline { 2 - 5 } & Issue & Page & $2017-04-10$ & land couer \\
\cline { 2 - 5 } & 2.0 & 20 & cci
\end{tabular}

\section{2) Lower priority}

a. Seek options for including land management (forestry, agriculture, livestock) with land cover datasets.

b. Provide additional relevant attributes of LC classes such as aboveground tree biomass, vegetation density, and permafrost fraction.

c. Improve the description of the results and products. Besides the detailed technical reports, short technical summaries highlighting important points should be provided.

d. Provide additional LS seasonality such as the FaPAR.

The requirements and their fulfillments are summarized in Figure 2-1.

\begin{tabular}{|c|c|c|c|c|}
\hline & $\begin{array}{c}\text { Threshold } \\
\text { requirement } \\
\text { Phase I }\end{array}$ & $\begin{array}{c}\text { Target } \\
\text { requirement } \\
\text { Phase I }\end{array}$ & $\begin{array}{c}\text { Threshold } \\
\text { requirement } \\
\text { Phase II }\end{array}$ & $\begin{array}{c}\text { Target } \\
\text { requirement } \\
\text { Phase II }\end{array}$ \\
\hline & \multicolumn{4}{|c|}{ Coverage and sampling } \\
\hline $\begin{array}{r}\text { Geographic } \\
\text { Coverage }\end{array}$ & Global & $\begin{array}{l}\text { Global with } \\
\text { regional and local } \\
\text { specific products }\end{array}$ & $\begin{array}{c}\text { Global with regional } \\
\text { specific } \\
\text { products }\end{array}$ & $\begin{array}{c}\text { Global with } \\
\text { regional specific } \\
\text { products }\end{array}$ \\
\hline $\begin{array}{c}\text { Temporal } \\
\text { sampling }\end{array}$ & $\begin{array}{c}\text { Best/stable map } \\
\text { and regular } \\
\text { updates }\end{array}$ & $\begin{array}{l}\text { Monthly data on } \\
\text { vegetation } \\
\text { dynamics and } \\
\text { change }\end{array}$ & $\begin{array}{c}\text { 5-10 year epoch maps } \\
\text { with monthly vegetation } \\
\text { dynamics(NDVI) }\end{array}$ & $\begin{array}{c}\text { 1-year epoch maps. } \\
\text { Monthly data on } \\
\text { vegetation } \\
\text { dynamics (NDVI) }\end{array}$ \\
\hline \multirow[t]{2}{*}{$\begin{array}{r}\text { Temporal } \\
\text { extent }\end{array}$} & $\begin{array}{l}\text { 1-2 years, most } \\
\text { recent }\end{array}$ & $\begin{array}{c}1990 \text { (or earlier)- } \\
\text { present }\end{array}$ & $\begin{array}{c}1990 \text { (or earlier) - } \\
\text { present }\end{array}$ & $\begin{array}{c}1980 \text { (or earlier) - } \\
\text { present }\end{array}$ \\
\hline & \multicolumn{4}{|c|}{ Resolution } \\
\hline $\begin{array}{l}\text { Horizontal } \\
\text { Resolution }\end{array}$ & $1000 \mathrm{~m}$ & $30 \mathrm{~m}$ & $\begin{array}{c}300 \mathrm{~m} \text { with regional } \\
30 \mathrm{~m} \text { products }\end{array}$ & $30 \mathrm{~m}$ \\
\hline \multirow[t]{2}{*}{$\begin{array}{r}\text { Vertical } \\
\text { Resolution }\end{array}$} & - & - & & \\
\hline & \multicolumn{4}{|c|}{ Error/Uncertainty } \\
\hline Precision & $\begin{array}{c}\text { Thematic land } \\
\text { cover detail } \\
\text { sufficient to meet } \\
\text { current modelling } \\
\text { user needs }\end{array}$ & $\begin{array}{l}\text { Thematic land } \\
\text { cover detail } \\
\text { sufficient to meet } \\
\text { future model needs }\end{array}$ & $\begin{array}{c}\text { Thematic land } \\
\text { cover detail (incl. } \\
\text { conversion tables to } \\
\text { PFT for climatic } \\
\text { regions) } \\
\text { sufficient to meet } \\
\text { current and future } \\
\text { model needs, incl. key } \\
\text { land IPCC changes }\end{array}$ & $\begin{array}{l}\text { Thematic land } \\
\text { cover detail (incl. } \\
\text { conversion tables to } \\
\text { PFT for climatic } \\
\text { regions) and traits) } \\
\text { sufficient to meet } \\
\text { current and future } \\
\text { model needs, incl. } \\
\text { land changes and }\end{array}$ \\
\hline
\end{tabular}




\begin{tabular}{|c|c|c|c|c|}
\hline \multirow{2}{*}{ Cesa } & Ref & \multicolumn{2}{|c|}{ CCI LC PUG v2 } \\
\cline { 2 - 4 } & Issue & Page & Date & Iand couer \\
\cline { 2 - 5 } & 2.0 & 21 & $2017-04-10$ & Ici \\
\hline
\end{tabular}

\begin{tabular}{|c|c|c|c|c|}
\hline & & & & land management \\
\hline Accuracy & $\begin{array}{c}\text { Higher accuracy } \\
\text { than existing } \\
\text { datasets }\end{array}$ & $\begin{array}{c}\text { Errors of 5-10\% } \\
\text { either per class or } \\
\text { as overall } \\
\text { accuracy }\end{array}$ & $\begin{array}{c}\text { Higher accuracy } \\
\text { than existing } \\
\text { datasets }\end{array}$ & $\begin{array}{l}\text { Errors of } 5-10 \% \\
\text { either per class or } \\
\text { as overall accuracy }\end{array}$ \\
\hline Stability & $\begin{array}{c}\text { Higher stability } \\
\text { than existing } \\
\text { datasets }\end{array}$ & $\begin{array}{c}\text { Errors of } 5-10 \% \\
\text { either per class or } \\
\text { as overall } \\
\text { accuracy }\end{array}$ & $\begin{array}{l}\text { Higher stability } \\
\text { than existing } \\
\text { datasets }\end{array}$ & $\begin{array}{l}\text { Errors of } 5-10 \% \\
\text { either per class or } \\
\text { as overall accuracy }\end{array}$ \\
\hline $\begin{array}{c}\text { Error } \\
\text { Characteristics }\end{array}$ & $\begin{array}{c}\text { Independent } \\
\text { onetime accuracy } \\
\text { assessment }\end{array}$ & $\begin{array}{c}\text { Operational and } \\
\text { independent } \\
\text { multi-date } \\
\text { validation }\end{array}$ & $\begin{array}{c}\text { Independent } \\
\text { multi-date validation }\end{array}$ & $\begin{array}{c}\text { Operational and } \\
\text { independent } \\
\text { multi-date validation }\end{array}$ \\
\hline
\end{tabular}

Figure 2-1: Threshold (minimum) and target (optimal) requirements identified for LC products in the User Requirements Survey carried out in the CCI - LC project Phases I and II. Check-marks indicate fulfilled requirements (from [AD.4]).

\subsection{Project outputs}

The outputs of the CCI-LC Phase II project concern global SR time series, global annual LC maps, global LS seasonality products and a global WB product (hereafter named WBP), all of them being delivered along with metadata. The outputs also include software systems, products documentation and validation reports.

At the end of the 3-year long Phase II, the key global datasets for the end-users will be:

1) Global SR time series and associated metadata over different epochs and from different sensors:

a. Time series of AVHRR 7-day composites ${ }^{1}$ from 1992 through 1999;

b. Time series of Envisat MERIS Full Resolution (FR) 7-day composites from 2003 through 2012;

c. Time series of Envisat MERIS Reduced Resolution (RR) 7-day composites from 2003 through 2012;

\footnotetext{
${ }^{1}$ A 7-day compositing period is foreseen to be consistent with the other sensors, but this has to be confirmed according to the data coverage
} 


\begin{tabular}{|c|c|c|c|c|}
\hline \multirow{2}{*}{ CeSa } & Ref & \multicolumn{2}{|c|}{ CCI LC PUG v2 } \\
\cline { 2 - 5 } & Issue & Page & Date & land couer \\
& 2.0 & 22 & $2017-04-10$ & lai \\
\hline
\end{tabular}

d. Time series of PROBA-V 7-day composites from 2014 and 2015 (and beyond);

e. Time series of Sentinel-3 Ocean and Land Colour Instrument (OLCI) and Sea and Land Surface Temperature Radiometer (SLSTR) 7-day composites from 2016 (and beyond).

2) Global annual LC maps starting from the 1990s through 2015 based on the above AVHRR, SPOT-VGT, MERIS FR and RR, PROBA-V and associated metadata;

3) An updated global LC map for 2016 including the above Sentinel-3 OLCI and SLSTR composites and associated metadata ${ }^{2}$;

4) Global LS seasonality products and associated metadata for the NDVI and water bodies;

5) Global map of permanent open WB for the 2010 epoch based on Envisat ASAR time series, associated with an additional data product detailing the dates of ice-free conditions over inland water bodies.

In addition, prototypes products are foreseen, which will demonstrate the pre-processing and classification algorithms developed for the Sentinel-1 and -2 missions and to expand historical time series. They include:

1) Sentinel-2 time series of regional SR composites from 2015 (and beyond) and associated metadata;

2) Africa-wide mosaic of Sentinel-2 cloud-free surface reflectances at $10 \mathrm{~m}$;

3) Africa-wide LC map based on the above Sentinel-2 composites and associated metadata;

4) Prototype WB and urban products based on Sentinel-1 SAR data, tuned geographically to the regional LC maps obtained with Sentinel-2 data;

Those products will be generated throughout the project following a yearly planning. They will be delivered in the form of Climate Research Data Package (CRDP), versioned 1 to 3 for years 1 to 3, as illustrated in Figure 2-2.

\footnotetext{
${ }^{2}$ According to the availability of Sentinel-3 data in terms of quantity and timing with respect to the overall project planning
} 


\begin{tabular}{|c|c|c|c|c|}
\hline \multirow{2}{*}{ CeSa } & Ref & \multicolumn{2}{|c|}{ CCI LC PUG v2 } \\
\cline { 2 - 5 } & Issue & Page & Date & Iand couer \\
\cline { 2 - 5 } & 2.0 & 23 & $2017-04-10$ & Ici \\
\hline
\end{tabular}

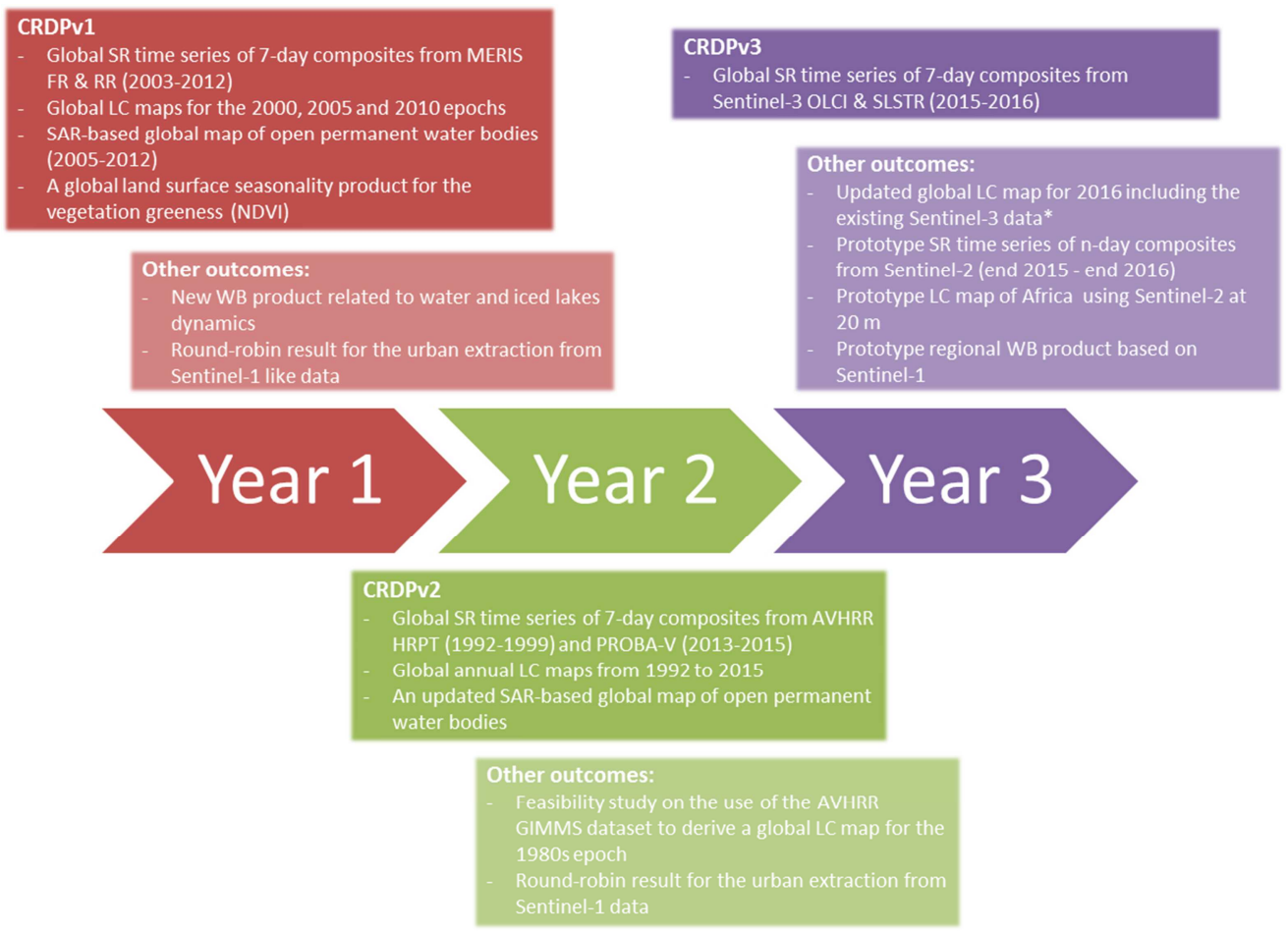

* According to the availability of Sentinel-3 data in terms of quantity and timing with respect to the overall project planning.

Figure 2-2: Planning of datasets to be produced in the CCI-LC Phase II (updated from [AD.5])

This version of the PUGv2 focuses on the products available in the CRPDv2. Their main specifications are summarized in Table 2-1.

Table 2-1: Summary of the CCI-LC products

\begin{tabular}{|c|c|c|c|c|c|c|c|}
\hline \multirow{2}{*}{ PRODUCT } & \multicolumn{2}{|c|}{ COVERAGE } & \multicolumn{2}{|c|}{ RESOLUTION } & \multirow{2}{*}{ SENSOR } & \multirow{2}{*}{ PROJECTION } & \multirow{2}{*}{ FORMAT } \\
\hline & SPATIAL & TEMPORAL & SPATIAL & TEMPORAL & & & \\
\hline \multirow{2}{*}{$\begin{array}{l}\text { MERIS SR } \\
\text { time series }\end{array}$} & \multirow{2}{*}{ Global } & \multirow{2}{*}{ 2003-2012 } & $300 \mathrm{~m}$ & \multirow{2}{*}{ 7-day } & MERIS FR & \multirow{2}{*}{ WGS 84} & \multirow{2}{*}{ NetCDF } \\
\hline & & & $1000 \mathrm{~m}$ & & MERIS RR & & \\
\hline $\begin{array}{l}\text { AVHRR SR } \\
\text { time series }\end{array}$ & Global & 1992-1999 & $1000 \mathrm{~m}$ & 7-day & AVHRR & WGS 84 & NetCDF \\
\hline $\begin{array}{c}\text { PROBA-V } \\
\text { SR time } \\
\text { series }\end{array}$ & Global & $\begin{array}{c}\text { 2014-2015 } \\
\text { (and } \\
\text { beyond) }\end{array}$ & 300 m & 7-day & PROBA-V & WGS 84 & NetCDF \\
\hline $\begin{array}{c}\text { Annual LC } \\
\text { maps }\end{array}$ & Global & $1992-2015$ & 300 m & 1-year & $\begin{array}{c}\text { MERIS } \\
\text { FR/RR } \\
\text { SPOT-VGT } \\
\text { AVHRR } \\
\text { PROBA-V }\end{array}$ & WGS 84 & $\begin{array}{c}\text { NetCDF \& } \\
\text { GeoTiff }\end{array}$ \\
\hline $\begin{array}{c}\text { NDVI LS } \\
\text { seasonality }\end{array}$ & Global & 1999-2012 & $1000 \mathrm{~m}$ & 7-day & SPOT-VGT & WGS 84 & $\begin{array}{c}\text { NetCDF \& } \\
\text { GeoTiff }\end{array}$ \\
\hline $\begin{array}{l}\text { Water } \\
\text { body }\end{array}$ & Global & $2000-2012$ & $150 \mathrm{~m}$ & 13-year & ASAR WSM & WGS 84 & $\begin{array}{c}\text { NetCDF \& } \\
\text { GeoTiff }\end{array}$ \\
\hline
\end{tabular}




\begin{tabular}{|c|c|c|c|c|}
\hline \multirow{2}{*}{ e esa } & Ref & & CCI LC PUG v2 & Date \\
\cline { 2 - 5 } & Issue & Page & $2017-04-10$ & land couer \\
\cline { 2 - 5 } & 2.0 & 24 & cci \\
\hline
\end{tabular}

\section{LAND COVER MAPS}

\subsection{Products description}

The CCI-LC project delivers consistent global LC maps at $300 \mathrm{~m}$ spatial resolution on an annual basis from 1992 to 2015. The Coordinate Reference System used for the global land cover database is a geographic coordinate system (GCS) based on the World Geodetic System 84 (WGS84) reference ellipsoid.

Figure 3-1 presents the LC map from the year 2015 at global scale and Figure 3-2 shows the classification obtained throughout the years over a region of Argentina.

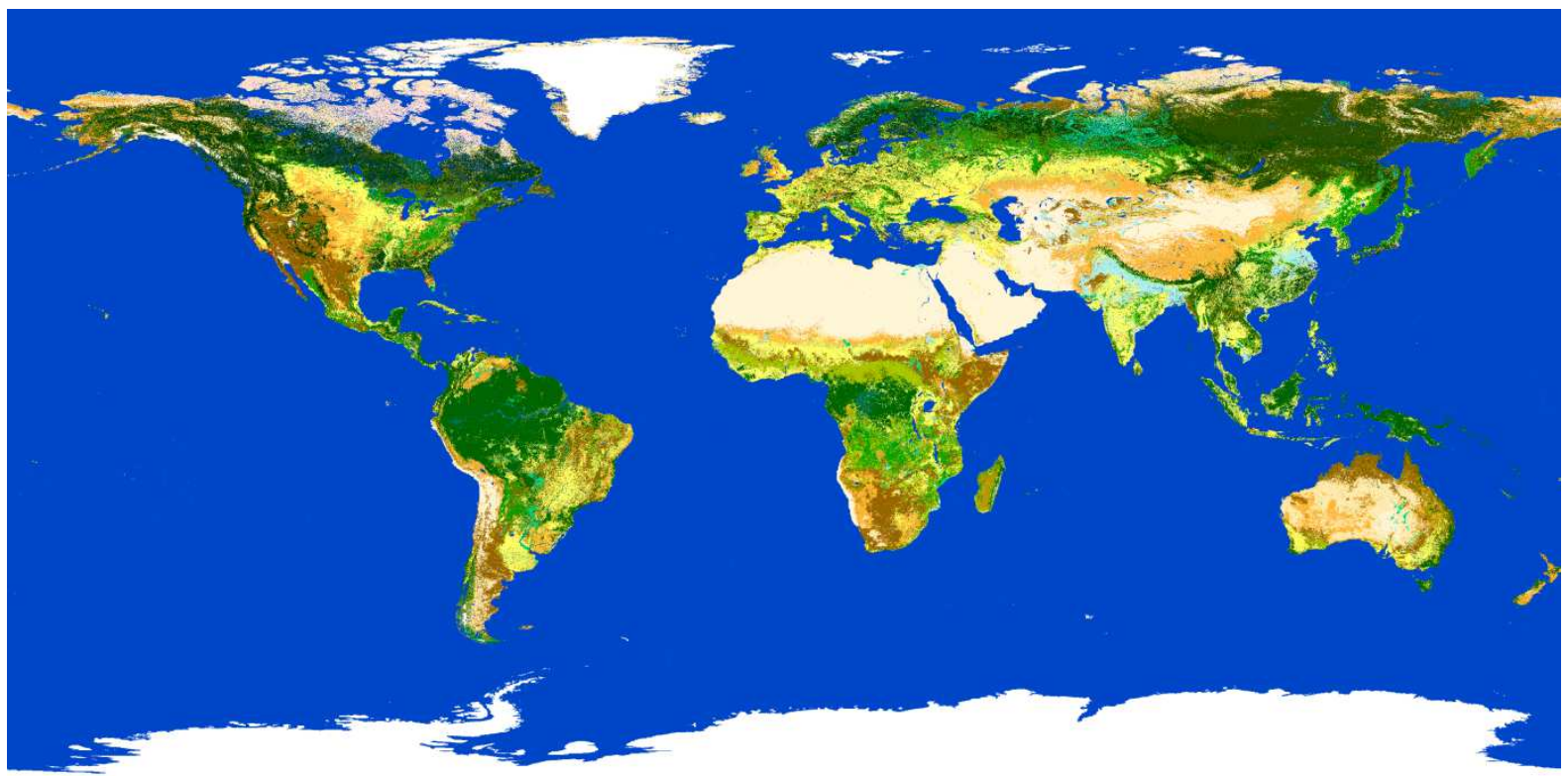

Figure 3-1: The most recent map from the LC map series from the year 2015, at $300 \mathrm{~m}$ spatial resolution. 


\begin{tabular}{|c|c|c|c|c|}
\hline \multirow{2}{*}{ CeSa } & Ref & \multicolumn{2}{|c|}{ CCI LC PUG v2 } \\
\cline { 2 - 5 } & Issue & Page & Date & land couer \\
\cline { 2 - 5 } & 2.0 & 25 & $2017-04-10$ & cci \\
\hline
\end{tabular}

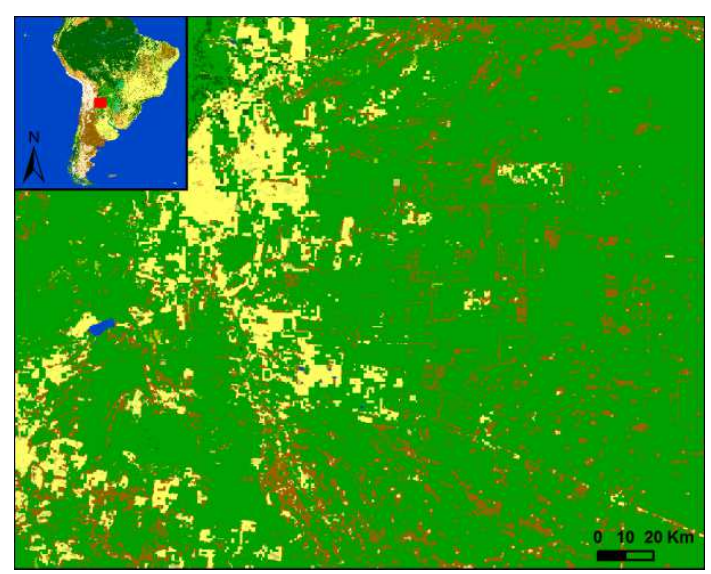

Year 1992

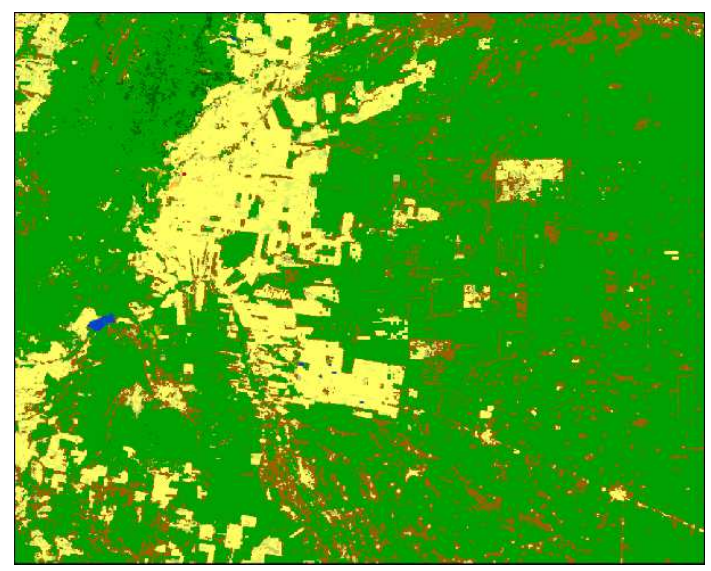

Year 2004

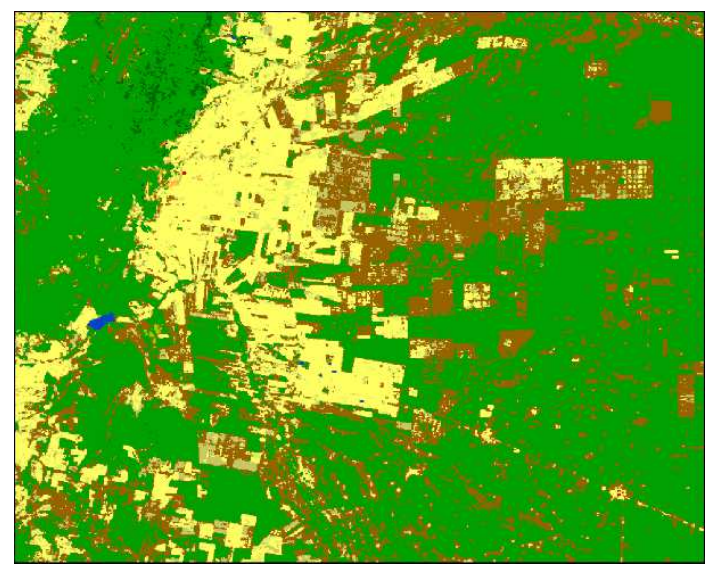

Year 2011

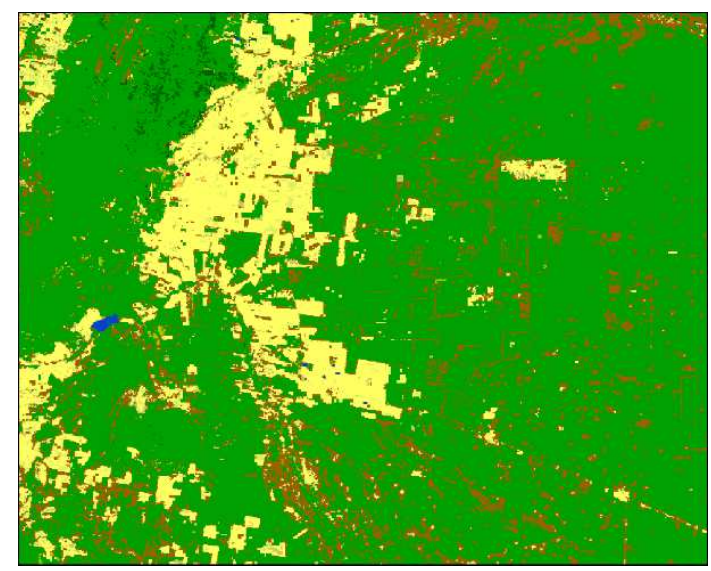

Year 2000

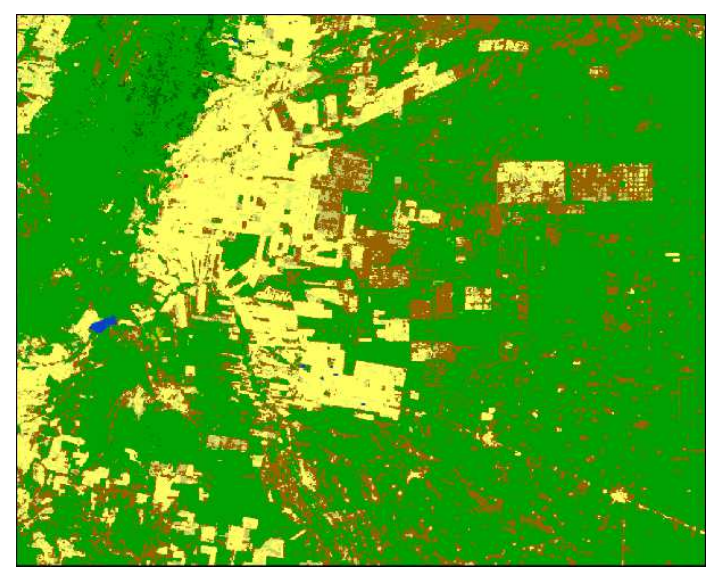

Year 2007

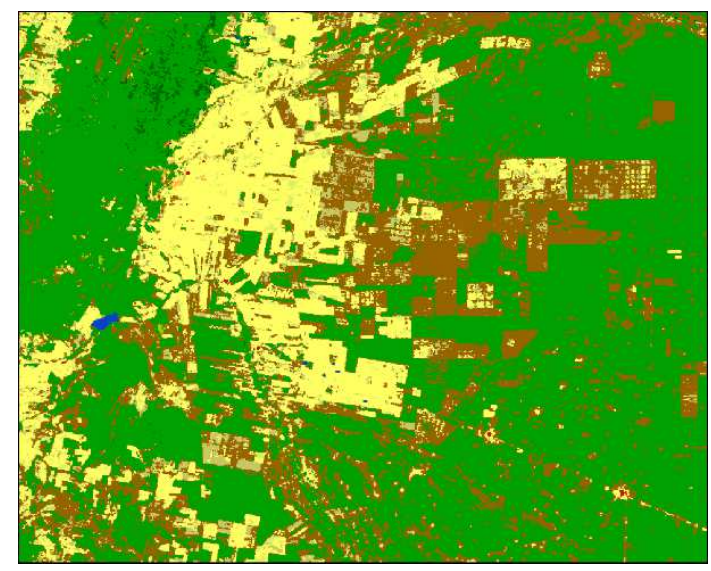

Year 2015

Figure 3-2: Illustration of a sequence of the CCI global annual land cover maps for years 1992, 2000, 2004, 2007, 2011 and 2015 for an area of the Salta Province in Argentina. 


\begin{tabular}{|c|c|c|c|c|}
\hline \multirow{2}{*}{ CeSa } & Ref & \multicolumn{2}{|c|}{ CCI LC PUG v2 } \\
\cline { 2 - 5 } & Issue & Page & Date & land couer \\
& 2.0 & 26 & $2017-04-10$ & lai \\
\hline
\end{tabular}

The following sections describe the legend of the CCI-LC maps, the processing chain including the classification and change detection modules and finally, the format of the maps and their four quality flags, valid for the full time series.

The project also delivers a user tool along with the land cover products, which allows users to aggregate LC maps to the spatial resolution, projection and format suitable for their models. This tool is described in Section 7.3 in detail.

\subsubsection{Legend}

The typology was defined using the Land Cover Classification System (LCCS) developed by the United Nations (UN) Food and Agriculture Organization (FAO), with the view to be as much as possible compatible with the GLC2000, GlobCover 2005 and 2009 products. In addition, the UNLCCS was found quite compatible with the Plant Functional Types (PFTs) used in climate models [RD.1].

The UN-LCCS defines LC classes using a set of classifiers. The system was designed as a hierarchical classification, which allows adjusting the thematic detail of the legend to the amount of information available to describe each LC class, whilst following a standardized classification approach.

As the CCI-LC maps are designed to be globally consistent, their legend is determined by the level of information that is available and that makes sense at the scale of the entire world. The "level 1" legend - also called "global" legend - presented in Table 3-1 meets this requirement. This legend counts 22 classes and each class is associated with a ten values code (i.e. class codes of 10, 20, 30, etc.).

The CCI-LC maps are also described by a more detailed legend, called "level 2" or "regional". This level 2 legend makes use of more accurate and regional information - where available - to define more LCCS classifiers and so to reach a higher level of detail in the legend. This regional legend has therefore more classes which are listed in Appendix 1. The regional classes are associated with nonten values (i.e. class codes such as 11, 12, etc.). They are not present all over the world since they were not properly discriminated at the global scale.

The explicit LCCS definition of each CCI-LC global and regional class is provided in Appendix 1.

Table 3-1: Level 1 (or global) legend of the CCI-LC maps, based on the UN-LCCS.

\begin{tabular}{|l|l|l|}
\hline VALUE & \multicolumn{1}{|c|}{ LABEL } & COLOR \\
\hline 0 & No Data & \\
\hline 10 & Cropland, rainfed & \\
\hline 20 & Cropland, irrigated or post-flooding & \\
\hline 30 & $\begin{array}{l}\text { Mosaic cropland }(>50 \%) / \text { natural vegetation (tree, shrub, herbaceous cover) } \\
(<50 \%)\end{array}$ & $\begin{array}{l}\text { Mosaic natural vegetation (tree, shrub, herbaceous cover) }(>50 \%) / \text { cropland } \\
(<50 \%)\end{array}$ \\
\hline 40 & Tree cover, broadleaved, evergreen, closed to open $(>15 \%)$ & \\
\hline 50 & Tree cover, broadleaved, deciduous, closed to open $(>15 \%)$ & \\
\hline 60 &
\end{tabular}




\begin{tabular}{|c|c|c|c|c|}
\hline \multirow{2}{*}{ CeSa } & Ref & \multicolumn{3}{|c|}{ CCI LC PUG v2 } \\
\cline { 2 - 5 } & Issue & Page & Date & Iand couer \\
\cline { 2 - 5 } & 2.0 & 27 & $2017-04-10$ & Ia \\
\hline
\end{tabular}

\begin{tabular}{|l|l|l|}
\hline 70 & Tree cover, needleleaved, evergreen, closed to open $(>15 \%)$ \\
\hline 80 & Tree cover, needleleaved, deciduous, closed to open $(>15 \%)$ \\
\hline 90 & Tree cover, mixed leaf type (broadleaved and needleleaved) & \\
\hline 100 & Mosaic tree and shrub $(>50 \%) /$ herbaceous cover $(<50 \%)$ & \\
\hline 110 & Mosaic herbaceous cover $(>50 \%) /$ tree and shrub $(<50 \%)$ & \\
\hline 120 & Shrubland & \\
\hline 130 & Grassland & \\
\hline 140 & Lichens and mosses & \\
\hline 150 & Sparse vegetation (tree, shrub, herbaceous cover) $(<15 \%)$ & \\
\hline 160 & Tree cover, flooded, fresh or brakish water & \\
\hline 170 & Tree cover, flooded, saline water & \\
\hline 180 & Shrub or herbaceous cover, flooded, fresh/saline/brakish water & \\
\hline 190 & Urban areas & \\
\hline 200 & Bare areas & \\
\hline 210 & Water bodies & \\
\hline 220 & Permanent snow and ice & \\
\hline
\end{tabular}

Among these LC classes, four were largely identified thanks to external dataset: the "tree cover, flooded, saline water" (class value 170) class which is based on the global mangrove atlas [RD.11], the "urban areas" (class value 190) which relies both on the Global Human Settlement Layer [RD.30] and on the Global Urban Footprint [RD.35], the "water bodies" (class value 210) which have been inherited from the CCI global map of open water bodies (see Section 4) and the "permanent snow and ice" (class value 220) which comes from the Randolph Glaciers Inventory [RD.12] (to which the CCIGlaciers project is one of the main contributors).

\subsubsection{Processing chain}

A key aspect of the CCI-LC maps consists in their consistency over time. As a result, the set of annual maps are not produced independently but they are derived from a unique baseline LC map which is generated thanks to the entire MERIS FR and RR archive from 2003 to 2012. Independently from this baseline, LC changes are detected at $1 \mathrm{~km}$ based on the AVHRR time series between 1992 to 1999 , SPOT-VGT time series between 1999 and 2013 and PROBA-V data for years 2013, 2014 and 2015. When MERIS FR or PROBA-V time series are available, changes detected at $1 \mathrm{~km}$ are re-mapped at $300 \mathrm{~m}$. The last step consists in back- and up-dating the 10-year baseline LC map to produce the 24 annual LC maps from 1992 to 2015.

The logical model underlying this processing chain is illustrated in Figure 3-3 and the EO data used to generate the global LC maps are summarized Table 3-2. 


\begin{tabular}{|c|c|c|c|c|}
\hline \multirow{2}{*}{ CeSa } & Ref & & CCI LC PUG v2 & Date \\
\cline { 2 - 5 } & Issue & Page & $2017-04-10$ & land couer \\
& 2.0 & 28 & cci \\
\hline
\end{tabular}

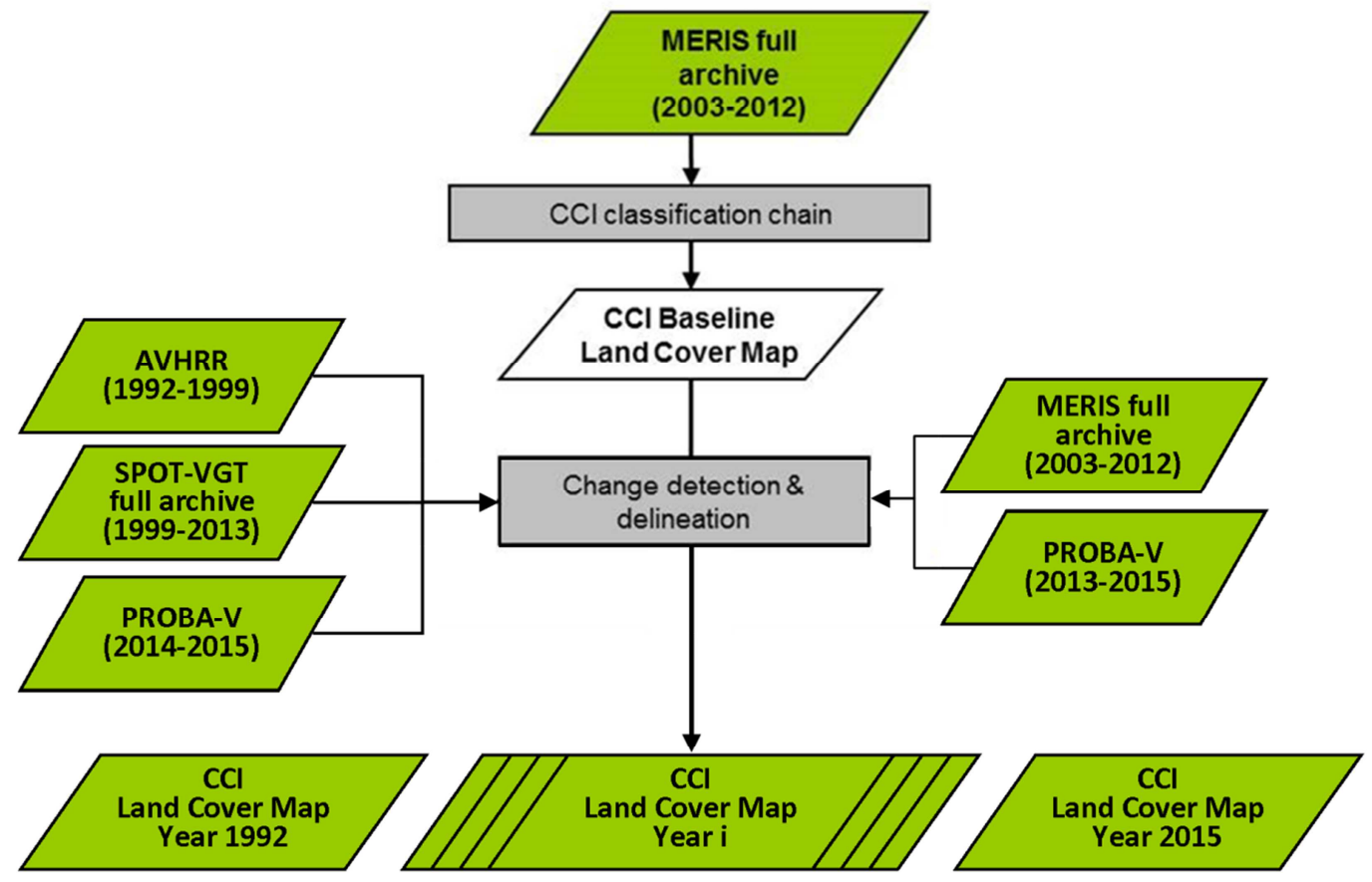

Figure 3-3: Schematic representation of the CCI-LC classification chain that generates global annual LC maps. The chain is made of 2 main processes and makes use of the entire archives of Envisat MERIS (2003 -2012), AVHRR (1992 - 1999), SPOT-VGT (1999 - 2013) and PROBA-V data for 2013, 2014 and 2015.

Table 3-2: Satellite data sources used to generate the global LC maps.

\begin{tabular}{|c|c|c|}
\hline GLOBAL LC DATABASE & $\begin{array}{l}\text { REFERENCE } \\
\text { PERIOD }\end{array}$ & SATELLITE DATA SOURCE \\
\hline $\begin{array}{c}\text { Baseline 10-year global } \\
\text { LC map }\end{array}$ & 2003-2012 & - MERIS FR/RR global SR composites between 2003 and 2012 \\
\hline \multirow{3}{*}{ Global annual LC maps } & 1992-1999 & $\begin{array}{l}\text { - Baseline 10-year global LC map } \\
\text { - AVHRR global SR composites between } 1992 \text { and } 1999 \text { for } \\
\text { back-dating the baseline }\end{array}$ \\
\hline & $1999-2013$ & $\begin{array}{l}\text { - Baseline 10-year global LC map } \\
\text { - SPOT-VGT global SR composites between } 1999 \text { and } 2013 \text { for } \\
\text { up and back-dating the baseline } \\
\text { MERIS FR global SR composites between } 2003 \text { and } 2012 \text { to } \\
\text { delineate the identified changes at } 300 \mathrm{~m} \text { spatial resolution } \\
\text { PROBA-V global SR composites at } 300 \mathrm{~m} \text { for year } 2013 \text { to } \\
\text { delineate the identified changes at } 300 \mathrm{~m} \text { spatial resolution }\end{array}$ \\
\hline & 2014-2015 & $\begin{array}{l}\text { - Baseline } 10 \text {-year global LC map } \\
\text { - PROBA-V global SR composites at } 1 \mathrm{~km} \text { for years } 2014 \text { and } \\
2015 \text { for up-dating the baseline } \\
\text { - PROBA-V time series at } 300 \mathrm{~m} \text { for } 2014 \text { and } 2015 \text { to delineate } \\
\text { the identified changes the LC map spatial resolution }\end{array}$ \\
\hline
\end{tabular}




\begin{tabular}{|c|c|c|c|c|}
\hline \multirow{2}{*}{ CeSa } & Ref & \multicolumn{2}{|c|}{ CCI LC PUG v2 } \\
\cline { 2 - 5 } & Issue & Page & Date & land couer \\
& 2.0 & 29 & $2017-04-10$ & lai \\
\hline
\end{tabular}

The classification module that generates the baseline map was developed by the Universite catholique de Louvain (UCL). It was designed to be globally consistent while regionally-tuned. It capitalized on the GlobCover unsupervised classification chain [RD.9] while also relying on a machine learning algorithm and on a multiple-year strategy [RD.10]. In this way, it combined both the spectral and temporal richness of the MERIS FR time series.

The change module works independently from the above-mentioned classification module. It consists of 2 consecutive steps: change detection at $1 \mathrm{~km}$ and change delineation at $300 \mathrm{~m}$.

The first step of the change module consists in mapping the dynamics of the land surface by analyzing, on a per-pixel basis, annual time series of 1-km global classifications from 1992 to 2015 [AD.9]. These annual classifications are derived from AVHRR time series between 1992 to 1999, SPOT-VGT time series from 1999 to 2013 and PROBA-V time series from 2014 to 2015. With their $1 \mathrm{~km}$ resolution, they allow capturing the dominant land cover transitions. Yet, in order to avoid false change detections due to the inter-annual variability in classifications, each change has to be confirmed over more than two successive years in the classification time series. An exception is made for changes occurring in 2014 and 2015. They are allowed with only one or two years of confirmation but conversely, they are limited to forests changes that are well detected.

In the most dynamic regions of the world, more than one land cover change can be detected between 1992 and 2015. Most of the pixels are associated with 0,1, 2 or 3 land cover changes, knowing that each change needs to last at least two years to be detected. For instance, a forest loss to shrubland during two years followed by a forest recovery is too short to be detected as LC change.

Examples of annual classification time series analyses are given in Figure 3-4.

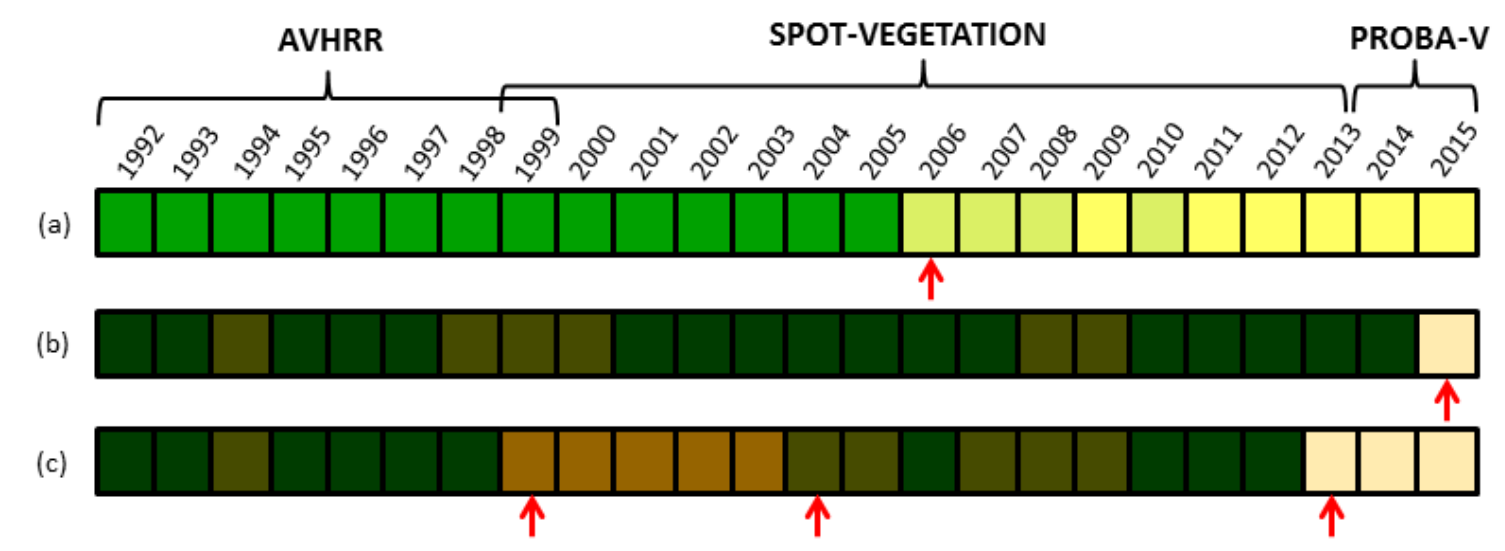

Figure 3-4: Change detection on a pixel basis from a time series of 24 annual 1-km global classifications (1992 to 2015: AVHRR, SPOT-VGT and PROBA-V). Red arrows indicate years of change detected along the time series.

The change is detected between CCI land cover classes grouped into the six IPCC land categories, i.e. cropland, forest, grassland, wetland, settlement and other land. This latter class is further split into shrubland, sparse vegetation, bare area and water. This grouping was a requirement expressed by the climate users. It also avoids false change detection between LC classes which are semantically close. 


\begin{tabular}{|c|c|c|c|c|}
\hline \multirow{2}{*}{ CeSa } & Ref & \multicolumn{3}{|c|}{ CCI LC PUG v2 } \\
\cline { 2 - 5 } & Issue & Page & Date & Iand couer \\
\cline { 2 - 5 } & 2.0 & 30 & $2017-04-10$ & Ia \\
\hline
\end{tabular}

The correspondence between these IPCC land categories and the LCCS legend used in the CCI-LC maps is defined in Table 3-3.

Table 3-3: Correspondence between the IPCC land categories used for the change detection and the LCCS legend used in the CCI-LC classes.

\begin{tabular}{|c|c|c|c|}
\hline \multicolumn{2}{|c|}{$\begin{array}{c}\text { IPCC CLASSES CONSIDERED } \\
\text { FOR THE CHANGE } \\
\text { DETECTION }\end{array}$} & \multicolumn{2}{|r|}{ LCCS LEGEND USED IN THE CCI-LC MAPS } \\
\hline \multirow{4}{*}{\multicolumn{2}{|c|}{ 1. Agriculture }} & $10,11,12$ & Rainfed cropland \\
\hline & & 20 & Irrigated cropland \\
\hline & & 30 & $\begin{array}{l}\text { Mosaic cropland }(>50 \%) \text { / natural vegetation (tree, shrub, } \\
\text { herbaceous cover) }(<50 \%)\end{array}$ \\
\hline & & 40 & $\begin{array}{l}\text { Mosaic natural vegetation (tree, shrub, herbaceous cover) } \\
(>50 \%) / \text { cropland }(<50 \%)\end{array}$ \\
\hline \multirow{8}{*}{\multicolumn{2}{|c|}{ 2. Forest }} & 50 & Tree cover, broadleaved, evergreen, closed to open (>15\%) \\
\hline & & $60,61,62$ & Tree cover, broadleaved, deciduous, closed to open (> 15\%) \\
\hline & & $70,71,72$ & Tree cover, needleleaved, evergreen, closed to open (>15\%) \\
\hline & & $80,81,82$ & Tree cover, needleleaved, deciduous, closed to open (> 15\%) \\
\hline & & 90 & Tree cover, mixed leaf type (broadleaved and needleleaved) \\
\hline & & 100 & Mosaic tree and shrub (>50\%) / herbaceous cover $(<50 \%)$ \\
\hline & & 160 & Tree cover, flooded, fresh or brakish water \\
\hline & & 170 & Tree cover, flooded, saline water \\
\hline \multirow{2}{*}{\multicolumn{2}{|c|}{ 3. Grassland }} & 110 & Mosaic herbaceous cover $(>50 \%) /$ tree and shrub $(<50 \%)$ \\
\hline & & 130 & Grassland \\
\hline \multicolumn{2}{|c|}{ 4. Wetland } & 180 & $\begin{array}{l}\text { Shrub or herbaceous cover, flooded, fresh-saline or brakish } \\
\text { water }\end{array}$ \\
\hline \multicolumn{2}{|c|}{ 5. Settlement } & 190 & Urban \\
\hline \multirow[t]{5}{*}{ 6. Other } & Shrubland & $120,121,122$ & Shrubland \\
\hline & \multirow[t]{2}{*}{ Sparse vegetation } & 140 & Lichens and mosses \\
\hline & & $\begin{array}{l}150,151,152 \\
153\end{array}$ & Sparse vegetation (tree, shrub, herbaceous cover) \\
\hline & Bare area & $200,201,202$ & Bare areas \\
\hline & Water & 210 & Water \\
\hline
\end{tabular}

The second step of the change module is the detailed delineation of the change detection 1-km hot spots and their surroundings (up to $5 \mathrm{~km}$ ) at $300 \mathrm{~m}$ between 2004 and 2015 thanks to the MERIS and PROBA-V time series available at a spatial resolution of $300 \mathrm{~m}$ at this period.

\subsubsection{Format}

\section{- Naming Convention}

The filename convention of the global LC maps delivered by the CCI-LC project is the following:

Filename $=\langle\mathrm{id}\rangle-\mathrm{v}\langle\mathrm{version}>$.nc $/ \mathrm{tif}$

where $\langle$ id $\rangle=\langle$ project $\rangle-\langle$ level $\rangle-\langle$ var $\rangle-\langle$ code $\rangle-\langle$ spatres $\rangle-\langle$ tempres $\rangle-\langle$ epoch $\rangle-\langle$ area $\rangle$ 


\begin{tabular}{|c|c|c|c|c|}
\hline \multirow{2}{*}{ CeSa } & Ref & \multicolumn{2}{|c|}{ CCI LC PUG v2 } \\
\cline { 2 - 5 } & Issue & Page & Date & land couer \\
\cline { 2 - 5 } & 2.0 & 31 & $2017-04-10$ & cci \\
\hline
\end{tabular}

The dash "-" is the separator between name components. The filename convention obeys NetCDF CF by using the postfix ".nc" and can be written as a GeoTiff file using the extension ".tif". The different name components are defined in Table 3-4.

Table 3-4. Components that make the name of the LC maps delivered by the CCI-LC project.

\begin{tabular}{|l|l|l|}
\hline \multicolumn{1}{|c|}{ FIELD } & \multicolumn{1}{|c|}{ SIGNIFICATION } & \multicolumn{1}{c|}{ VALUE } \\
\hline project & Project acronym & ESACCI- LC (constant) \\
\hline level & Processing level & L4 (constant) \\
\hline var & Unit of the LC product & LCCS (constant) \\
\hline code & Product code identifier for CCI-LC products & Map (constant) \\
\hline spatres & Spatial resolution & 300 m (constant) \\
\hline tempres & Temporal resolution & P1Y (constant) \\
\hline epoch & Year of the product & {$[1992 \ldots$ 2015] } \\
\hline version & $\begin{array}{l}\text { Incremental that follows the successive } \\
\text { revisions of the CCI-LC Processing lines }\end{array}$ & $\begin{array}{l}\text { Version of product revision, preferably major.minor, } \\
\text { optionally with processing centre [a-zA-ZO-9._]* }\end{array}$ \\
\hline
\end{tabular}

An example filename of the global LC map for year 2010 would be: "ESACCI-LC-L4-LCCS-Map300m-P1Y-2010-v2.0.nc/tif ».

\section{- Processing Level}

Level 4 (i.e. "variables that are not directly measured by the instruments, but are derived from these measurements" [RD.14])

\section{- Units}

Each pixel value corresponds to the label of a land cover class defined using UN-LCCS classifiers (see Table 3-1 in Section 3.1.1 and Appendix 1 in Section 9).

\section{- Spatial Extent}

All terrestrial zones of the Earth between the parallels $90^{\circ} \mathrm{N}$ and $90^{\circ} \mathrm{S}$.

\section{- Spatial Resolution}

$300 \mathrm{~m}$

\section{- Temporal resolution}

Annual

\section{- Product layers}

The land cover maps are delivered along with 4 quality flags which document the reliability of the classification and change detection (Table 3-5).

Table 3-5: Quality flags of the LC maps.

\begin{tabular}{|c|l|l|}
\hline NAME IN PRODUCT & \multicolumn{1}{|c|}{ DATA TYPE } & DESCRIPTION \\
\hline ESACCI-LC-L4-LCCS-Map-300m-P5Y- & byte & LC classification in LCCS (22 global classes + NoData \\
\hline
\end{tabular}




\begin{tabular}{|c|c|c|c|c|}
\hline \multirow{2}{*}{ CeSa } & Ref & \multicolumn{3}{|c|}{ CCI LC PUG v2 } \\
\cline { 2 - 5 } & Issue & Page & Date & Iand couer \\
\cline { 2 - 5 } & 2.0 & 32 & $2017-04-10$ & Ici \\
\hline
\end{tabular}

\begin{tabular}{|c|c|c|}
\hline NAME IN PRODUCT & DATA TYPE & DESCRIPTION \\
\hline YYYY-vx.x.nc/tif & & coded as 0) \\
\hline $\begin{array}{l}\text { ESACCI-LC-L4-LCCS-Map-300m-P5Y- } \\
\text { YYYY-v1.0_qualityflag1.nc/tif }\end{array}$ & byte & $\begin{array}{l}\text { Indicates if the pixel has been processed (1) or not (0) } \\
0 \text { - pixel not processed } \\
1 \text { - pixel processed }\end{array}$ \\
\hline $\begin{array}{l}\text { ESACCI-LC-L4-LCCS-Map-300m-P5Y- } \\
\text { YYYY-v1.0_qualityflag2.nc/tif }\end{array}$ & byte & $\begin{array}{l}\text { Indicates the pixel status as defined by the pre- } \\
\text { processing: } \\
1 \text { - Pixel flagged as "clear land" } \\
2 \text { - Pixel flagged as "clear water" } \\
3 \text { - Pixel flagged as "clear snow and ice" } \\
4 \text { - Pixel flagged as "cloud" } \\
5 \text { - Pixel flagged as "cloud shadow" } \\
6 \text { - Pixel flagged as "filled" }\end{array}$ \\
\hline $\begin{array}{l}\text { ESACCI-LC-L4-LCCS-Map-300m-P5Y- } \\
\text { YYYY-v1.0_qualityflag3.nc/tif }\end{array}$ & byte & $\begin{array}{l}\text { Indicates the number of valid observations available } \\
\text { to derive the classification }\end{array}$ \\
\hline $\begin{array}{l}\text { ESACCI-LC-L4-LCCS-Map-300m-P5Y- } \\
\text { YYYY-v1.0_qualityflag4.nc/tif }\end{array}$ & byte & $\begin{array}{l}\text { Provides the number of LC change observed during } \\
\text { the period 1992-2015 (ranging from } 0 \text { to 5) per pixel }\end{array}$ \\
\hline
\end{tabular}

\section{- Projection}

The projection is a Plate-Carree with a geographic Lat/Long representation based on the WGS84 ellipsoid (Figure 3-5). The Coordinate Reference System (CRS) used for the global LC products is a geographic coordinate system (GCS) based on the World Geodetic System 84 (WGS84) reference ellipsoid and using a Plate Carrée projection.

The projection makes use of an equatorial radius (also called semi-major axis) of $6378.14 \mathrm{~km}$ and of a polar radius (also called semi-minor axis) of $6356.76 \mathrm{~km}$. The inverse flattening parameter is of $298.26 \mathrm{~m}$. The coordinates are specified in decimal degrees. A complete description of the CRS is given in as an ISO 19111 WKT representation.

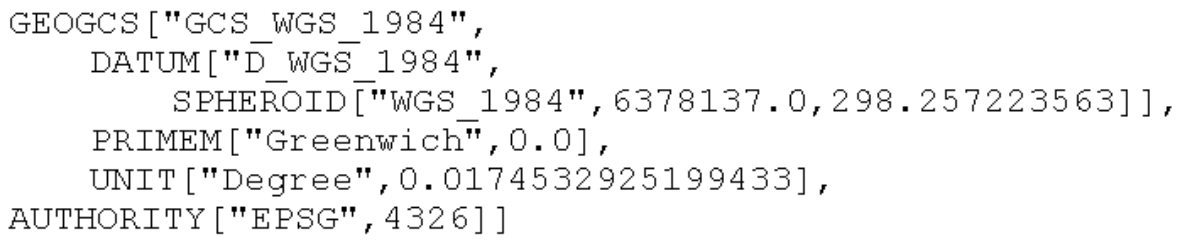

Figure 3-5: Description of the coordinate reference system defining the global LC products.

\section{- Format}

The LC maps are delivered in NetCDF-4 and GeoTiff format. The NetCDF files specification follows CF conventions [RD.16].

\section{- Metadata}

The metadata for the LC maps are provided as global attributes in the NetCDF file and are included in the GeoTiff raster. It follows the CCI guidelines [RD.17]. 


\begin{tabular}{|c|c|c|c|c|}
\hline \multirow{2}{*}{ CeSa } & Ref & \multicolumn{2}{|c|}{ CCI LC PUG v2 } \\
\cline { 2 - 5 } & Issue & Page & Date & land couer \\
\cline { 2 - 5 } & 2.0 & 33 & $2017-04-10$ & cci \\
\hline
\end{tabular}

\section{- Estimated size}

The size of one global land cover map is around $260 \mathrm{MB}$. The size of the quality flags varies between $80 \mathrm{MB}$ and $2 \mathrm{~GB}$. These estimations take an internal LZW compression into account.

\subsection{Qualitative assessment}

The following figures present the annual LC products, with a focus on the year 2015 which is the most recent one of the map series. This presentation is done, through snapshots and visual comparison with reference datasets and with the previous version of the CCI-LC map for the 2010 epoch (v1.6.1), in various regions of the world. These comparisons show the accomplished progress.

The high level of thematic detail present in the CCI-LC maps is illustrated in Figure 3-6, Figure 3-7 and Figure 3-8. Figure 3-6 illustrates the increased representativeness of CCI-LC map 2015 for the Boreal zone with a reduction of the bare areas class.

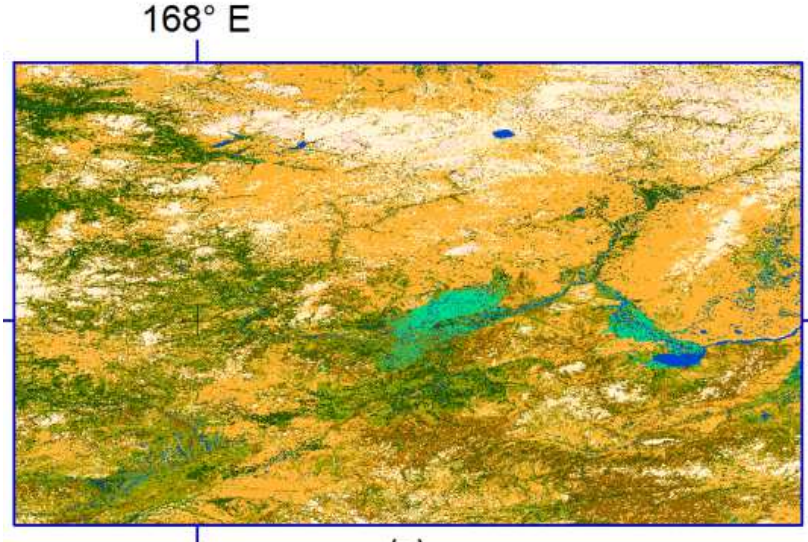

(a)

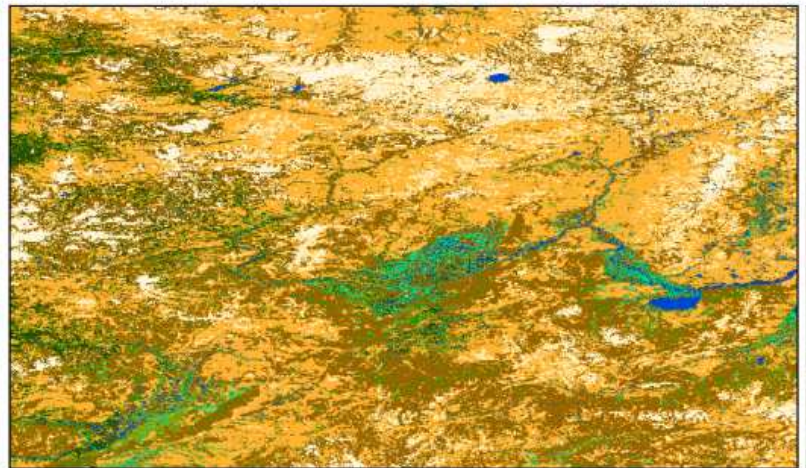

(c)

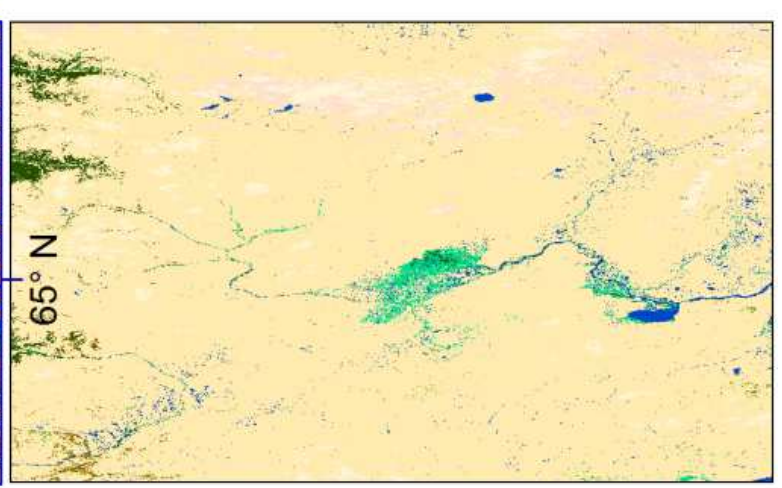

(b)

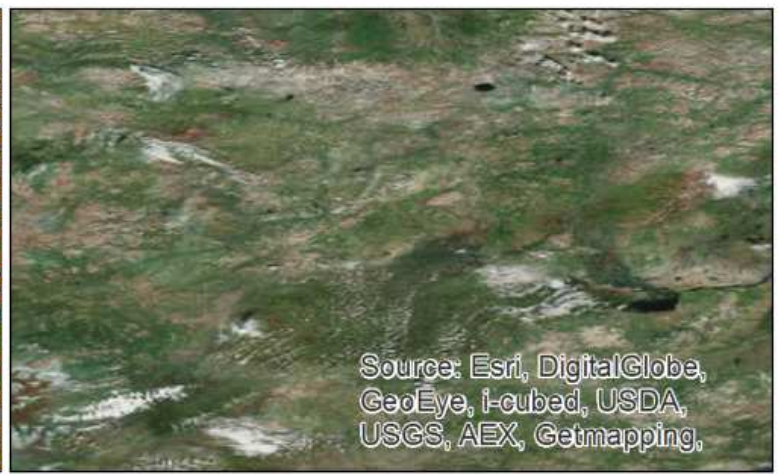

(d)

Figure 3-6: Comparison, over Russia, between the 2015 LC map (a), the CCI LC v1.6.1 from the 2010 epoch (b), the Northern Eurasia Land Cover database [RD.31] (c) and the ESRI high resolution base map layer (d). 


\begin{tabular}{|c|c|c|c|c|}
\hline \multirow{2}{*}{ e esa } & Ref & \multicolumn{2}{|c|}{ CCI LC PUG v2 } \\
\cline { 2 - 4 } & Issue & Page & Date & Iand couer \\
\cline { 2 - 5 } & 2.0 & 34 & $2017-04-10$ \\
cci
\end{tabular}

In general, good agreement between the CCI-LC map 2015 and other existing reference maps is also observed, even if these reference datasets are of higher spatial resolution. This is the case with the SERVIR datasets [RD.34], as illustrated over Zambia in Figure 3-7.

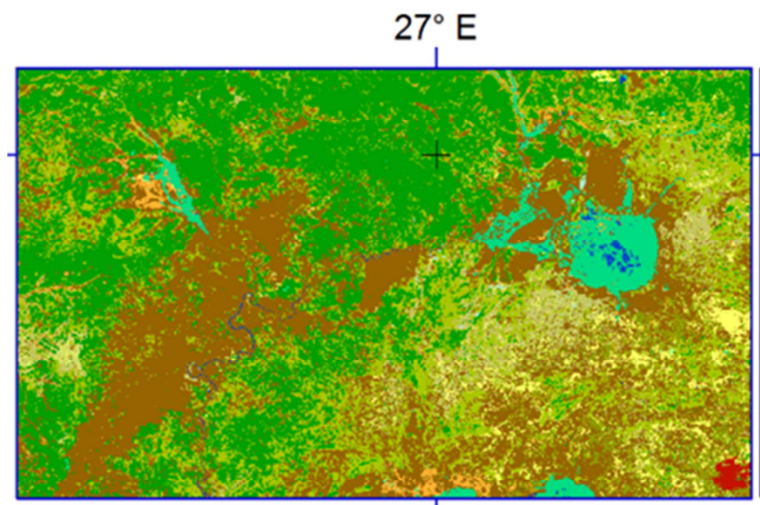

(a)

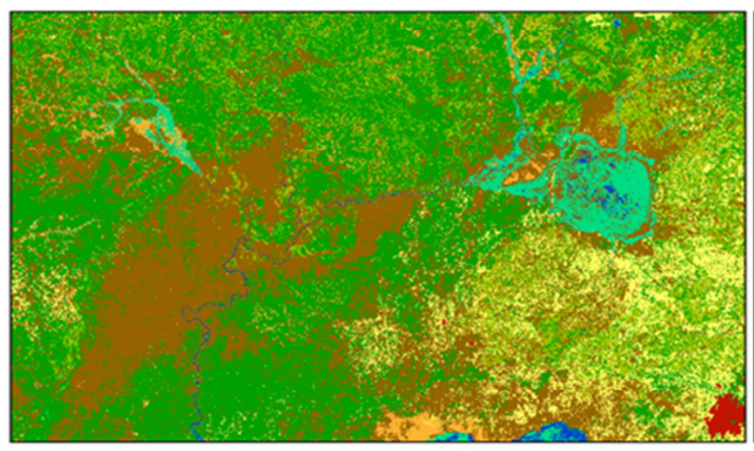

(c)

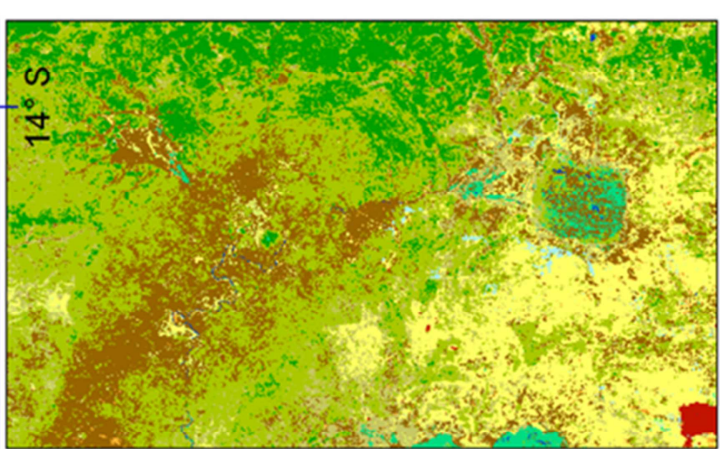

(b)

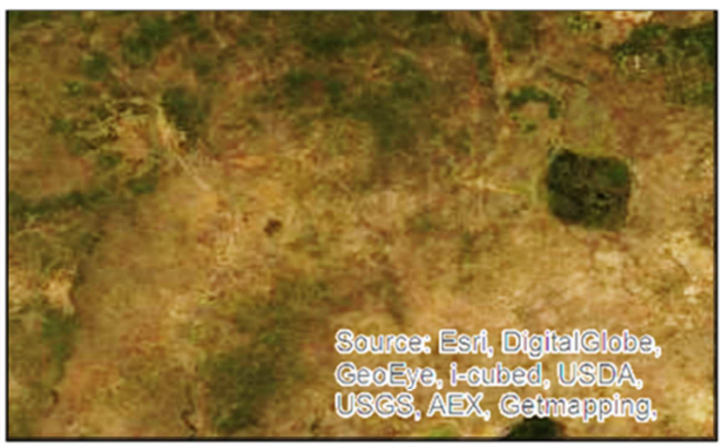

(d)

Figure 3-7: Comparison, over Zambia, between the 2015 LC map (a), the CCI-LC v1.6.1 from the 2010 epoch (b), the SERVIR land cover of Zambia (c) and the ESRI high resolution base map layer (d).

Good agreement is also observed with lower spatial resolution datasets, as illustrated in Figure 3-8 in Angola. 


\begin{tabular}{|c|c|c|c|c|}
\hline \multirow{2}{*}{ CeSa } & Ref & \multicolumn{2}{|c|}{ CCI LC PUG v2 } \\
\cline { 2 - 4 } & Issue & Page & Date & Iand couer \\
\cline { 2 - 5 } & 2.0 & 35 & $2017-04-10$ \\
\hline
\end{tabular}

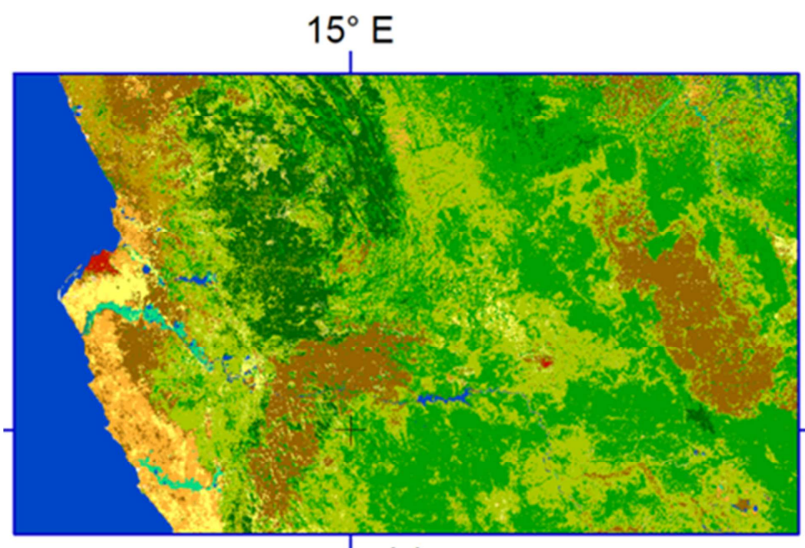

(a)

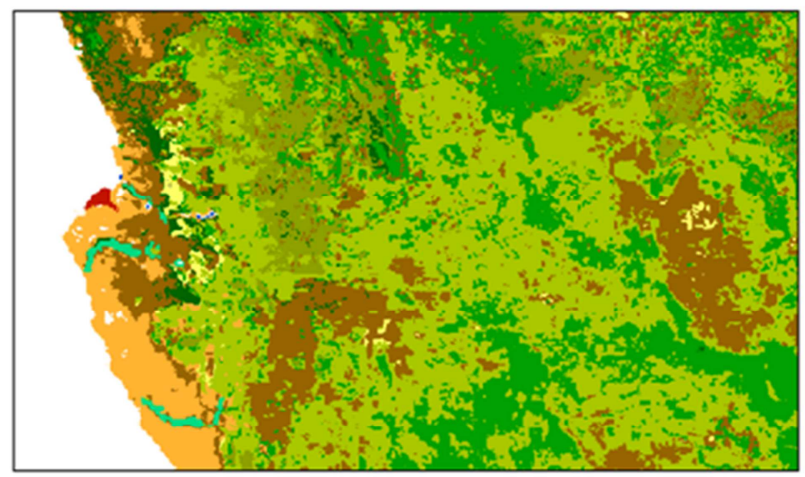

(c)

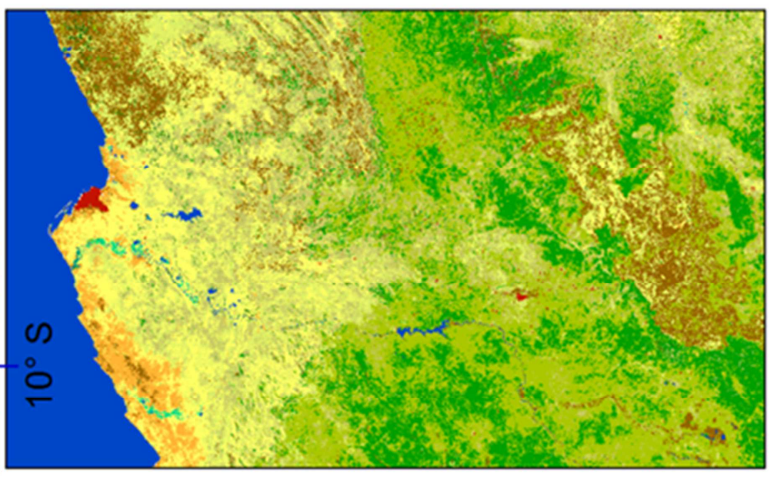

(b)

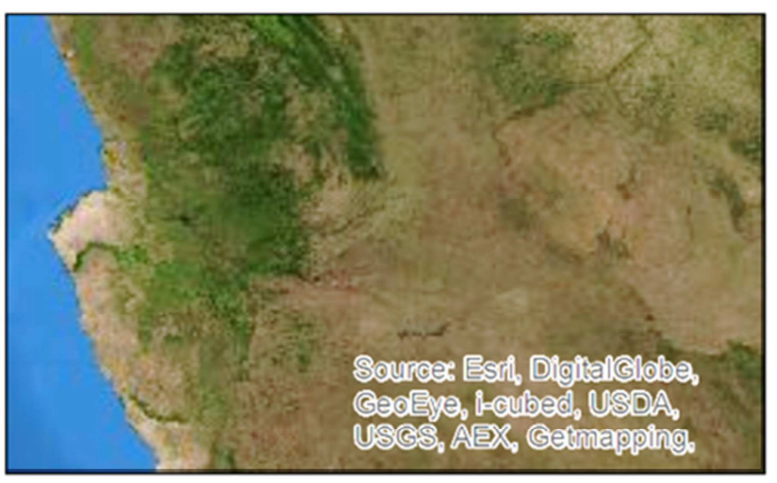

(d)

Figure 3-8: Comparison, over Angola, between the 2015 LC map (a), the CCI-LC v1.6.1 from the 2010 epoch (b), the regional GLC2000 for Africa [RD.32] (c) and the ESRI high resolution base map layer (d).

Figure 3-9 and Figure 3-10 illustrate the land cover dynamics of major LC changes captured in the annual CCI-LC maps from 1992 to 2015 over an area in Brazil and over the Aral Sea, respectively.

In Brazil, the evolution of the deforestation patterns is consistent with what is observed in the Landsat imagery from the Timelapse Google Earth Engine [RD.33]. The slight underestimation of croplands in 1992 is explained by the use of the 1-km AVHRR in the 1990s. The drying up of the Aral Sea is in agreement with recent published research [RD.42]. 


\begin{tabular}{|c|c|c|c|c|}
\hline \multirow{2}{*}{ CeSa } & Ref & \multicolumn{2}{|c|}{ CCI LC PUG v2 } \\
\cline { 2 - 5 } & Issue & Page & Date & 2017-04-10 \\
\cline { 2 - 5 } & 2.0 & 36 & Iand couer \\
cci
\end{tabular}

Figure 3-9: Comparison of deforestation patterns in Brazil between annual LC maps for years 1992, 1997, 2000, 2005, 2010 and 2015 (a) and the corresponding Landsat imagery from Timelapse Google Earth Engine (b). 


\begin{tabular}{|c|c|c|c|c|}
\hline \multirow{2}{*}{ CeSa } & Ref & \multicolumn{3}{|c|}{ CCI LC PUG v2 } \\
\cline { 2 - 5 } & Issue & Page & Date & Iand couer \\
\cline { 2 - 5 } & 2.0 & 37 & $2017-04-10$ & Ici \\
\hline
\end{tabular}

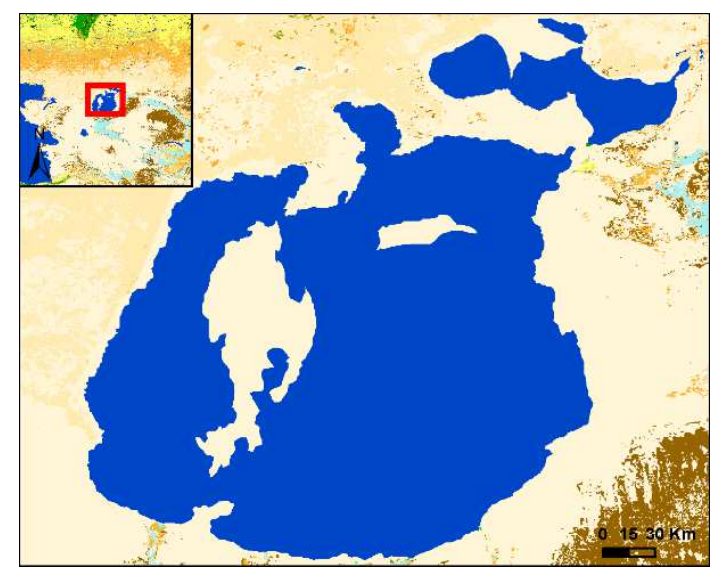

Year 1992

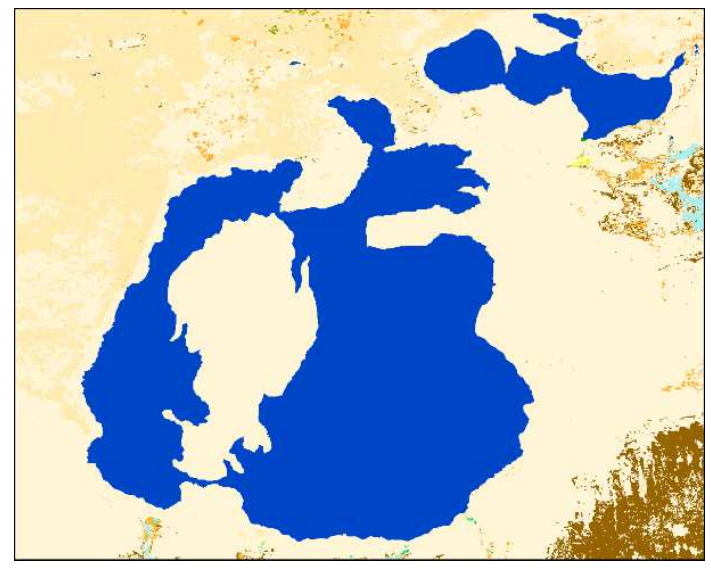

Year 1999

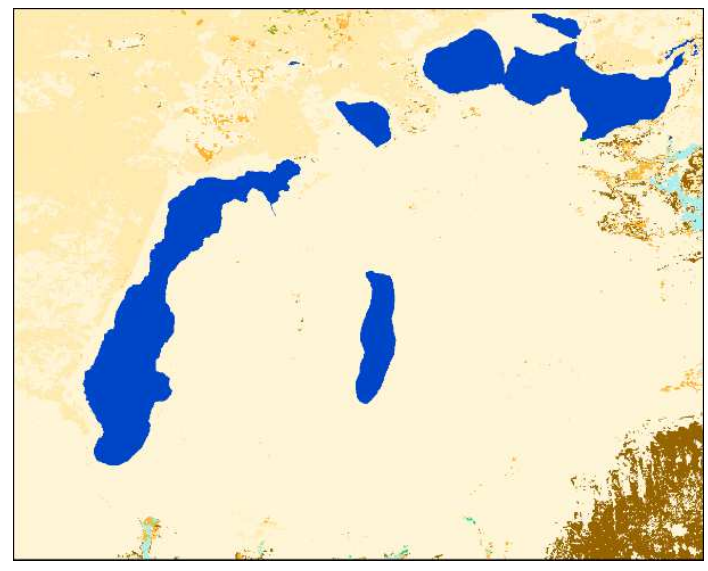

Year 2009

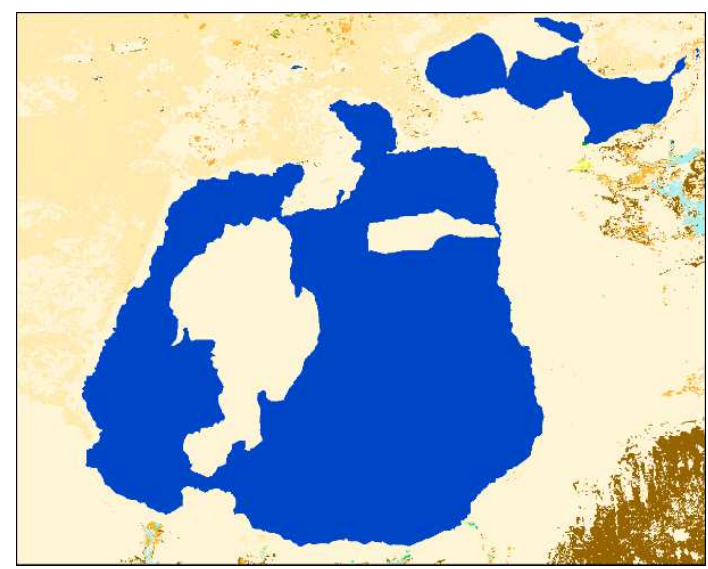

Year 1996

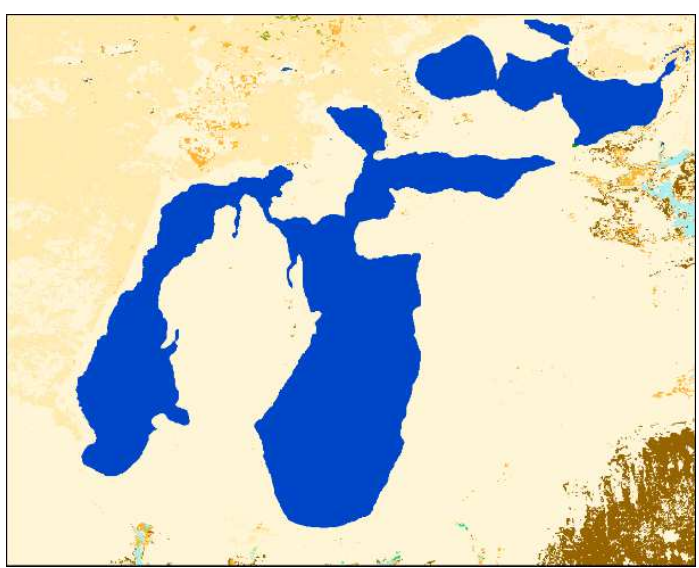

Year 2003

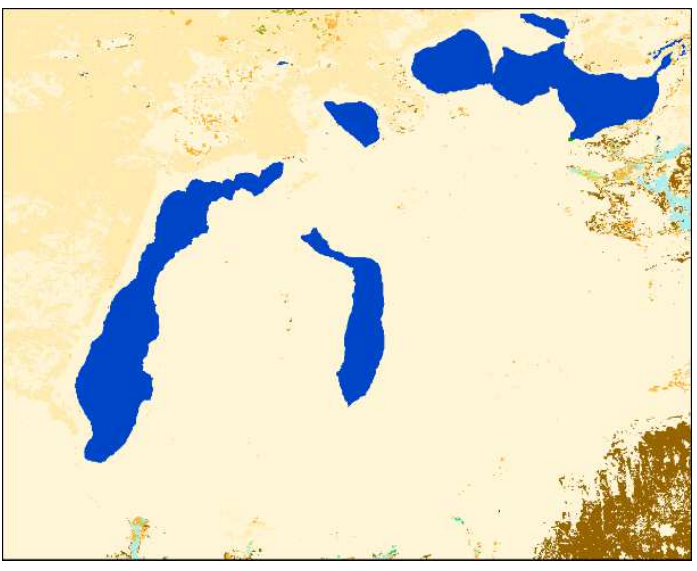

Year 2015

Figure 3-10: Dynamics of the Aral Sea illustrated by the CCl global annual land cover maps for years 1992, 1996, 1999, 2003, 2009 and 2015. 


\begin{tabular}{|c|c|c|c|c|}
\hline \multirow{2}{*}{ CeSa } & Ref & \multicolumn{2}{|c|}{ CCI LC PUG v2 } \\
\cline { 2 - 5 } & Issue & Page & Date & land couer \\
& 2.0 & 38 & $2017-04-10$ & lai \\
\hline
\end{tabular}

\subsection{Validation}

A critical step in the acceptance of the CCI-LC maps by the user communities is providing confidence in their quality through validation against independent data such as ground-based reference measurements or alternate estimates from other projects and sensors.

The main objective of the validation is to allow a potential user determining the "map's fitness for use" for his / her application. There are several definitions of validation available from various agencies, and it was agreed that the Committee on Earth Observation Satellites (CEOS) Working Group on Calibration and Validation (CEOS-WGCV) definition would be adopted within the CCI program:

"The process of assessing, by independent means, the quality of the data products derived from the system outputs".

The validation process independence has been ensured (i) using validation datasets that were not used during the production of the LC maps and (ii) being carried out by external parties, i.e. by staff not involved in the production of the LC maps.

As a preliminary validation process, the accuracy of the CCI-LC map of year 2015 was assessed using the GlobCover 2009 validation dataset such as in the GlobCover validation exercises [RD-3] [RD-4]. Due to the fact that the GlobCover and CCI-LC legends are not fully identical, not all the points of the GlobCover 2009 validation database could be used.

Contingency matrices were built and overall accuracies were not only calculated based on the diagonal cells of the matrix but also accounted for other cells which mark agreement between the product and the validation dataset. Table 3-6 presents a first contingency matrix calculated by comparing the CCI-LC map from 2015 with all the points interpreted as "certain" by the experts, whether "homogeneous" (i.e. made of a single LC class) or "heterogeneous" (i.e. made of several or mosaic LC classes). A second contingency matrix is derived using only the "homogeneous" and "certain" points of the GlobCover 2009 validation set, which is presented in Table 3-7. These two matrices indicate that the accuracy level is found to be $71.45 \%$ in the first case and $75.4 \%$ in the second case. 


\begin{tabular}{|c|c|c|c|c|}
\hline \multirow{2}{*}{ CeS2 } & Ref & \multicolumn{3}{|c|}{ CCI LC PUG v2 } \\
\cline { 2 - 5 } & Issue & Page & Date & land couer \\
\cline { 2 - 5 } & 2.0 & 39 & $2017-04-10$ & cci \\
\hline
\end{tabular}

Table 3-6: Adjusted contingency matrix that considers the CCI-LC 2015 map and the "certain" ("homogeneous" and "heterogeneous") points of the GlobCover 2009 validation dataset. Green cells mark diagonal cells while yellow cells represent other samples that also mark a clear agreement between the product and the reference.

\begin{tabular}{|c|c|c|c|c|c|c|c|c|c|c|c|c|c|c|c|c|c|c|c|c|c|c|c|c|c|}
\hline & \multicolumn{25}{|c|}{ REFERENCE: GLOBCOVER 2009 VALIDATION DATASET } \\
\hline & 0 & 10 & 20 & 30 & 40 & 50 & 60 & 70 & 80 & 90 & 100 & 110 & 120 & 130 & 140 & 150 & 160 & 170 & 180 & 190 & 200 & 210 & 220 & SUM & $\begin{array}{c}\text { User } \\
\text { Acc. (\%) }\end{array}$ \\
\hline \multirow{24}{*}{ 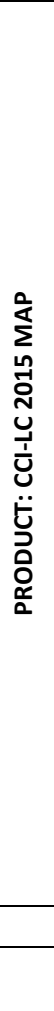 } & 10 & 342 & 50 & 0 & 0 & 7 & 0 & 0 & 0 & 6 & 0 & 0 & 9 & 13 & 0 & 1 & 0 & 0 & 3 & 7 & 4 & 0 & 0 & 442 & 89 \\
\hline & 20 & 9 & 16 & 0 & 0 & 0 & 0 & 0 & 0 & 0 & 0 & 0 & 0 & 1 & 0 & 0 & 0 & 0 & 0 & 1 & 1 & 0 & 0 & 28 & 89 \\
\hline & 30 & 22 & 2 & 21 & 0 & 3 & 2 & 1 & 0 & 4 & 0 & 0 & 5 & 1 & 0 & 0 & 0 & 0 & 0 & 1 & 0 & 0 & 0 & 62 & 73 \\
\hline & 40 & 15 & 0 & 0 & 13 & 3 & 2 & 0 & 0 & 0 & 0 & 0 & 2 & 4 & 0 & 2 & 0 & 0 & 0 & 0 & 0 & 0 & 0 & 41 & 59 \\
\hline & 50 & 9 & 2 & 0 & 0 & 257 & 2 & 1 & 0 & 15 & 0 & 0 & 1 & 1 & 0 & 0 & 0 & 0 & 0 & 0 & 0 & 0 & 0 & 288 & 94 \\
\hline & 60 & 13 & 1 & 0 & 0 & 21 & 74 & 2 & 5 & 43 & 0 & 0 & 26 & 8 & 0 & 1 & 0 & 0 & 3 & 0 & 1 & 2 & 0 & 200 & 59 \\
\hline & 70 & 3 & 0 & 0 & 0 & 3 & 3 & 63 & 3 & 57 & 0 & 0 & 13 & 14 & 7 & 2 & 0 & 0 & 7 & 0 & 7 & 3 & 2 & 187 & 64 \\
\hline & 80 & 0 & 0 & 0 & 0 & 0 & 2 & 0 & 37 & 3 & 0 & 0 & 2 & 1 & 3 & 1 & 0 & 0 & 0 & 0 & 2 & 0 & 0 & 51 & 78 \\
\hline & 90 & 0 & 0 & 0 & 0 & 1 & 9 & 11 & 1 & 12 & 0 & 0 & 0 & 0 & 0 & 0 & 0 & 0 & 0 & 0 & 0 & 0 & 0 & 34 & 35 \\
\hline & 100 & 20 & 0 & 0 & 0 & 3 & 2 & 3 & 0 & 2 & 5 & 0 & 6 & 8 & 3 & 2 & 0 & 0 & 0 & 2 & 2 & 0 & 0 & 58 & 36 \\
\hline & 110 & 1 & 0 & 0 & 0 & 1 & 0 & 0 & 0 & 0 & 0 & 2 & 1 & 2 & 0 & 2 & 0 & 0 & 2 & 0 & 0 & 0 & 0 & 11 & 36 \\
\hline & 120 & 20 & 2 & 0 & 0 & 4 & 5 & 2 & 0 & 5 & 0 & 0 & 118 & 24 & 3 & 11 & 0 & 0 & 1 & 1 & 12 & 1 & 2 & 211 & 56 \\
\hline & 130 & 33 & 3 & 0 & 0 & 0 & 0 & 1 & 1 & 4 & 0 & 0 & 19 & 99 & 2 & 12 & 0 & 0 & 0 & 4 & 23 & 1 & 2 & 204 & 49 \\
\hline & 140 & 0 & 0 & 0 & 0 & 0 & 0 & 1 & 0 & 0 & 0 & 0 & 0 & 4 & 10 & 0 & 0 & 0 & 5 & 0 & 4 & 0 & 2 & 26 & 38 \\
\hline & 150 & 3 & 0 & 0 & 0 & 0 & 0 & 0 & 1 & 0 & 0 & 0 & 10 & 9 & 6 & 33 & 0 & 0 & 0 & 2 & 28 & 0 & 2 & 94 & 35 \\
\hline & 160 & 1 & 0 & 0 & 0 & 8 & 1 & 0 & 0 & 0 & 0 & 0 & 0 & 1 & 2 & 0 & 6 & 1 & 3 & 0 & 0 & 0 & 0 & 23 & 26 \\
\hline & 170 & 0 & 0 & 0 & 0 & 1 & 0 & 0 & 0 & 0 & 0 & 0 & 0 & 0 & 0 & 0 & 1 & 6 & 0 & 0 & 0 & 0 & 0 & 8 & 75 \\
\hline & 180 & 0 & 0 & 0 & 0 & 0 & 0 & 0 & 0 & 0 & 0 & 0 & 1 & 3 & 1 & 0 & 0 & 0 & 8 & 0 & 0 & 2 & 0 & 15 & 53 \\
\hline & 190 & 1 & 2 & 0 & 0 & 0 & 0 & 0 & 0 & 0 & 0 & 0 & 0 & 0 & 0 & 0 & 0 & 0 & 0 & 22 & 0 & 0 & 0 & 25 & 88 \\
\hline & 200 & 1 & 1 & 0 & 0 & 0 & 0 & 0 & 0 & 1 & 0 & 0 & 1 & 2 & 1 & 4 & 0 & 0 & 0 & 2 & 160 & 2 & 6 & 181 & 88 \\
\hline & 210 & 0 & 2 & 0 & 0 & 0 & 0 & 0 & 0 & 1 & 0 & 0 & 1 & 0 & 1 & 1 & 0 & 0 & 1 & 1 & 0 & 102 & 1 & 111 & 92 \\
\hline & 220 & 0 & 0 & 0 & 0 & 0 & 0 & 0 & 0 & 0 & 0 & 0 & 0 & 0 & 0 & 0 & 0 & 0 & 0 & 0 & 1 & 0 & 28 & 29 & 97 \\
\hline & SUM & 493 & 81 & 21 & 13 & 312 & 102 & 85 & 48 & 153 & 5 & 2 & 215 & 195 & 39 & 72 & 7 & 7 & 33 & 43 & 245 & 113 & 45 & 2329 & \\
\hline & $\begin{array}{l}\text { Prod. } \\
\text { Acc (\%) }\end{array}$ & 76 & 84 & 100 & 100 & 84 & 76 & 78 & 77 & 86 & 100 & 100 & 59 & 54 & 26 & 46 & 86 & 86 & 24 & 51 & 65 & 90 & 62 & & 71.45 \\
\hline
\end{tabular}

(c) UCL-Geomatics 2017

This document is the property of the LAND_COVER_CCI partnership, no part of it shall be reproduced or transmitted without the express prior written authorization of UCLGeomatics (Belgium). 


\begin{tabular}{|c|c|c|c|c|}
\hline \multirow{2}{*}{ CeS2 } & Ref & \multicolumn{3}{|c|}{ CCI LC PUG v2 } \\
\cline { 2 - 5 } & Issue & Page & Date & land couer \\
\cline { 2 - 5 } & 2.0 & 40 & $2017-04-10$ \\
\hline
\end{tabular}

Table 3-7: Adjusted contingency matrix that considers the CCI-LC 2015 map and the "certain" and "homogeneous" points of the GlobCover 2009 validation dataset. Green cells mark diagonal cells while yellow cells represent other samples that also mark a clear agreement between the product and the reference.

\begin{tabular}{|c|c|c|c|c|c|c|c|c|c|c|c|c|c|c|c|c|c|c|c|c|c|c|c|c|c|}
\hline & \multicolumn{23}{|c|}{ REFERENCE: GLOBCOVER 2009 VALIDATION DATASET } & \multirow[b]{2}{*}{ SUM } & \multirow[b]{2}{*}{ User Acc. (\%) } \\
\hline & 0 & 10 & 20 & 30 & 40 & 50 & 60 & 70 & 80 & 90 & 100 & 110 & 120 & 130 & 140 & 150 & 160 & 170 & 180 & 190 & 200 & 210 & 220 & & \\
\hline \multirow{24}{*}{ 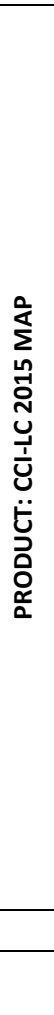 } & 10 & 245 & 27 & 0 & 0 & 4 & 0 & 0 & 0 & 1 & 0 & 0 & 6 & 7 & 0 & 0 & 0 & 0 & 2 & 5 & 0 & 0 & 0 & 297 & 92 \\
\hline & 20 & 5 & 5 & 0 & 0 & 0 & 0 & 0 & 0 & 0 & 0 & 0 & 0 & 1 & 0 & 0 & 0 & 0 & 0 & 0 & 1 & 0 & 0 & 12 & 83 \\
\hline & 30 & 18 & 2 & 0 & 0 & 2 & 1 & 0 & 0 & 1 & 0 & 0 & 2 & 1 & 0 & 0 & 0 & 0 & 0 & 1 & 0 & 0 & 0 & 28 & 71 \\
\hline & 40 & 12 & 0 & 0 & 0 & 3 & 1 & 0 & 0 & 0 & 0 & 0 & 2 & 3 & 0 & 2 & 0 & 0 & 0 & 0 & 0 & 0 & 0 & 23 & 39 \\
\hline & 50 & 4 & 2 & 0 & 0 & 224 & 2 & 1 & 0 & 8 & 0 & 0 & 0 & 0 & 0 & 0 & 0 & 0 & 0 & 0 & 0 & 0 & 0 & 241 & 96 \\
\hline & 60 & 5 & 0 & 0 & 0 & 18 & 44 & 1 & 4 & 31 & 0 & 0 & 16 & 3 & 0 & 1 & 0 & 0 & 2 & 0 & 0 & 1 & 0 & 126 & 60 \\
\hline & 70 & 1 & 0 & 0 & 0 & 2 & 2 & 35 & 2 & 28 & 0 & 0 & 8 & 5 & 1 & 1 & 0 & 0 & 5 & 0 & 2 & 2 & 1 & 95 & 66 \\
\hline & 80 & 0 & 0 & 0 & 0 & 0 & 0 & 0 & 12 & 2 & 0 & 0 & 2 & 1 & 0 & 0 & 0 & 0 & 0 & 0 & 0 & 0 & 0 & 17 & 82 \\
\hline & 90 & 0 & 0 & 0 & 0 & 1 & 6 & 2 & 0 & 4 & 0 & 0 & 0 & 0 & 0 & 0 & 0 & 0 & 0 & 0 & 0 & 0 & 0 & 13 & 31 \\
\hline & 100 & 5 & 0 & 0 & 0 & 3 & 1 & 0 & 0 & 1 & 0 & 0 & 3 & 6 & 1 & 1 & 0 & 0 & 0 & 1 & 1 & 0 & 0 & 23 & 35 \\
\hline & 110 & 1 & 0 & 0 & 0 & 1 & 0 & 0 & 0 & 0 & 0 & 0 & 1 & 2 & 0 & 2 & 0 & 0 & 2 & 0 & 0 & 0 & 0 & 9 & 22 \\
\hline & 120 & 15 & 2 & 0 & 0 & 4 & 4 & 1 & 0 & 1 & 0 & 0 & 92 & 10 & 0 & 10 & 0 & 0 & 1 & 1 & 7 & 0 & 1 & 149 & 62 \\
\hline & 130 & 25 & 1 & 0 & 0 & 0 & 0 & 1 & 1 & 1 & 0 & 0 & 13 & 48 & 0 & 8 & 0 & 0 & 0 & 2 & 2 & 1 & 1 & 104 & 46 \\
\hline & 140 & 0 & 0 & 0 & 0 & 0 & 0 & 0 & 0 & 0 & 0 & 0 & 0 & 2 & 3 & 0 & 0 & 0 & 1 & 0 & 2 & 0 & 1 & 9 & 33 \\
\hline & 150 & 3 & 0 & 0 & 0 & 0 & 0 & 0 & 0 & 0 & 0 & 0 & 7 & 4 & 1 & 9 & 0 & 0 & 0 & 1 & 17 & 0 & 0 & 42 & 21 \\
\hline & 160 & 0 & 0 & 0 & 0 & 4 & 1 & 0 & 0 & 0 & 0 & 0 & 0 & 1 & 1 & 0 & 5 & 1 & 1 & 0 & 0 & 0 & 0 & 14 & 36 \\
\hline & 170 & 0 & 0 & 0 & 0 & 1 & 0 & 0 & 0 & 0 & 0 & 0 & 0 & 0 & 0 & 0 & 1 & 5 & 0 & 0 & 0 & 0 & 0 & 7 & 71 \\
\hline & 180 & 0 & 0 & 0 & 0 & 0 & 0 & 0 & 0 & 0 & 0 & 0 & 1 & 3 & 1 & 0 & 0 & 0 & 3 & 0 & 0 & 1 & 0 & 9 & 33 \\
\hline & 190 & 1 & 2 & 0 & 0 & 0 & 0 & 0 & 0 & 0 & 0 & 0 & 0 & 0 & 0 & 0 & 0 & 0 & 0 & 18 & 0 & 0 & 0 & 21 & 86 \\
\hline & 200 & 0 & 1 & 0 & 0 & 0 & 0 & 0 & 0 & 1 & 0 & 0 & 1 & 2 & 1 & 4 & 0 & 0 & 0 & 1 & 135 & 1 & 6 & 153 & 88 \\
\hline & 210 & 0 & 1 & 0 & 0 & 0 & 0 & 0 & 0 & 0 & 0 & 0 & 0 & 0 & 1 & 0 & 0 & 0 & 1 & 0 & 0 & 78 & 0 & 81 & 96 \\
\hline & 220 & 0 & 0 & 0 & 0 & 0 & 0 & 0 & 0 & 0 & 0 & 0 & 0 & 0 & 0 & 0 & 0 & 0 & 0 & 0 & 1 & 0 & 25 & 26 & 96 \\
\hline & SUM & 340 & 43 & 0 & 0 & 267 & 62 & 41 & 19 & 79 & 0 & 0 & 154 & 99 & 10 & 38 & 6 & 6 & 18 & 30 & 168 & 84 & 35 & 1499 & \\
\hline & $\begin{array}{l}\text { Prod. } \\
\text { Acc (\%) }\end{array}$ & 79 & 79 & N/A & N/A & 86 & 74 & 85 & 63 & 94 & N/A & N/A & 63 & 54 & 30 & 24 & 83 & 83 & 17 & 60 & 80 & 93 & 71 & & 75.38 \\
\hline
\end{tabular}

(c) UCL-Geomatics 2017

This document is the property of the LAND_COVER_CCI partnership, no part of it shall be reproduced or transmitted without the express prior written authorization of UCLGeomatics (Belgium). 


\begin{tabular}{|c|c|c|c|c|}
\hline \multirow{2}{*}{ CeSa } & Ref & \multicolumn{2}{|c|}{ CCI LC PUG v2 } \\
\cline { 2 - 5 } & Issue & Page & Date & land couer \\
\cline { 2 - 5 } & 2.0 & 41 & $2017-03-31$ & cci \\
\hline
\end{tabular}

According to the CEOS recommendations, overall accuracy values weighted by the area proportions of the land cover classes are also calculated. The surfaces of the various land cover classes were determined based on the CCI-LC 2015 product itself, projected in an equal area projection. Using the 1499 "certain" and "homogeneous" points, the weighted-area overall accuracy figure of the 2015 CCI-LC map is of $71.1 \%$, while with the 2329 "certain" points (without homogeneity constraint), it is of $71.7 \%$. In the first case, accounting for the LC classes area decreases a little bit the overall accuracy while in the second case, it does not modify it the value significantly. These figures are higher than the ones of GlobCover 2009 product.

Attention should also be paid to the producer and user accuracy values, which give more information about the accuracy of the different thematic classes and which can also explain the effects observed when weighting the overall accuracy values by the land cover class areas.

The highest user accuracy values ${ }^{3}$ are found for the classes of rainfed cropland (class value 10; 8992\%), irrigated cropland (class value 20; 89-83\%), broadleaved evergreen forest (class value 50; 94$96 \%$ ), urban areas (class value $190 ; 88-86 \%$ ), bare areas (class value $200 ; 88-88 \%$ ), water bodies (class value 210; 92-96\%) and permanent snow and ice (class value 220; 97-96\%). This is generally not surprising as these classes are homogeneous, unambiguous and recognisable. What is more unexpected - and therefore a highly positive result - is the high accuracy associated with the cropland classes. These classes are of paramount importance for food security [RD.38, RD.39, RD.40] but which are unfortunately often poorly captured in global land cover products due to their dynamic nature and the large variety of agro-systems [RD.41].

Conversely, mosaic classes of natural vegetation (class values 100,110) are associated with the lowest user accuracy values, as well as the three classes of lichens and mosses (class value 140), sparse vegetation (class value 150) and flooded forest with fresh water (class value 160). The class of mixed broadleaved and needleleaved forest (class value 90) has also a low user accuracy value, but all errors relate to confusion between this class and other forest classes, which very much limits the impact of this low value.

Finally, it shall be mentioned that the quality of the map varies according to the region of interest. Looking at the number of valid observations available over a region (information provided in the quality flag 3) can give a first indication about the input data quality and the expected classification reliability.

This validation based on the GlobCover 2009 validation dataset is to be seen as a preliminary validation process. A more detailed validation is currently undergoing based on a new validation dataset collected in the framework of this project and which should allow capturing better the complexity of the landscape and also validating the LC changes.

${ }^{3}$ The figures given into brackets correspond to the ones given in Table 3-6 first (certain points, homogeneous and heterogeneous) and in Table 3-7 second (certain points, homogeneous only) 


\begin{tabular}{|c|c|c|c|c|}
\hline \multirow{2}{*}{ CeSa } & Ref & \multicolumn{2}{|c|}{ CCI LC PUG v2 } \\
\cline { 2 - 5 } & Issue & Page & Date & land couer \\
& 2.0 & 42 & $2017-03-31$ & cci \\
\hline
\end{tabular}

\subsection{Limitations}

\section{- Classification accuracy related to the number of observations in the MERIS archive}

As already mentioned, users have to know that the quality of the map varies according to the region of interest. Looking at the number of valid observations available over a region (information which is provided in the quality flag 3) can give a first indication about the input data quality and the expected classification reliability. Areas affected by a lower MERIS FR coverage are the western part of the Amazon basin, Chili and the southern part of Argentina, the western part of Congo basin as well as the gulf of Guinea, the eastern part of Russia, the eastern coast of China and Indonesia.

\section{- Classification accuracy in the light of the contingency matrix}

The overall accuracy figures presented in the previous section must be balanced by the fact that the LC maps quality varies according to the thematic class. In particular, land cover classes such as rainfed and irrigated croplands, broadleaved evergreen forest, urban areas, bare areas, water bodies and permanent snow are found quite accurately mapped. On the other hand, classes such as lichens and mosses, sparse vegetation and flooded forest with fresh water can be affected by errors. The mosaic classes of natural vegetation have also lower user accuracy values, such as the class of mixed broadleaved and needleleaved forest. Yet, in this latter case, most of the errors occur between this class and other forest classes, which very much limits the thematic impact of this lower accuracy value.

\section{- Not all possible changes between the 22 LC classes are captured in the dataset}

Given the methodology to detect the change (section 3.1.2), it is of paramount importance to highlight that the CCI-LC dataset does not capture all the possible changes between the 22 LCCS land cover classes.

The 22 LCCS land cover classes are indeed grouped into the 6 IPCC land categories, with the consideration of the subcategories shrubland, sparse vegetation, bare area and water (forming the "Other" IPCC main land category), as explained in Table 3-3. Consequently, any change occurring between LCCS classes being part of the same IPCC land category is not captured by the CCI-LC dataset. More precisely, the CCI-LC dataset does not provide information on:

- the conversions between rainfed (class values 10,11 and 12) and irrigated agriculture (class value 20). As a result, the agriculture intensification through the irrigation will not be detected as a change;

- the conversion between forest classes (e.g. conversion of broadleaved to mixed forests, flooded forest dewatering or salinization of a forest flooded with fresh water); 


\begin{tabular}{|c|c|c|c|c|}
\hline \multirow{2}{*}{ CeSa } & Ref & \multicolumn{2}{|c|}{ CCI LC PUG v2 } \\
\cline { 2 - 5 } & Issue & Page & Date & land couer \\
& 2.0 & 43 & $2017-03-31$ & lai \\
\hline
\end{tabular}

- the conversion between sparse vegetation (class value 150) and lichens and mosses (class value 140);

- the conversion between a "pure"4 class and a mosaic class (e.g. forest degradation characterized by the evolution of a pure forest (class values 50 to 90 ) to a mosaic of natural vegetation (class values 100 and 110); cropland intensification characterized by the conversion of a mosaic of cropland and natural vegetation (class values 30 and 40) to a rainfed or irrigated cropland (class values 10 to 20); forest regeneration characterized a mosaic of natural vegetation (class values 100 and 110) to a pure forest (class values 50 to 90).

- the conversion between "level 2" or "regional" classes (see section 3.1.1), whatever the IPCC land category. This corresponds to any dynamics specific to herbaceous vs woody cropland (class values 11 and 12), to the density of the forests (depicted in the level 2 of the forest classes $61,62,71,72,81$ and 82), to the phenology of the shrubland (class values 121 and 122 ), to the type of the sparse vegetation (class values $151,152,153$ ) or the type of bare area (class values 201 and 202).

\section{- Abrupt changes better captured than gradual ones}

To allow the detection of a change from a class $\mathrm{X}$ to a class $\mathrm{Y}$, the developed method needs to observe the new class $\mathrm{Y}$ during at least 2 consecutive years. This was explained in detail in section 3.1.2, Figure 3-4. As a consequence, abrupt changes are better captured than gradual ones.

Abrupt changes are characterized by sudden LC transitions from one IPCC class to another that most often last more than 2 years (e.g. a forest loss to an agriculture class in Figure 3-2).

Conversely, gradual changes that can be understood as slow transitions between two IPCC classes by going through intermediate mosaic classes are not so well detected. An example of gradual change would be transitions from shrubland (class value 120) to bare area (class value 200) by going through successive land cover states such as mosaics and grasslands classes lasting during maximum 2 years.

\section{- Change delineated at $300 \mathrm{~m}$ based on hot spots of change detected at $1 \mathrm{~km}$}

All annual CCI-LC maps are delivered at $300 \mathrm{~m}$ spatial resolution but it is to be reminded that the change detection is performed at $1 \mathrm{~km}$ spatial resolution, based on the AVHRR, SPOT-VGT and PROBA-V missions. It means that only land cover changes visible at $1 \mathrm{~km}$ are detected. These hot spots of change and their surroundings (up to $5 \mathrm{~km}$ ) are then further delineated at $300 \mathrm{~m}$ starting 2004 onwards thanks to the availability of the $300 \mathrm{~m}$ MERIS and PROBA-V time series at this period.

As a result, several cases of change omissions are observed in the annual LC maps. First, changes of low intensity and/or surface below $1 \mathrm{~km}^{2}$ are not detected. Second, changes are not delineated at 300

4 "pure" is here expressed as opposed to "mosaic" or "mixed" class, which have the values 30, 40, 100 and 110 


\begin{tabular}{|c|c|c|c|c|}
\hline \multirow{2}{*}{ CeSa } & Ref & \multicolumn{3}{|c|}{ CCI LC PUG v2 } \\
\cline { 2 - 5 } & Issue & Page & Date & Iand couer \\
\cline { 2 - 5 } & 2.0 & 44 & $2017-03-31$ & cci \\
\hline
\end{tabular}

$\mathrm{m}$ if it does not occur in the surroundings of a hot spot of change detected at $1 \mathrm{~km}$. In other words, if the change occurs at a distance greater than $5 \mathrm{~km}$ away from the $1 \mathrm{~km}$ change hot spot. Finally, changes will not be delineated at $300 \mathrm{~m}$ if they occur before year 2004 as no MERIS and PROBA-V time series exist at $300 \mathrm{~m}$ before 2003 .

- Changes along the coastlines and of permanent snow and ice class not included in the CCI-LC products

Changes along the coastlines are not captured with a change detection algorithm based on 1-km observations. Yet, an exception is made for changes related to the Saudi Arabia manmade islands.

In addition, the permanent snow and ice (class value 220) remains constant over time and relies solely on the Randolph Glaciers Inventory [RD.12].

\section{- Changes occurring in the 2014 - 2015 period}

Changes occurring in the 2014 - 2015 period are limited to forests changes. This is a consequence of the methodology that needs to have confirmation of the land cover change during at least 2 years. During this period, this confirmation cannot be ensured and so, only the forest changes - which are the easiest to detect - are included in the maps.

\section{- Change during the AVHRR 1992 - 1999 period}

The performance of the change detection is highly dependent on the input data quality and availability. The general lower quality of AVHRR surface reflectances and georeferencing implies a less reliable change detection. In addition, the lack of AVHRR data in year 1994 reduces the change detection reliability for this particular year. 


\begin{tabular}{|c|c|c|c|c|}
\hline \multirow{2}{*}{ CeSa } & Ref & \multicolumn{2}{|c|}{ CCI LC PUG v2 } \\
\cline { 2 - 5 } & Issue & Page & Date & 2017-03-31 \\
\cline { 2 - 5 } & 2.0 & 45 & Iand couer \\
cci
\end{tabular}

\section{LAND SURFACE SEASONALITY PRODUCTS}

\subsection{Products description}

To meet the climate modeling community needs and describe the natural variability of the land surface, two climatological variables, also named "LS seasonality", have been produced: the NDVI LS seasonality, representative of the vegetation greenness and the WB LS seasonality, representative of the the water occurrence. Three climatological variables were produced in Phase I (the NDVI, burned areas and snow seasonality products).

On a per pixel basis, the NDVI LS seasonality reflects, along the year, the average trajectory and the inter-annual variability of a land surface feature over the 1999-2012 period. It is built from existing long-term global datasets with high temporal frequency and moderate spatial resolution $(1 \mathrm{~km})$. It is a result from a compilation of 13 years of 7-day instantaneous observations into 1 temporarily aggregated profile depicting, along the year, the reference behaviour for the vegetation greenness. These measurements are described in Table 4-1.The methodology underlying the generation of these products was developed by the Université catholique de Louvain (UCL). 


\begin{tabular}{|c|c|c|c|c|}
\hline \multirow{2}{*}{ CeSa } & Ref & \multicolumn{3}{|c|}{ CCI LC PUG v2 } \\
\cline { 2 - 5 } & Issue & Page & Date & Iand couer \\
\cline { 2 - 5 } & 2.0 & 46 & $2017-03-31$ & Iai \\
\hline
\end{tabular}

Table 4-1: Main characteristics of the LS seasonality products.

\begin{tabular}{|c|l|l|l|l|l|l|}
\hline $\begin{array}{c}\text { CLIMATOLOGICAL } \\
\text { DATASET }\end{array}$ & MEASUREMENTS & DATA SOURCES & $\begin{array}{c}\text { SPATIAL } \\
\text { COVERAGE } \\
\text { AND } \\
\text { RESOLUTION }\end{array}$ & $\begin{array}{l}\text { TEMPORAL } \\
\text { COVERAGE }\end{array}$ & $\begin{array}{c}\text { TEMPORAL } \\
\text { RESOLUTION }\end{array}$ & $\begin{array}{c}\text { TOTAL } \\
\text { DATA } \\
\text { VOLUME }\end{array}$ \\
\hline NDVI & $\begin{array}{l}- \text { Mean } \\
- \text { Standard } \\
\text { deviation } \\
- \text { Number of valid } \\
\text { weekly } \\
\text { composites } \\
- \text { Status }\end{array}$ & $\begin{array}{l}\text { 14 years of } \\
\text { daily S1 SPOT- } \\
\text { VGT surface } \\
\text { reflectance } \\
\text { time series }\end{array}$ & $\begin{array}{l}\text { Global } \\
1000 \mathrm{~m}\end{array}$ & $1999-2012$ & Weekly & $\sim 30 \mathrm{BB}$ \\
\hline
\end{tabular}

\subsection{NDVI seasonality product}

\subsubsection{Description}

The NDVI seasonality product describes globally the yearly reference dynamic of the vegetation greenness characterizing the 1999-2012 period. It is therefore a valuable reference dataset for phenology studies and phenological metrics extraction at global scale [RD.15]. It is built from 14 years of SPOT-VGT daily top of canopy SR syntheses (S1 products) and of related quality flags.

It comprises 4 measurements in total. The annual behaviour of the vegetation is characterised by two time series of 7-day composites, corresponding first to the NDVI smoothed average and second to the inter-annual variability over the aggregation period (14 years). In addition, 2 quality flags are provided at the pixel-level: the number of valid and cloud-free weekly composites used to generate the NDVI average and the status qualifying the pixel. These items are described thoroughly in Section 4.2.3.

The average component of the resulting NDVI seasonality is illustrated for the 4 seasons of the year in Figure 4-1. As it can be seen, the product clearly captures the spatial pattern of many land features, including the ones situated in the cloudiest regions of the world like the equatorial areas. 


\begin{tabular}{|c|c|c|c|c|}
\hline \multirow{3}{*}{ - e esa } & Ref & \multicolumn{2}{|c|}{ CCI LC PUG v2 } & \multirow{3}{*}{$\begin{array}{l}\text { land couer } \\
\text { cci }\end{array}$} \\
\hline & Issue & Page & Date & \\
\hline & 2.0 & 47 & 2017-03-31 & \\
\hline
\end{tabular}

A
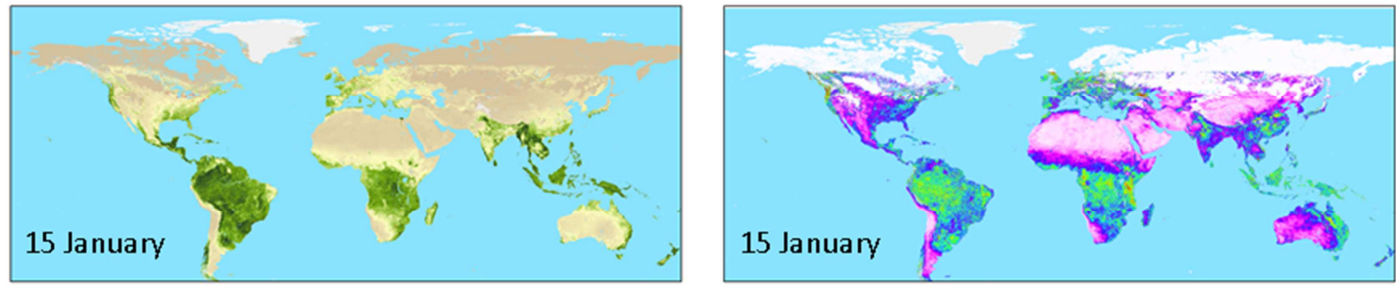

B
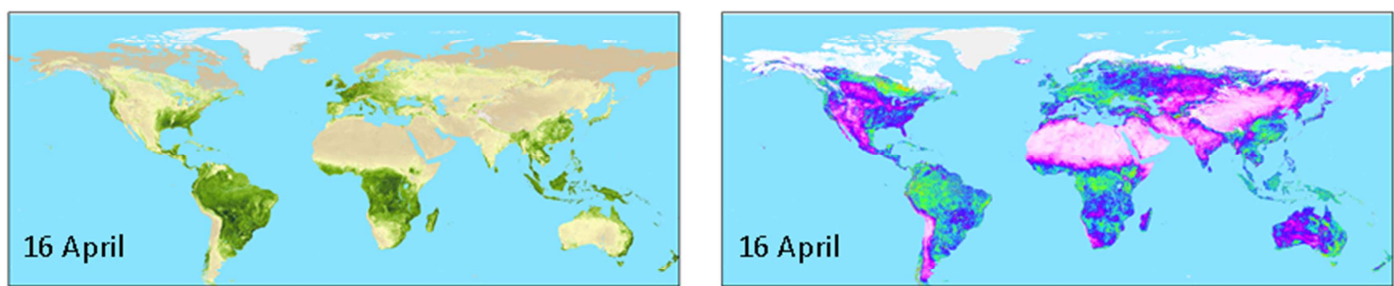

$\mathrm{C}$
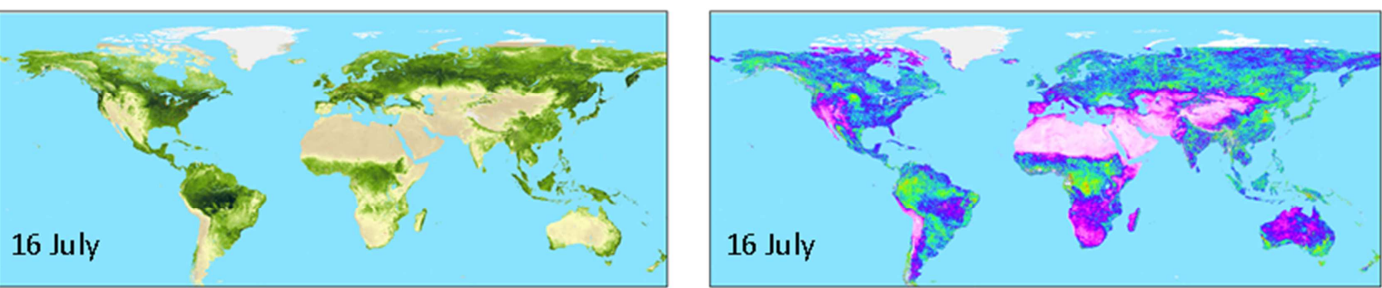

D
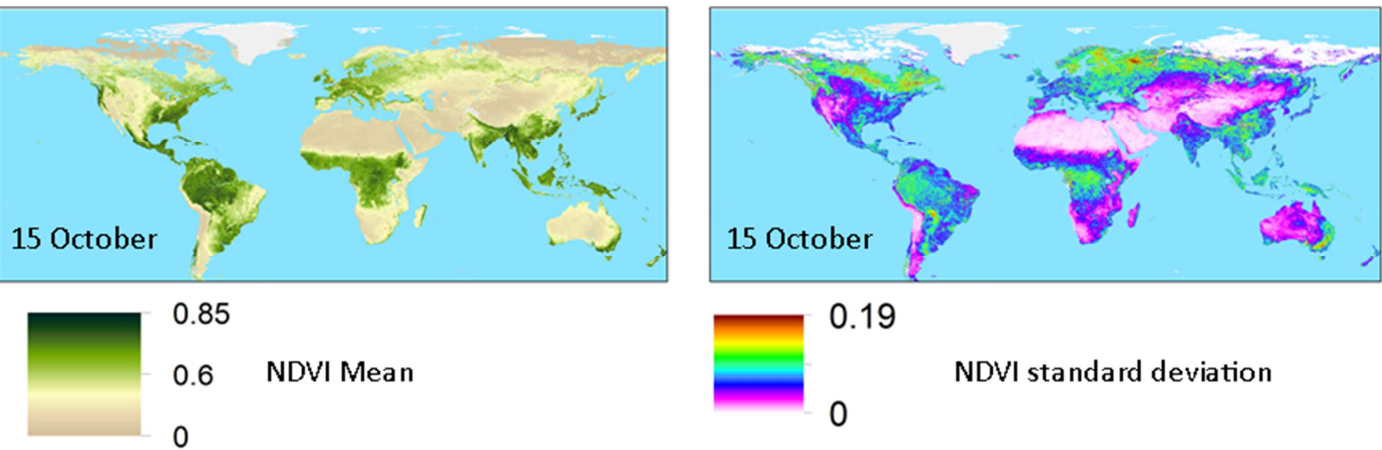

0.19

NDVI standard deviation

Figure 4-1: Average (left) and standard deviation (right) components of the NDVI Seasonality Product at 4 weeks of the year. The dates indicated in Figure A, B, C and D correspond to starting day of the 7-day composite period. White colour situated in high latitudes corresponds to NaN values [RD.15]

The SPOT-VGT 1-km spatial resolution associated with a high geometric accuracy allows producing meaningful profiles, even in highly fragmented areas such as in Africa (Figure 4-2). The 3 NDVI profiles, extracted on (i) a mosaic class of different cropland areas, (ii) a mosaic class of tree and shrub cover types and (iii) a land cover class made of broadleaved deciduous trees, demonstrate the spatial consistency of the product and its capacity to depict the intra-annual variability of the vegetation greenness. 


\begin{tabular}{|c|c|c|c|c|}
\hline \multirow{2}{*}{ CeSa } & Ref & & CCI LC PUG v2 & Date \\
\cline { 2 - 5 } & Issue & Page & $2017-03-31$ & land couer \\
\cline { 2 - 5 } & 2.0 & 48 & cci \\
\hline
\end{tabular}

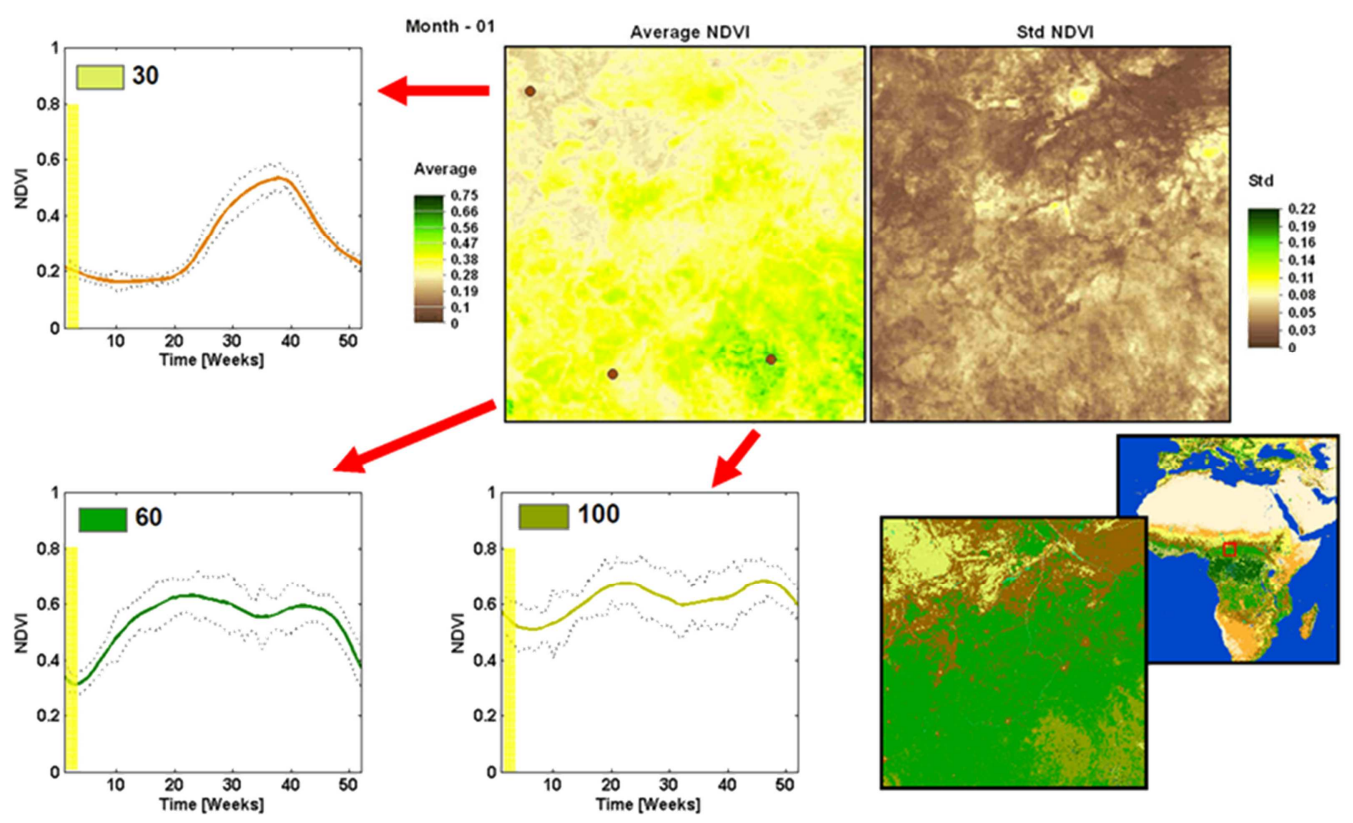

30 : Mosaic cropland $(>50 \%) \square 100$ : Mosaic tree and shrub $(>50 \%)$

60 : Tree cover, broadleaved, deciduous, closed to open (>15\%)

Figure 4-2: Detailed spatial example of NDVI seasonality profiles - average (plain line) and standard deviation (dotted line) - extracted in the region of Central Africa. The profiles are extracted from 3 pixels belonging to 3

classes of the 2010 LC state map product. The variety of the dynamic of vegetation is clearly captured.

\subsubsection{Products evaluation}

The potentialities for the NDVI seasonality were highlighted in the contexts of cropland diversity (intensity of agricultural practices, crop cycles), thematically close land cover classes diversity (bare areas, grassland and shrubland), vegetation seasonalities and leaf types.

Yet, it shall be mentioned that the reliability of the products is spatially variable and dependant on the number of valid and cloud-free weekly composites which is to be used as a quality indicator. The lowest numbers of valid and cloud-free observations are found over the western coast of central Africa and extreme latitudes.

One of the drawbacks with using optical time series for global mapping is the inconsistency of the valid coverage along the year. Data are missing over high latitudes during winter time when there is no solar illumination.

The lack of validation and uncertainty estimates is also a limitation.

\subsubsection{Format}

The global NDVI seasonality characterizing the 1999-2012 epoch includes 4 series of measurements distributed in the form of 52*7-day layers for a total compressed data volume of $30 \mathrm{~GB}$. Two of the series represent variables describing the yearly reference dynamic of the vegetation greenness and its 


\begin{tabular}{|c|c|c|c|c|}
\hline \multirow{2}{*}{ CeSa } & Ref & \multicolumn{2}{|c|}{ CCI LC PUG v2 } \\
\cline { 2 - 5 } & Issue & Page & Date & land couer \\
& 2.0 & 49 & $2017-03-31$ & lai \\
\hline
\end{tabular}

inter-annual variation: the smoothed averaged NDVI and the standard deviation. The other two layers are the number of valid and cloud-free weekly composites and the status of the pixel.

Each layer has a spatial resolution of $1 \mathrm{~km}$ and a geographic Lat/Long WGS84 projection (see Section 3.1.3 for a complete description).

The layers are delivered in NetCDF-4 and GeoTiff format. The NetCDF files specification follows CF conventions [RD.16].

\section{- Science dataset}

Table 4-2 summarizes the description of each 52*7-day layers in terms of variable description, valid values range, scaling factor, $\mathrm{NaN}$ value and pixel depth.

Table 4-2: The description of the 4 series layers included in the global NDVI seasonality product.

\begin{tabular}{|l|l|l|l|l|l|}
\hline \multicolumn{1}{|c|}{$\begin{array}{c}\text { NDVI } \\
\text { SEASONALITY } \\
\text { SERIES }\end{array}$} & \multicolumn{1}{|c|}{ DESCRIPTION } & $\begin{array}{l}\text { VALID VALUES } \\
\text { RANGE }\end{array}$ & $\begin{array}{l}\text { SCALING } \\
\text { FACTOR }\end{array}$ & $\begin{array}{c}\text { NAN } \\
\text { VALUE }\end{array}$ & $\begin{array}{c}\text { PIXEL } \\
\text { DEPTH }\end{array}$ \\
\hline AggMean & $\begin{array}{l}\text { Smoothed NDVI values corresponding to the } \\
\text { averaged NDVI over the 1999-2012 period. It } \\
\text { gives the yearly reference dynamic of the } \\
\text { vegetation greenness at a 7-day frequency. }\end{array}$ & $\begin{array}{l}{[-10000 \text { to }} \\
10000]\end{array}$ & 0.0001 & 32767 & Int16 \\
\hline Std & $\begin{array}{l}\text { Standard deviation of the averaged NDVI over } \\
\text { the } 1999-2012 \text { period. It represents the inter- } \\
\text { annual variability of the average NDVI for each } \\
\text { 7-day period. }\end{array}$ & {$[0$ to 10000$]$} & 0.0001 & 32767 & Int16 \\
\hline NYearObs & $\begin{array}{l}\text { Number of valid and cloud-free weekly } \\
\text { composites contributing to each 7-day period } \\
\text { of the AggMean and Std series. It is a quality } \\
\text { indicator of the average and std estimates. }\end{array}$ & {$[0$ to 14] } & None & None & Int16 \\
\hline Status & $\begin{array}{l}\text { Status of the pixel; 0: invalid, } 1: \text { land }, 2: \text { water } \\
\text { 3 : snow, } 4: \text { cloud }, 5: \text { filled ice }\end{array}$ & {$[0$ to 5$]$} & None & 0 & Int16 \\
\hline
\end{tabular}

- Metadata

The metadata of the global LS seasonality products is described in Appendix 3.

\section{- Naming convention}

The file name convention of the global LS seasonality products is as generic as possible. All seasonality products follow this structure:

File name $=\langle$ id $>-v<v e r s i o n>$.nc $/$ tif

$$
\text { where }\langle\text { id }\rangle=\langle\text { project }\rangle-\langle\text { level }\rangle-\langle\text { var }\rangle-\langle\text { prod }\rangle-\langle\text { spatres }\rangle-\langle\text { tempres }\rangle-\langle\text { epoch }\rangle-\langle\text { date }\rangle
$$

The dash "-" is the separator between name components. They are defined in Table 4-3. 


\begin{tabular}{|c|c|c|c|l|}
\hline \multirow{2}{*}{ CeSa } & Ref & \multicolumn{3}{|c|}{ CCI LC PUG v2 } \\
\cline { 2 - 5 } & Issue & Page & Date & land couer \\
\cline { 2 - 5 } & 2.0 & 50 & $2017-03-31$ & cci \\
\hline
\end{tabular}

Table 4-3: Naming convention in the NDVI seasonality filenames.

\begin{tabular}{|c|c|c|}
\hline FIELD & SIGNIFICATION & VALUE \\
\hline project & Project Acronym & ESACCI-LC (constant) \\
\hline level & Processing level & L4 (constant) \\
\hline var & Variable identifier for the LS seasonality & NDVI-Cond (constant) \\
\hline prod & Product identifier for LS seasonality & AggMean, Std, Status, NYearObs \\
\hline spatres & Spatial resolution & $1000 \mathrm{~m}$ (constant) \\
\hline tempres & $\begin{array}{l}\text { Multi-year period of the product defined } \\
\text { by the number of years }+ \text { Temporal } \\
\text { resolution of the product }\end{array}$ & P14Y7D (constant) \\
\hline epoch & $\begin{array}{l}\text { Multi-year epoch of the product, defined } \\
\text { by the start and end years }\end{array}$ & $\begin{array}{l}\text { [YYYY-YYYY] where the two "YYYY" are the first year and } \\
\text { the last year of the period. This field is } 1999-2012 \text { for } \\
\text { the NDVI Seasonality product. }\end{array}$ \\
\hline date & Start date of the compositing period & $\begin{array}{l}\text { [yyyymmdd] where "yyyy" is the starting year of the } \\
\text { epoch, "mm" is the month and " } d d \text { " is the day }\end{array}$ \\
\hline version & $\begin{array}{l}\text { Incremental that follows the successive } \\
\text { revisions of the CCI-LC Processing lines }\end{array}$ & Version of product, major-minor \\
\hline
\end{tabular}

An example file name of the global LS seasonality product related to the 1999-2012 NDVI standard deviation variable between the $1^{\text {st }}$ to $7^{\text {th }}$ January would be: "ESACCI-LC-L4-NDVI-Cond-Std1000m-P14Y7D-1999-2012-19990101-v2.0.tif". 


\begin{tabular}{|c|c|c|c|c|}
\hline \multirow{2}{*}{ e esa } & Ref & \multicolumn{2}{|c|}{ CCI LC PUG v2 } \\
\cline { 2 - 5 } & Issue & Page & Date & Iand couer \\
\cline { 2 - 5 } & 2.0 & 51 & $2017-03-31$ & cci \\
\hline
\end{tabular}

\section{GLOBAL MAP OF OPEN WATER BODIES}

\subsection{Product description}

The CCI global map of open water bodies (WBP v4.0) [RD.24] is an updated version of the CCI-LC WBP v3.0. Improvements originate from a revisit of commission and omission errors with high resolution WB products and auxiliary datasets, which also serves to improve the delineation of the SAR-based water bodies. Figure 5-1 illustrates the improvement of network connectivity in rivers achieved in the WB v4.0 product, compared to the previous version.

In addition to the SAR Water Body Indicator, the precursor of the CCI-LC WB v3.0, the CCI-LC WBP v4.0 relies on 6 external datasets. The 30-m optical GFC-datamask [RD.27] and Global Inland Water (GIW) v1.0 WB products [RD.28] were selected for their finer resolution and their strong complementarities. The Shuttle Radar Topography Mission (SRTM) [RD.21] was used exclusively to include islands below $60^{\circ} \mathrm{N}$. In order to remove commission errors over glaciers, extend the CCI-LC WBP v4.0 to $90^{\circ} \mathrm{S}$ and distinguish inland water from oceans, the following auxiliary products were also selected, respectively: the Randolph Glacier Inventory (RGI) [RD.12], the Scientific Committee on Antarctic Research Antarctic Digital Database (SCAR ADD) [RD.23] and the Global Selfconsistent, Hierarchical, High-resolution Shoreline (GSHHS) [RD.22]. The methodology to build the CCI-LC WBP v4.0 is fully described in [AD.11].

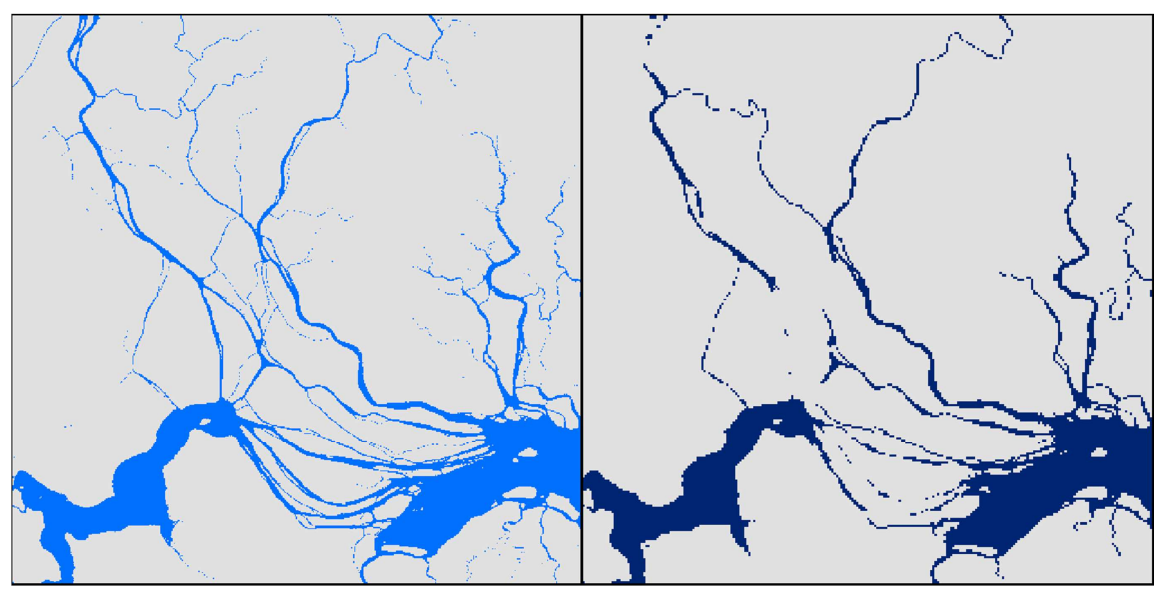

Figure 5-1: River network continuity has drastically improved in the CCI-LC WBP V4.0 (left, compared to the $W B P$ v3.0 on the right), adding high resolution WB dataset as inputs.

The CCI-LC WBP v4.0 is a fully global and precise map of open permanent WB and coastlines (Figure 5-2) that includes two separate layers: a land/inland water/ocean repartition at $150 \mathrm{~m}$ spatial resolution and an inland water fraction, in percent of the $150 \mathrm{~m}$ grid cell.

Although the CCI-LC WBP v4.0 is delivered as a separate layer at $150 \mathrm{~m}$, it forms class "Water Bodies" of the global annual LC Maps v2, after resampling to $300 \mathrm{~m}$ using an average algorithm. 


\begin{tabular}{|c|c|c|c|c|}
\hline \multirow{2}{*}{ CeSa } & Ref & \multicolumn{2}{|c|}{ CCI LC PUG v2 } \\
\cline { 2 - 5 } & Issue & Page & Date & land couer \\
& 2.0 & 52 & $2017-03-31$ & lai \\
\hline
\end{tabular}

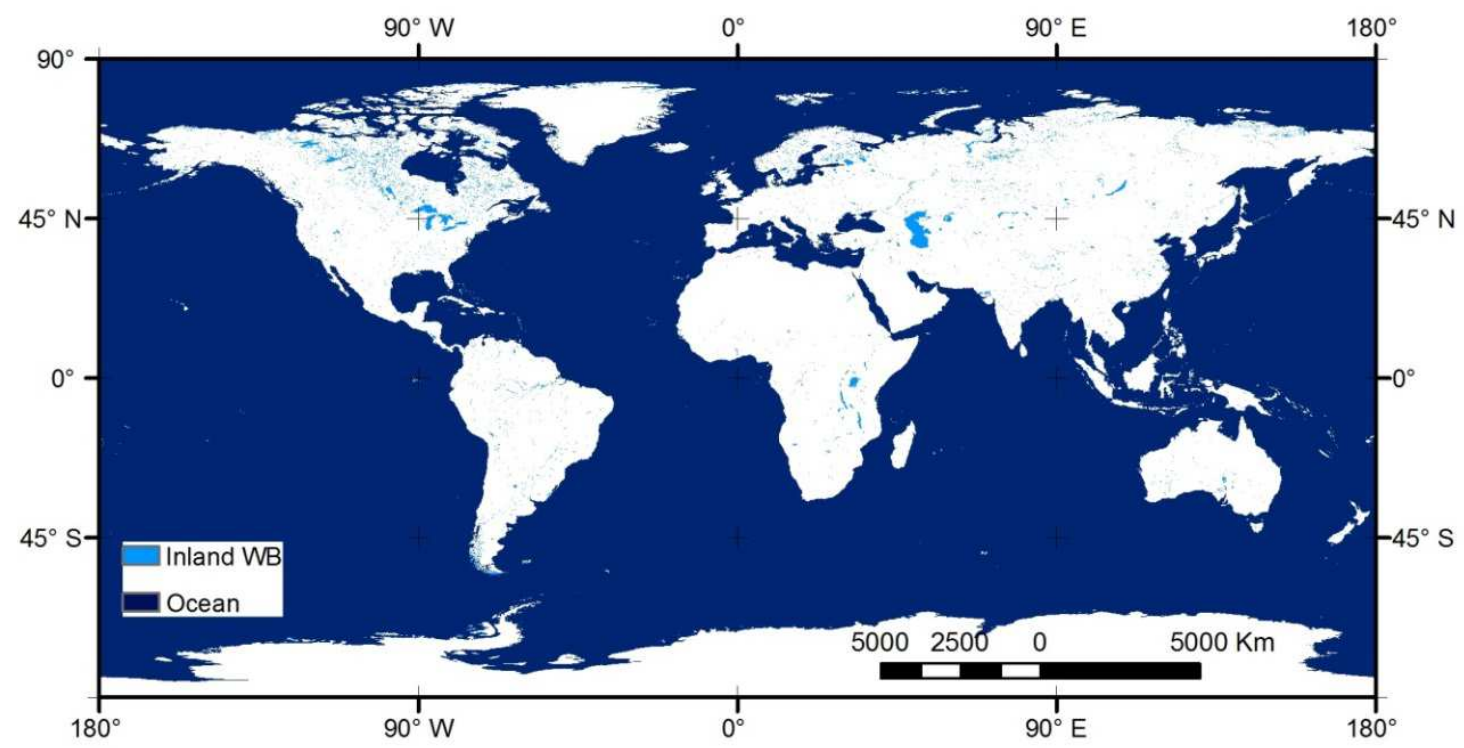

Figure 5-2: Illustration of the CCI-LC WBP v4.0 with distinction of the inland water from oceans.

\subsection{Validation}

In the same way as for the global land cover maps, the validation process included three different steps: elaborating the sampling strategy, collecting reference data sources and assessing the products accuracy.

The overall accuracy of the CCI-LC WBP v4.0 and its constitutive inputs was performed at global scale. In this document, only the accuracy results of the CCI-LC WBP v4.0 are shown but more detailed information can be found in [RD.24].

\subsubsection{Sampling strategy}

A validation reference database was built using 2400 samples of $150 \mathrm{~m} \times 150 \mathrm{~m}$ footprints, based on a two-fold stratified random sampling biased towards areas where errors are most expected (coastlines, river and lake banks, sand dunes, ice-covered regions, etc.). The rationale behind this design is to avoid assessing major parts of the Earth surface covered by large permanent WB (oceans, lakes) or land that coincide with areas of highest classification performances.

First, the samples were distributed proportionally to the surface of 21 equal reasoning regions (polar areas excluded) defined by bioclimatic and remote sensing criteria [RD.25]. This ensured that the whole Earth surface was homogeneously covered. Second, as surface water corresponds to a marginal class w.r.t. global land cover, the location of samples was further distributed according to areas typically mapped as land or water by independent WB products and zones where disagreements generally occur. Samples were selected according to the following class repartition: half of the samples in areas of disagreement between independent WB products, a quarter in areas of land 


\begin{tabular}{|c|c|c|c|c|}
\hline \multirow{2}{*}{ CeSa } & Ref & \multicolumn{2}{|c|}{ CCI LC PUG v2 } \\
\cline { 2 - 5 } & Issue & Page & Date & land couer \\
& 2.0 & 53 & $2017-03-31$ & lai \\
\hline
\end{tabular}

agreement and a quarter in areas of water agreement. The location of validation samples are illustrated in Figure 5-3.

Forcing half the samples in areas of disagreement between WB datasets biased the distribution towards challenging areas of WB mapping. Resulting biased validation figures allowed to be more sensitive to the performances of the different WB products but were only meaningful in relative terms. This bias was eventually corrected to derive overall accuracy figures by weighting them by the actual surface of the land and water classes of each stratum among land agreement, water agreement and discrepancies.

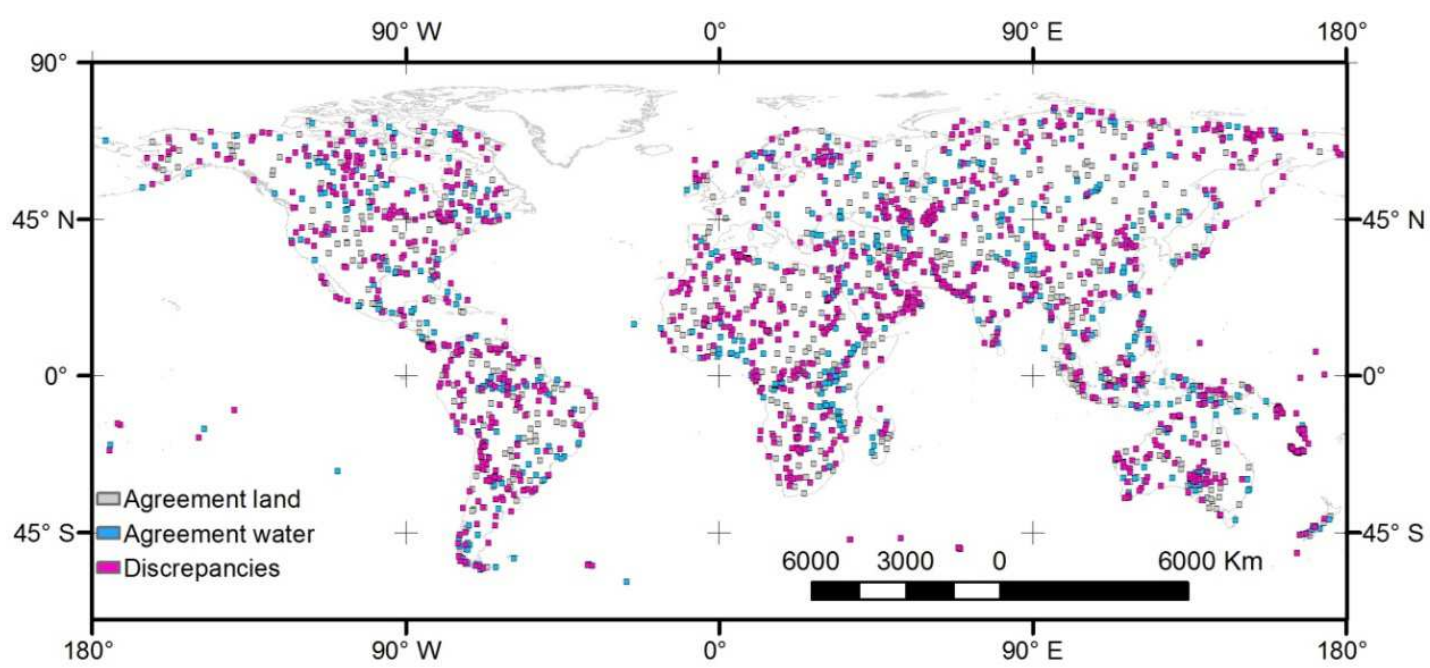

Figure 5-3: Location of the samples of $150 \mathrm{~m} \times 150 \mathrm{~m}$ of the validation reference database and distribution in the stratification (agreement land, agreement water and discrepancies) based on the three other independent WB sources.

\subsubsection{Reference data collection}

The validation samples were visually interpreted independently from the CCI-LC WBP v4.0 using high resolution imagery provided by Google Earth. Samples were labelled as water when at least half the sample was covered with open surface water.

Attention was paid to the temporal aspect of environmental events such as temporary snow cover or water evenly across the globe. The temporal character of an event relied on a careful use of the historical imagery of Google Earth. Samples, covered with temporary snow or water, were labelled as land systematically.

In addition, the date of high resolution imagery, seasonal or permanent character of WB and snow, the potentiality of being inundated, wetlands and swamps were recorded per sample.

\subsubsection{Results}

The overall accuracy of the CCI-LC WBP v4.0 was performed at global scale. Only reference samples intersecting valid areas of the CCI-LC WBP v4.0 and its constitutive inputs were retained. 


\begin{tabular}{|c|c|c|c|c|}
\hline \multirow{2}{*}{ CeSa } & Ref & \multicolumn{2}{|c|}{ CCI LC PUG v2 } \\
\cline { 2 - 5 } & Issue & Page & Date & land couer \\
& 2.0 & 54 & $2017-03-31$ & lai \\
\hline
\end{tabular}

Table 5-1 summarizes the accuracy figures resulting from the comparison between the CCI-LC WBP v4.0 and the validation reference samples weighted by the actual surface of the land and water classes. The spatial completeness, defined as the percentage of valid data in the product, the coverage, expressed in upper and lower latitudes and longitudes are also indicated.

Table 5-1: Spatial completeness, coverage and accuracy results of the WBP V4.0.

\begin{tabular}{|c|c|c|c|c|c|c|c|c|}
\hline SPATIAL COMPLETENESS & SPATIAL COVERAGE & & \multicolumn{3}{|c|}{ NON-WATER } & \multicolumn{3}{|c|}{ WATER } \\
\hline$(\%)$ & $($ LAT $)$ & $\begin{array}{c}\text { OA } \\
(\%)\end{array}$ & $\begin{array}{c}\text { PA } \\
(\%)\end{array}$ & UA $(\%)$ & $\begin{array}{c}\text { F-SCORE } \\
(\%)\end{array}$ & $\begin{array}{c}\text { PA } \\
(\%)\end{array}$ & $\begin{array}{c}\text { UA } \\
(\%)\end{array}$ & $\begin{array}{c}\text { F-SCORE } \\
(\%)\end{array}$ \\
\hline 100 & $\begin{array}{c}90^{\circ} \mathrm{N}-90^{\circ} \mathrm{S} \\
180^{\circ} \mathrm{W}-180^{\circ} \mathrm{E}\end{array}$ & 99 & 99 & 100 & 100 & 92 & 86 & 89 \\
\hline
\end{tabular}

The CCI-LC WBP v4.0 provides the best F-score performances in spite the fact that it tends to very slightly overestimate the permanent water area. The representation of the water class of the CCI-LC WBP v4.0 is clearly of higher accuracy than its constitutive inputs (see [RD.24] for more details). The completeness and spatial coverage of the CCI-LC WBP v4.0 are of $100 \%$ and $90^{\circ} \mathrm{N}-90^{\circ} \mathrm{S}$ and $180^{\circ}$ $\mathrm{W}-180^{\circ} \mathrm{E}$, respectively.

A second accuracy assessment focused on error-prone areas in WB mapping such as shoreline, lakes and rivers banks, yielded a wider range of accuracy results for the different classes and brought additional information. It is fully described in [RD.24].

\subsection{Format}

\section{- Science dataset}

The CCI-LC WBP v4.0 includes two separate layers: a land/inland water/ocean repartition at $150 \mathrm{~m}$ spatial resolution and an inland water fraction, in percent of the $150 \mathrm{~m}$ grid cell. It has a LAT/LONG WGS84 projection. Table 5-2 gives the layers variable description, valid values ranges, units, fill value and pixel depth.

Table 5-2: The description of the layers included in the CCI-LC WB V4.0 product.

\begin{tabular}{|l|l|l|l|l|l|}
\hline \multicolumn{1}{|c|}{\begin{tabular}{|} 
LAYER \\
NAMES
\end{tabular}} & \multicolumn{1}{|c|}{ DESCRIPTION } & $\begin{array}{l}\text { VALID VALUES } \\
\text { RANGE }\end{array}$ & \multicolumn{1}{|c|}{ UNITS } & \multicolumn{1}{c|}{$\begin{array}{c}\text { FILL } \\
\text { VALUE }\end{array}$} & $\begin{array}{c}\text { PIXEL } \\
\text { DEPTH }\end{array}$ \\
\hline Map & $\begin{array}{l}\text { Land/ inland water/ocean classification at 150m } \\
\text { spatial resolution. } \\
\text { Legend : 1-Land, 2-Inland Water, 3-Ocean }\end{array}$ & [1 to 3] & None & None & Byte \\
\hline IWF & $\begin{array}{l}\text { Inland water fraction, in percent of the } 150 \mathrm{~m} \\
\text { grid cell }\end{array}$ & {$[0$ to 100] } & Percent & None & Byte \\
\hline
\end{tabular}

- Naming convention

The layer is delivered at the global extent in GTiff format. The file name convention is as generic as possible and follows this structure: 


\begin{tabular}{|c|c|c|c|l|}
\hline \multirow{2}{*}{ CeSa } & Ref & \multicolumn{3}{|c|}{ CCI LC PUG v2 } \\
\cline { 2 - 5 } & Issue & Page & Date & land couer \\
\cline { 2 - 5 } & 2.0 & 55 & $2017-03-31$ & cci \\
\hline
\end{tabular}

File name $=\langle$ type $\rangle-\mathrm{v}\langle$ revision $\rangle$.(tif/netcdf $)$ where $\langle$ type $\rangle=$

$<$ project $>-<$ level $>-<$ code $>-<$ var $>-<$ spat res $\rangle-<$ period+ temporal res. $>-<$ epoch $>$

The dash "-" is the separator between name components. They are defined in Table 5-3.

Table 5-3: Naming convention in the CCI-LC WB v4.0 dataset.

\begin{tabular}{|l|l|l|}
\hline \multicolumn{1}{|c|}{ FIELD } & \multicolumn{1}{|c|}{ SIGNIFICATION } & \\
\hline project & Project Acronym & ESACCI-LC (constant) \\
\hline level & Processing level & L4 (constant) \\
\hline code & Product code identifier for CCI-LC products & WB (constant) \\
\hline var & $\begin{array}{l}\text { Variable code identifier for the LC } \\
\text { conditions }\end{array}$ & Variable name of the product: Map or IWF \\
\hline spat res & Spatial resolution & $150 \mathrm{~m}$ \\
\hline $\begin{array}{l}\text { period+ } \\
\text { temporal } \\
\text { res. }\end{array}$ & $\begin{array}{l}\text { Multi-year period of the product defined by } \\
\text { the number of years + Temporal resolution } \\
\text { of the product }\end{array}$ & P13Y \\
\hline epoch & $\begin{array}{l}\text { Multi-year epoch of the product, defined } \\
\text { by the start and end years }\end{array}$ & $\begin{array}{l}{[\text { YYYY] where "YYYY" is the first year of the period. This }} \\
\text { field is 2000 for this product. }\end{array}$ \\
\hline version & $\begin{array}{l}\text { Incremental that follows the successive } \\
\text { revisions of the CCI-LC Processing lines }\end{array}$ & $\begin{array}{l}\text { Version of product, preferably major-minor, optionally } \\
\text { with processing centre } \\
\text { [a-zA-ZO-9._]* }\end{array}$ \\
\hline
\end{tabular}

- Metadata

The following attributes are included in the CCI-LC WBP v4.0.

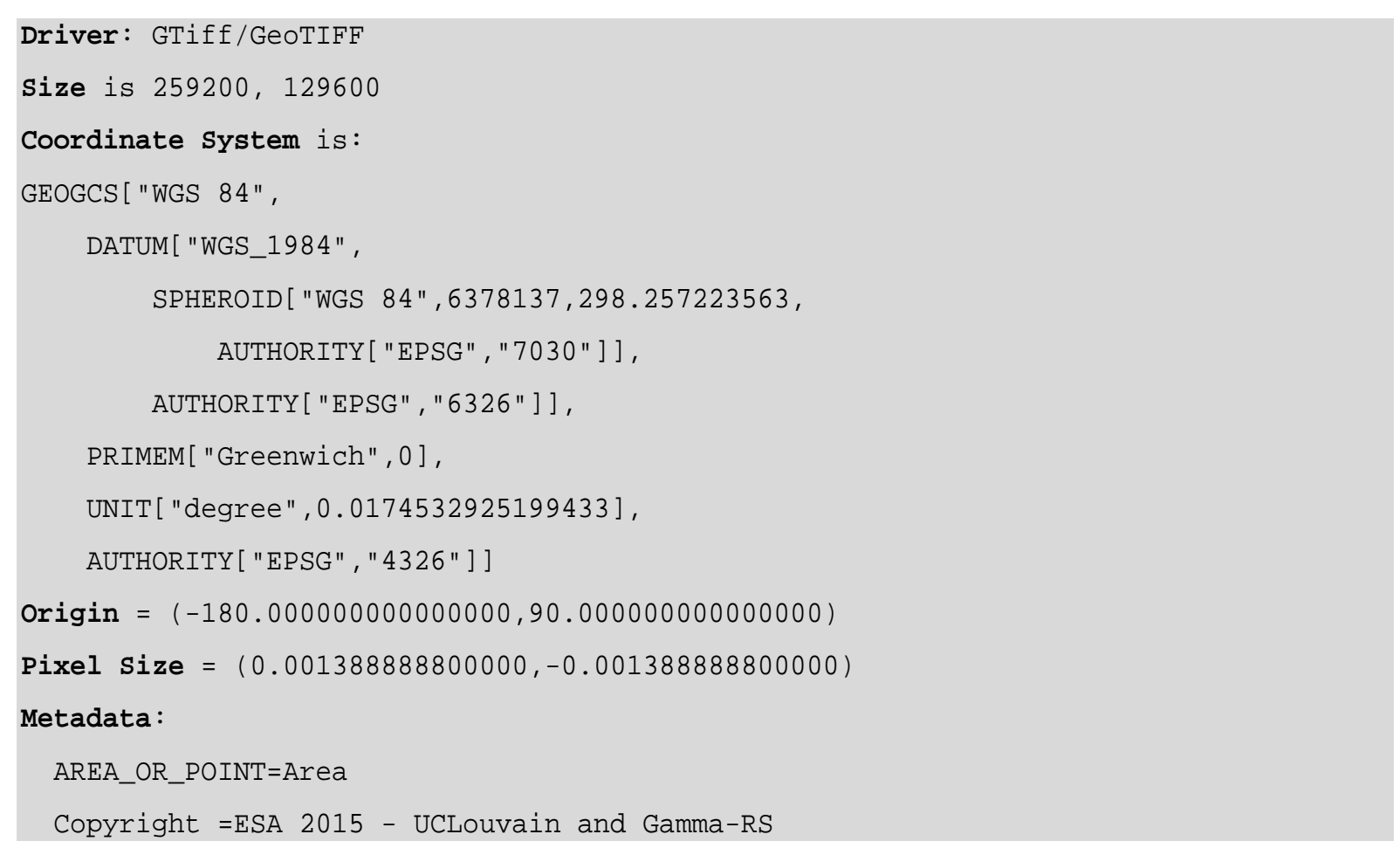
transmitted without the express prior written authorization of UCL-Geomatics (Belgium). 


\begin{tabular}{|c|c|c|c|c|}
\hline \multirow{2}{*}{ CeSa } & Ref & \multicolumn{3}{|c|}{ CCI LC PUG v2 } \\
\cline { 2 - 5 } & Issue & Page & Date & Iand couer \\
\cline { 2 - 5 } & 2.0 & 56 & $2017-03-31$ & cci \\
\hline
\end{tabular}

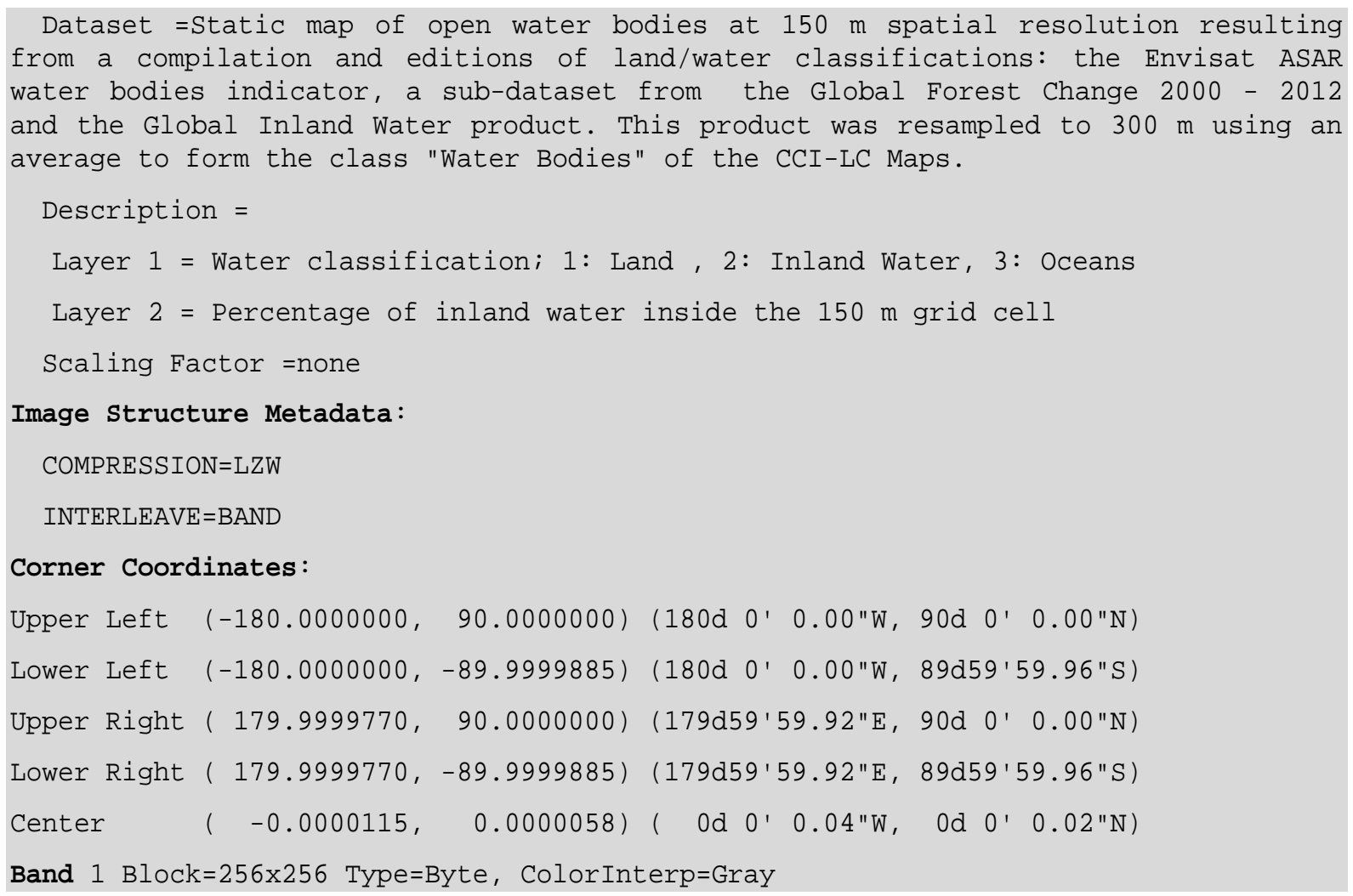




\begin{tabular}{|c|c|c|c|c|}
\hline \multirow{2}{*}{ CeSa } & Ref & & CCI LC PUG v2 & Date \\
\cline { 2 - 5 } & Issue & Page & $2017-03-31$ & land couer \\
\cline { 2 - 5 } & 2.0 & 57 & cci \\
\hline
\end{tabular}

\section{SURFACE REFLECTANCE PRODUCTS}

\subsection{Products description}

The SR products delivered by the CCI-LC project consist in different global SR composite time series covering the period 1992-2015 that are the input for the classification algorithms. The pre-processing module was developed by Brockmann-Consult (BC), capitalizing on the GlobCover and GlobAlbedo projects. The SR products delivered by the CCI-LC project are in detail:

1) Time series of AVHRR 7-day composites from 1992 through 1999;

2) Time series of Envisat MERIS FR 7-day composites from 2003 through 2012;

3) Time series of Envisat MERIS RR 7-day composites from 2003 through 2012.

4) Time series of PROBA-V 7-day composites from 2014 through 2015 (and beyond);

Table 6-1 details the satellite dataset that are planned to be used in order to generate the global SR composite time series.

Table 6-1: Satellite data that are planned to be used to generate the CCI-LC SR time series

\begin{tabular}{|c|c|c|c|}
\hline $\begin{array}{l}\text { GLOBAL SR COMPOSITE TIME } \\
\text { SERIES }\end{array}$ & $\begin{array}{l}\text { REFERENCE } \\
\text { PERIOD }\end{array}$ & $\begin{array}{l}\text { SATELLITE } \\
\text { DATA SOURCE }\end{array}$ & $\begin{array}{l}\text { TECHNICAL SPECIFICATIONS OF THE SATELLITE } \\
\text { DATA SOURCE }\end{array}$ \\
\hline $\begin{array}{l}\text { AVHRR global SR composite } \\
\text { time series }\end{array}$ & 1992-1998 & AVHRR 2 & $\begin{array}{l}\text { - } \quad 1 \mathrm{~km} \text { spatial resolution } \\
\text { - } \quad 5 \text { spectral bands in visible and } \\
\text { infrared } \\
\text { - } \quad \text { Global coverage }\end{array}$ \\
\hline $\begin{array}{l}\text { MERIS global SR composite } \\
\text { time series }\end{array}$ & $2003-2012$ & $\begin{array}{l}\text { Envisat } \\
\text { MERIS } \\
\text { FR \& RR }\end{array}$ & $\begin{array}{l}\text { - } 300-\mathrm{m} \text { or } 1000-\mathrm{m} \text { resolution full } \\
\text { - } \quad 15 \text { spectral bands in visible and near } \\
\text { infrared (NIR) } \\
\text { - } \quad \text { Global coverage }\end{array}$ \\
\hline $\begin{array}{l}\text { PROBA-V global SR } \\
\text { composite time series }\end{array}$ & $\begin{array}{l}\text { 2014-2015 } \\
\text { (and beyond) }\end{array}$ & PROBA-V & $\begin{array}{ll}\text { - } & 300 \mathrm{~m} \text { spatial resolution } \\
\text { - } & 4 \text { spectral bands in visible and } \\
\text { infrared } \\
\text { - } & \text { Global coverage }\end{array}$ \\
\hline
\end{tabular}

The time series are made of temporal syntheses obtained over a 7-day compositing period. The exact schema for the 7-day periods is to start at January 1 and go on 7-day by 7-day periods until the end of the year. In this way, it should be noted that the last period of December comprises 8 days. As for leap years, the 7-day period including February 29 comprises 8 days. There are separate time series for MERIS FR and MERIS RR, PROBA-V and AVHRR. 


\begin{tabular}{|c|c|c|c|c|}
\hline \multirow{2}{*}{ CeSa } & Ref & \multicolumn{3}{|c|}{ CCI LC PUG v2 } \\
\cline { 2 - 5 } & Issue & Page & Date & Iand couer \\
\cline { 2 - 5 } & 2.0 & 58 & $2017-03-31$ & cci \\
\hline
\end{tabular}

In order to simplify the handling and analysis of 300m spatial resolution global datasets, the 7-day SR time series are being delivered in tiles. Global products are subdivided into $72 \times 36$ tiles (Figure 6-1) following the tiling system already used in the GlobCover project ([RD.9] and [RD.13]). Tiles are 5 degrees by 5 degrees. The tile coordinate system starts at $(0,0)(85 \mathrm{~N} 180 \mathrm{~W})$ (horizontal tile number, vertical tile number) in the upper left corner and proceeds right (horizontal) and downward (vertical). The tile in the bottom right corner is $(71,35)(90 \mathrm{~S} 175 \mathrm{E})$. A tile is physically represented by a single file whose file name also indicates the tile south-west corner (see Section 6.2 for a complete description of the naming convention). In addition, tiles having no land contribution are not delivered. 


\begin{tabular}{|c|c|c|c|c|}
\hline \multirow{2}{*}{ CeSa } & Ref & \multicolumn{2}{|c|}{ CCI LC PUG v2 } & Date \\
\cline { 2 - 5 } & Issue & Page & $2017-03-31$ & ses land couer \\
\cline { 2 - 5 } & 2.0 & 59 & cci \\
\hline
\end{tabular}

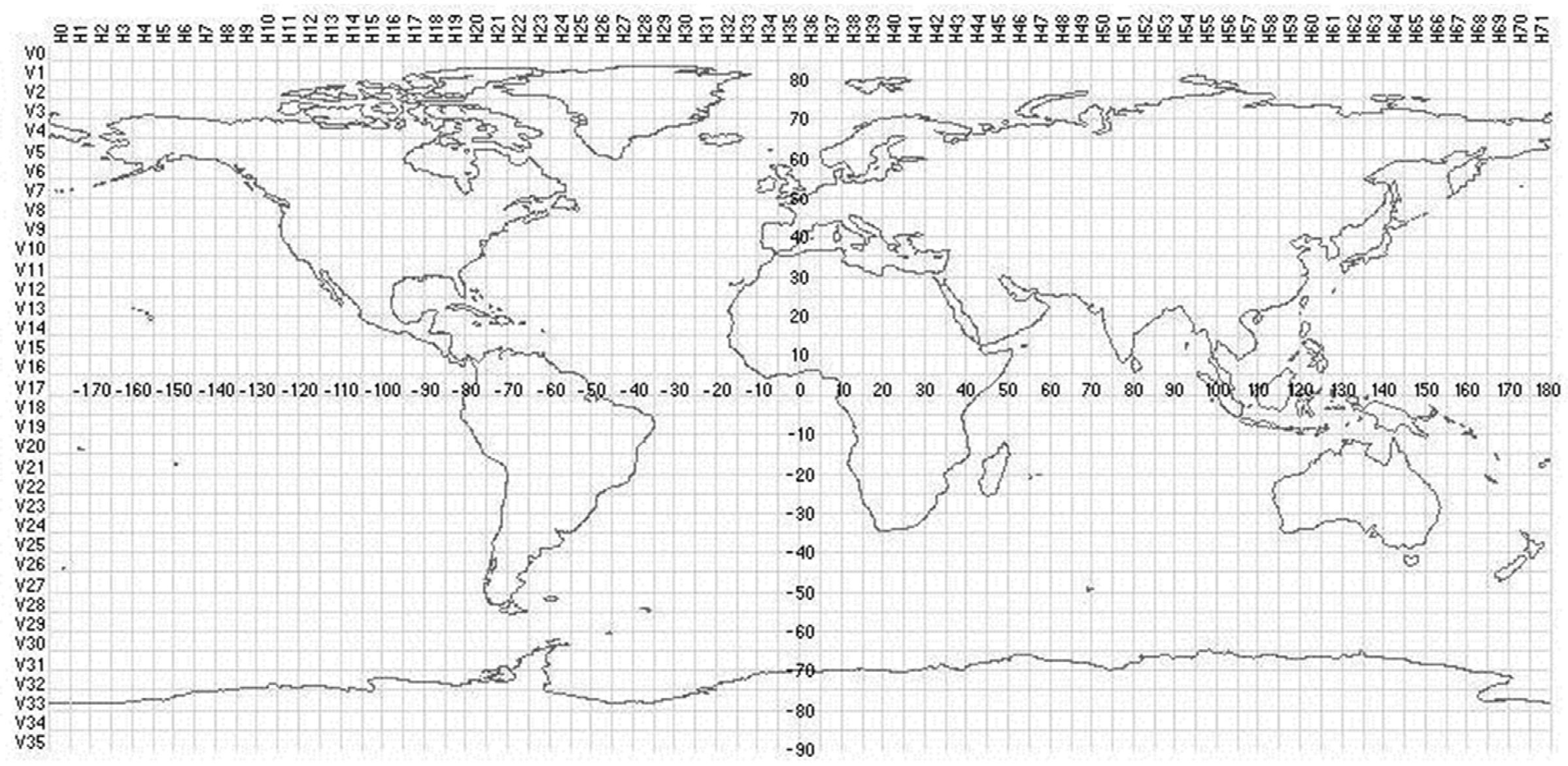

Figure 6-1: Description of the tiling system used for the SR products (from [RD.9] and [RD.13]) 


\begin{tabular}{|c|c|c|c|c|}
\hline \multirow{2}{*}{ CeSa } & Ref & \multicolumn{3}{|c|}{ CCI LC PUG v2 } \\
\cline { 2 - 5 } & Issue & Page & Date & Iand couer \\
\cline { 2 - 5 } & 2.0 & 60 & $2017-03-31$ & cci \\
\hline
\end{tabular}

\subsubsection{MERIS SR time series}

The MERIS FR and RR SR time series were already produced in Phase I. Improved versions have been generated during this Phase II. The spectral content encompasses 13 of 15 MERIS spectral channels - bands 11 and 15 being removed - (Table 6-2) and the spatial resolution is of $300 \mathrm{~m}$ for the Full Resolution (FR) and 1000m from the Reduced Resolution (RR).

Table 6-2: MERIS spectral channels.

\begin{tabular}{|c|c|c|c|}
\hline BAND NUMBER & $\begin{array}{c}\text { BAND CENTRE } \\
\text { (NM) }\end{array}$ & $\begin{array}{l}\text { BAND WIDTH } \\
\text { (NM) }\end{array}$ & USE \\
\hline 1 & 412.5 & 10 & Yellow substance and detrital pigments \\
\hline 2 & 442.5 & 10 & Chlorophyll absorption maximum \\
\hline 3 & 490 & 10 & Chlorophyll and other pigments \\
\hline 4 & 510 & 10 & Suspended sediment, red tides \\
\hline 5 & 560 & 10 & Chlorophyll absorption minimum \\
\hline 6 & 620 & 10 & Suspended sediment \\
\hline 7 & 665 & 10 & Chlorophyll absorption and fluorescence reference \\
\hline 8 & 681.25 & 7.5 & Chlorophyll fluorescence peak \\
\hline 9 & 705 & 10 & Fluorescence reference, atmospheric corrections \\
\hline 11 & 760.625 & 3.75 & O2 R-branch absorption band \\
\hline 10 & 753.75 & 7.5 & Vegetation, cloud \\
\hline 12 & 775 & 15 & Atmosphere corrections \\
\hline 13 & 865 & 20 & Vegetation, water vapour reference \\
\hline 14 & 885 & 10 & Atmosphere corrections \\
\hline 15 & 900 & 10 & Water vapour, land \\
\hline
\end{tabular}

Figure 6-2 shows the individual RGB image of tile h37v12 of CCI-LC MERIS FR SR 7-day composite from 2005-07-02 at 300m spatial resolution. 


\begin{tabular}{|c|c|c|c|c|}
\hline \multirow{2}{*}{ CeSa } & Ref & \multicolumn{2}{|c|}{ CCI LC PUG v2 } \\
\cline { 2 - 4 } & Issue & Page & Date & Iand couer \\
\cline { 2 - 5 } & 2.0 & 61 & $2017-03-31$ & cci \\
\hline
\end{tabular}

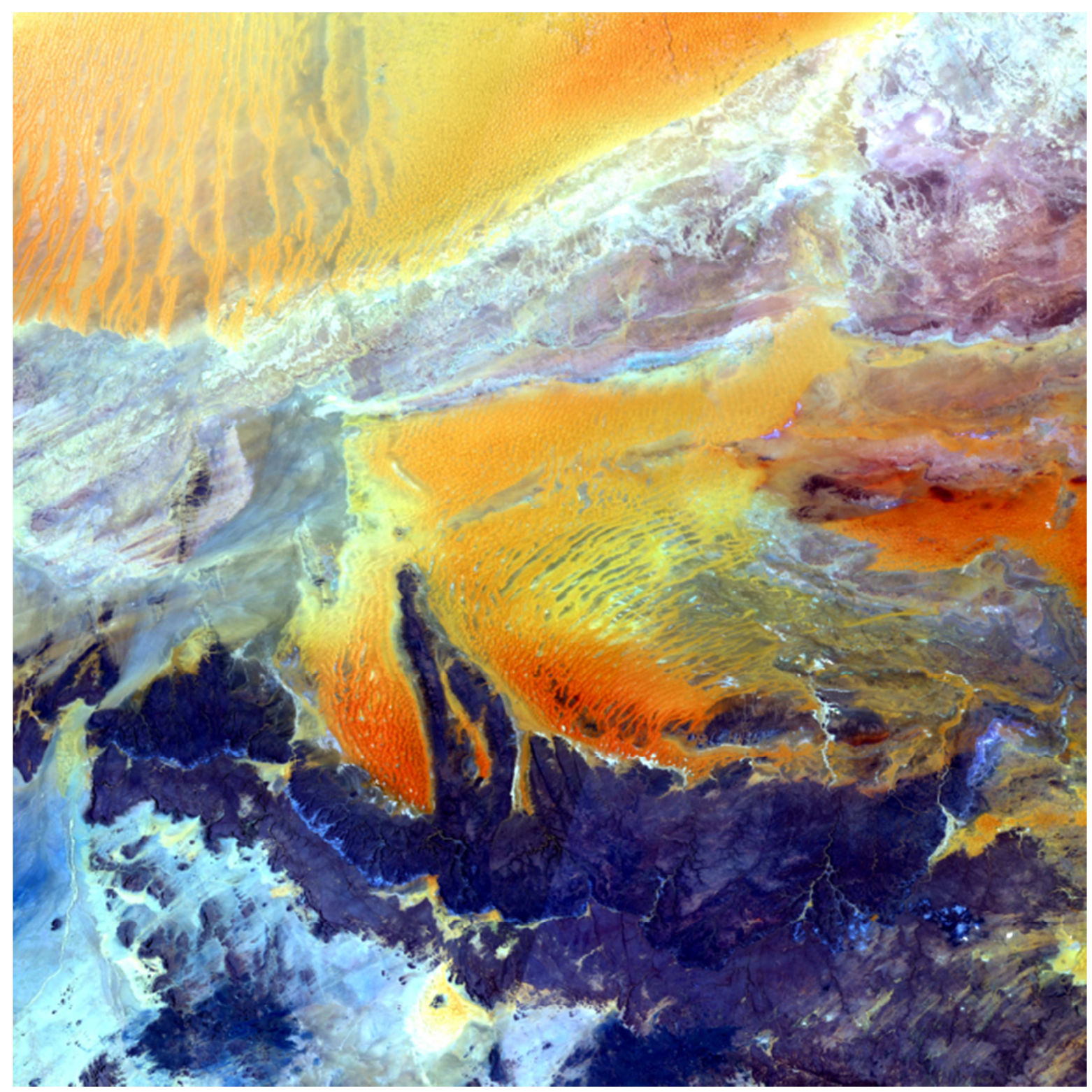

Figure 6-2: Example of CCI-LC MERIS FR SR 7-day composite, at 300m spatial resolution and tile h37v12 ESACCI-LC-L3-SR-MERIS-300m-P7D-h37v12-20050702-v1.0.nc (RGB with channels 7, 5, 2).

Two examples of the global RGB image of CCI-LC MERIS FR SR 7-day composites are illustrated in Figure 6-3 (2009-04-02) and Figure 6-4 (2003-01-15). The different coverage of the Earth is clearly visible and is mainly influenced by the different number of available input daily data. 


\begin{tabular}{|c|c|c|c|c|}
\hline \multirow{2}{*}{ e ESa } & Ref & \multicolumn{2}{|c|}{ CCI LC PUG v2 } \\
\cline { 2 - 5 } & Issue & Page & Date & land couer \\
\cline { 2 - 5 } & 2.0 & 62 & $2017-03-31$ & cci \\
\hline
\end{tabular}

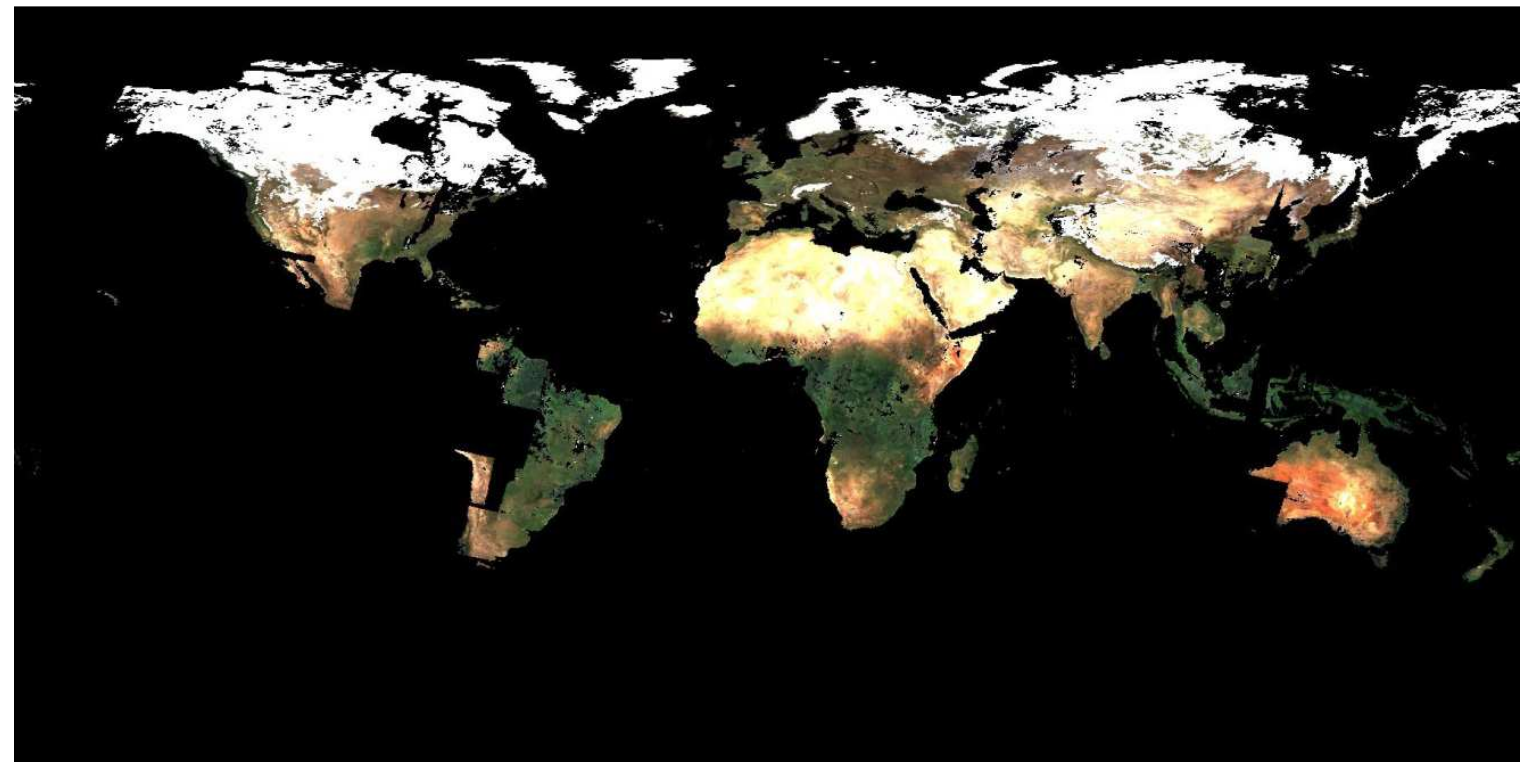

Figure 6-3: The CCI-LC Global Surface reflectance MERIS FR 7-day composite from the 2009-04-02 through 2009-04-08 at 300m spatial resolution (RGB with channels 7, 5, 3).

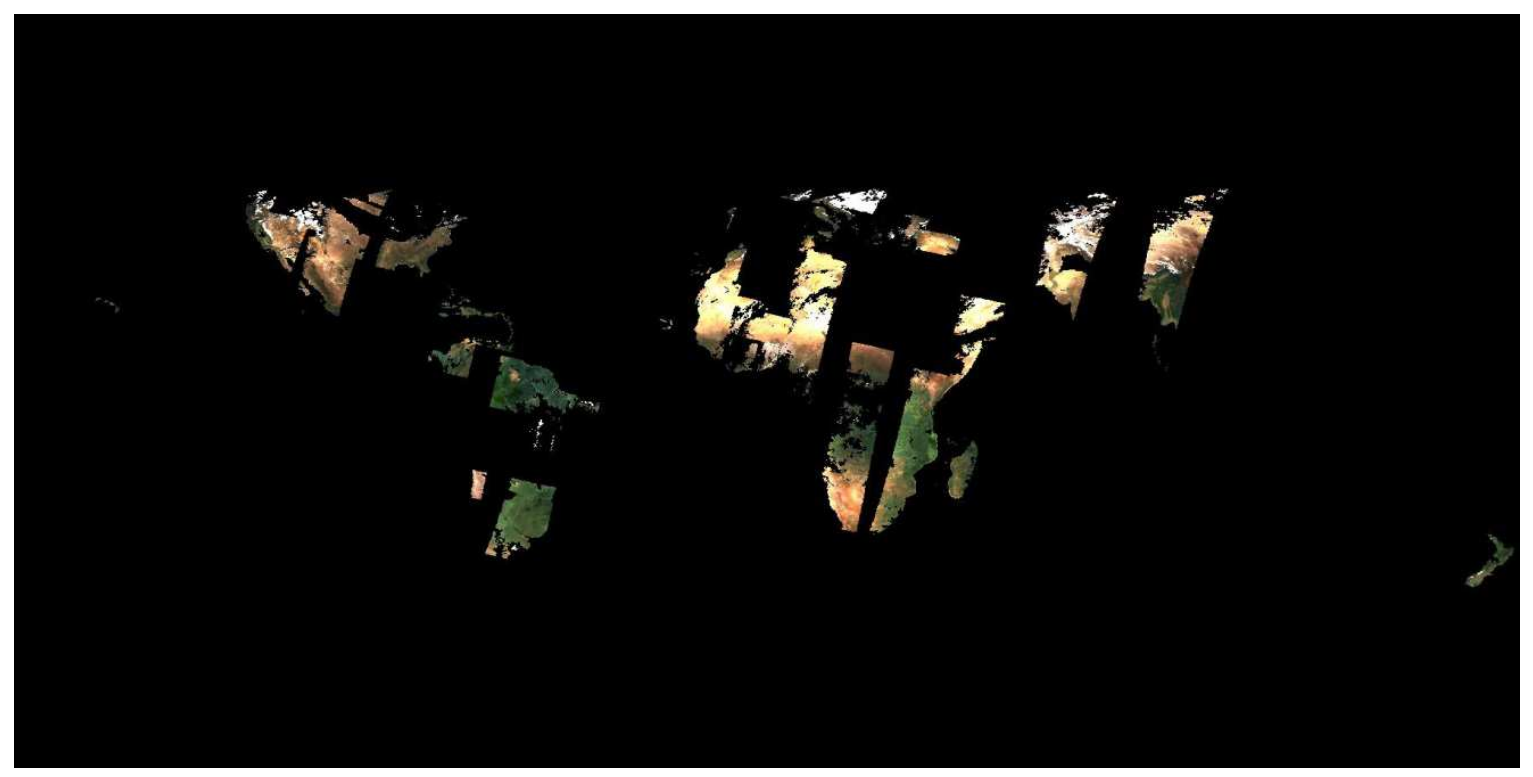

Figure 6-4: The CCI-LC Global Surface reflectance MERIS FR 7-day composite from the 2003-01-15 through 2003-01-21 at 300m spatial resolution (RGB with channels 7, 5, 3).

Figure 6-5 shows the average of all MERIS FR SR 7-day composites related to the 2010 epoch (i.e. the 5 years from 2008 to 2012) at $300 \mathrm{~m}$ spatial resolution. 


\begin{tabular}{|c|c|c|c|c|}
\hline \multirow{2}{*}{ CeSa } & Ref & \multicolumn{2}{|c|}{ CCI LC PUG v2 } \\
\cline { 2 - 4 } & Issue & Page & Date & Iand couer \\
\cline { 2 - 5 } & 2.0 & 63 & $2017-03-31$ \\
\hline
\end{tabular}

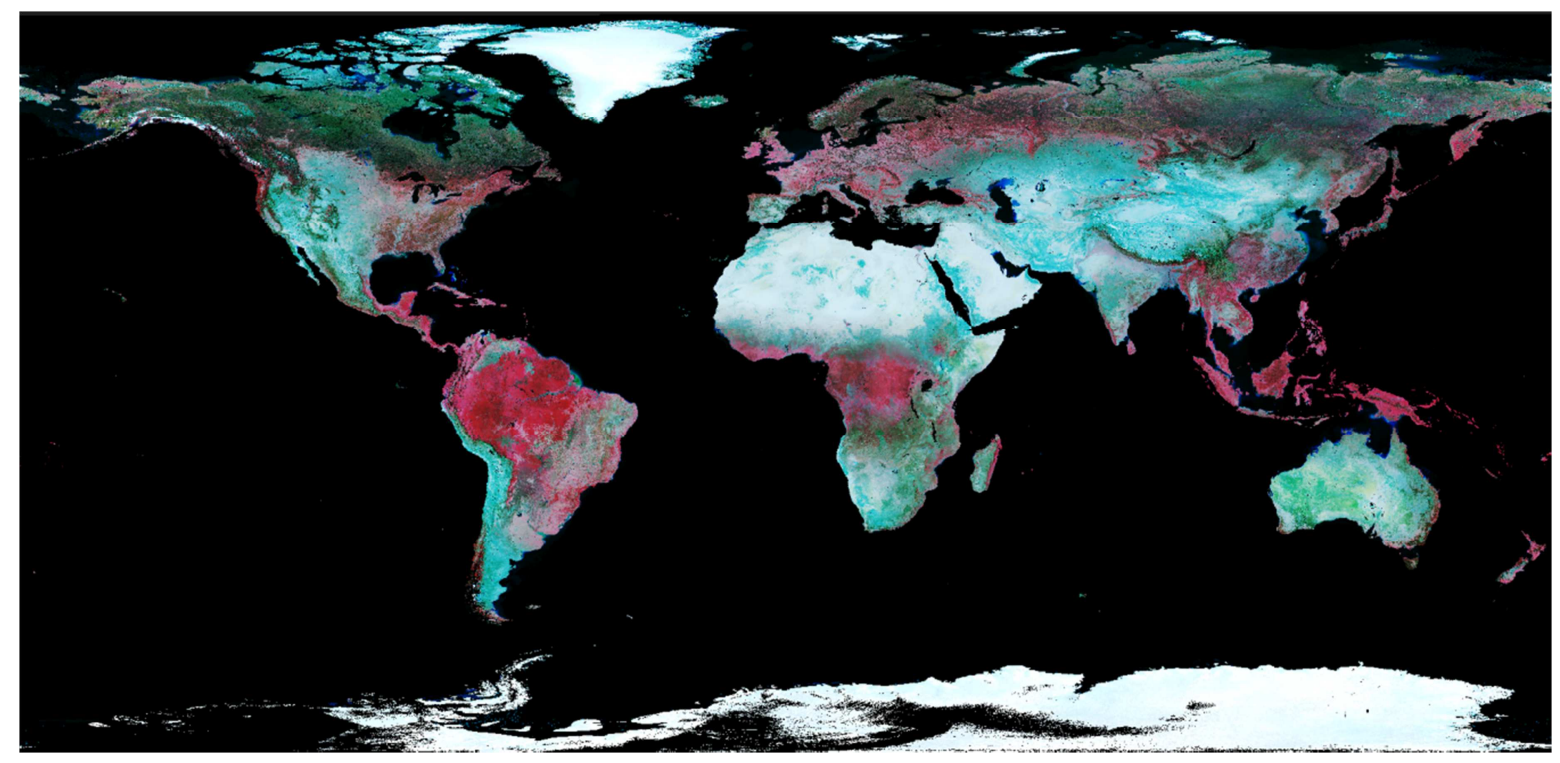

Figure 6-5: The CCI-LC Global Surface reflectance composite from all MERIS FR SR 7-day composites from the 2010 epoch (2008-2012), at 300m spatial resolution (RGB with channels 14, 7, 5).

\subsubsection{AVHRR SR time series}

The AVHRR SR time series have been generated during this Phase II. The spectral content encompasses the 2 VIS-NIR spectral channels as well as the 3 InfraRed spectral bands (Table 6-3) and the spatial resolution is of $1000 \mathrm{~m}$.

Table 6-3: AVHRR-2 spectral channels.

\begin{tabular}{|c|c|c|c|}
\hline BAND NUMBER & $\begin{array}{c}\text { BAND CENTRE } \\
(\mu \mathrm{M})\end{array}$ & $\begin{array}{c}\text { BAND WIDTH } \\
(\mu \mathrm{M})\end{array}$ & COMMENT \\
\hline 1 & 0.63 & 0.05 & Surface reflectance \\
\hline 2 & 0.9125 & 0.1875 & Surface reflectance \\
\hline 3 & 3.74 & 0.19 & Brightness temperature \\
\hline 4 & 11 & 0.5 & Brightness temperature \\
\hline 5 & Ch4 rep. & Ch4 rep. & \\
\hline
\end{tabular}

Figure 6-6 shows the individual RGB image of tile h26v18 of CCI-LC AVHRR SR 7-day composite from 1993-05-21 at 1000m spatial resolution. 


\begin{tabular}{|c|c|c|c|c|}
\hline \multirow{2}{*}{ CeSa } & Ref & \multicolumn{2}{|c|}{ CCI LC PUG v2 } \\
\cline { 2 - 5 } & Issue & Page & Date & land couer \\
\cline { 2 - 5 } & 2.0 & 64 & $2017-03-31$ & cci \\
\hline
\end{tabular}

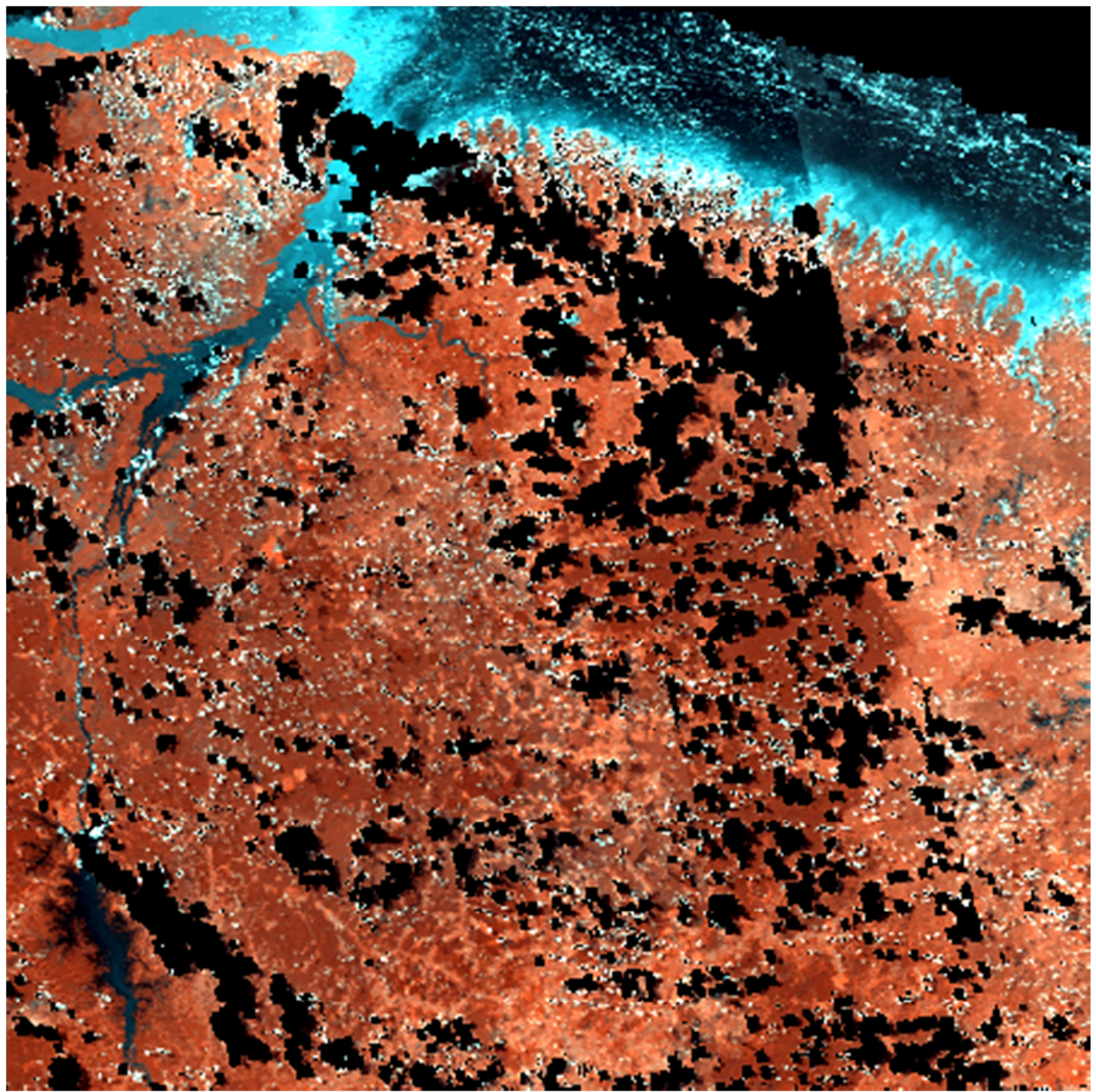

Figure 6-6: Example of CCI-LC AVHRR SR 7-day composite, at 1000m spatial resolution and tile h26v18 - ESACClLC-L3-SR-AVHRR-1000m-P7D-h26v18-19930521-v2.2.nc

Figure 6-7 shows the CCI-LC global surface reflectance composite from all AVHRR SR 7-day composites from 1996-05-21, at 1000m spatial resolution. 


\begin{tabular}{|c|c|c|c|c|}
\hline \multirow{2}{*}{ CeSa } & Ref & \multicolumn{2}{|c|}{ CCI LC PUG v2 } \\
\cline { 2 - 4 } & Issue & Page & Date & Iand couer \\
\cline { 2 - 5 } & 2.0 & 65 & $2017-03-31$ \\
\hline
\end{tabular}

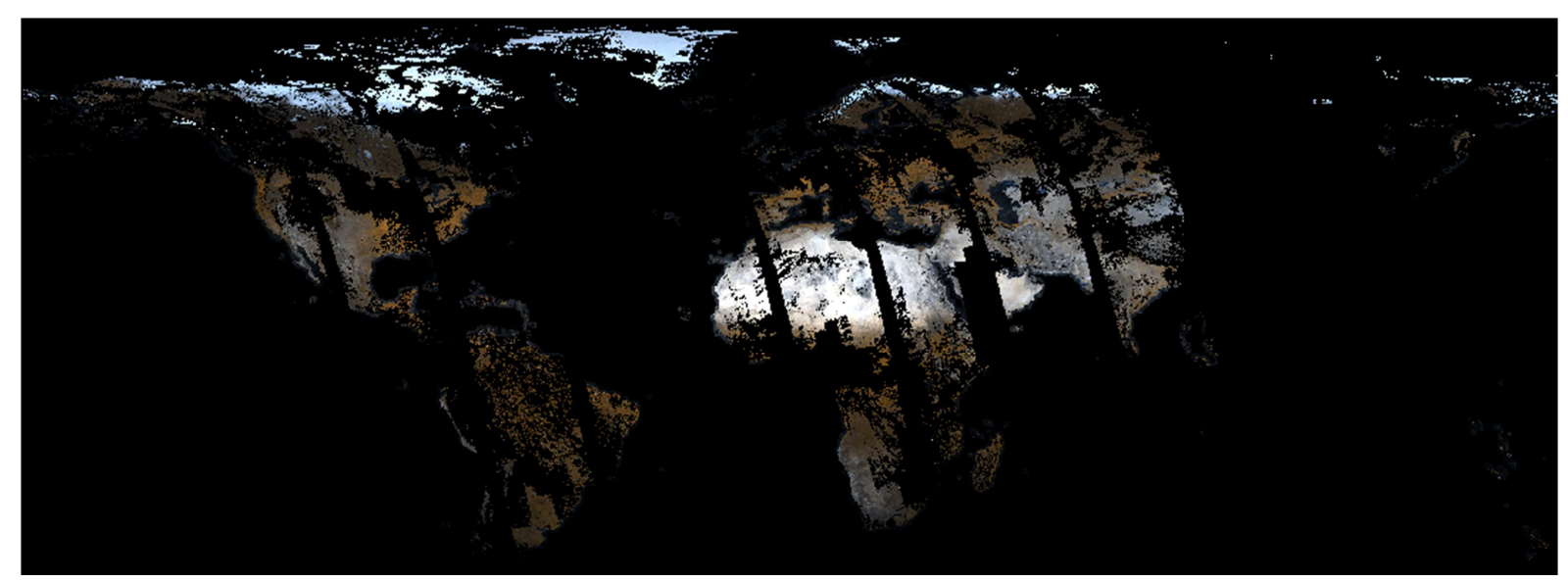

Figure 6-7: The CCI-LC Global Surface reflectance composite from all AVHRR SR 7-day composites from 1996-0521, at 1000m spatial resolution (ESACCI-LC-L3-SR-AVHRR-1000m-P7D- h00-71v00-35-19960521-v2.2.nc)

\subsubsection{PROBA-V time series}

The PROBA-V SR time series have been generated during this Phase II. The spectral content encompasses the 4 VIS-NIR-SWIR spectral channels (see Table 6-4) and the spatial resolution is of $300 \mathrm{~m}$.

Table 6-4: PROBA-V spectral channels.

\begin{tabular}{|c|c|c|c|}
\hline BAND NUMBER & $\begin{array}{c}\text { BAND CENTRE } \\
(\text { NM) }\end{array}$ & $\begin{array}{c}\text { BAND WIDTH } \\
(\text { NM) }\end{array}$ & COMMENT \\
\hline 1 & 464 & 47 & Surface reflectance for the Blue \\
\hline 2 & 655 & 82 & Surface reflectance for the Red \\
\hline 3 & 837 & 130 & Surface reflectance for the NIR \\
\hline 4 & 1603 & 65 & Surface reflectance for the SWIR \\
\hline
\end{tabular}

Figure 6-8 shows the individual RGB image of tile h36v13 of CCI-LC PROBA-V SR 7-day composite from 2015-03-19 at 300m spatial resolution. 


\begin{tabular}{|c|c|c|c|c|}
\hline \multirow{2}{*}{ CeSa } & Ref & \multicolumn{2}{|c|}{ CCI LC PUG v2 } \\
\cline { 2 - 4 } & Issue & Page & Date & Iand couer \\
\cline { 2 - 5 } & 2.0 & 66 & $2017-03-31$ & lai \\
\hline
\end{tabular}

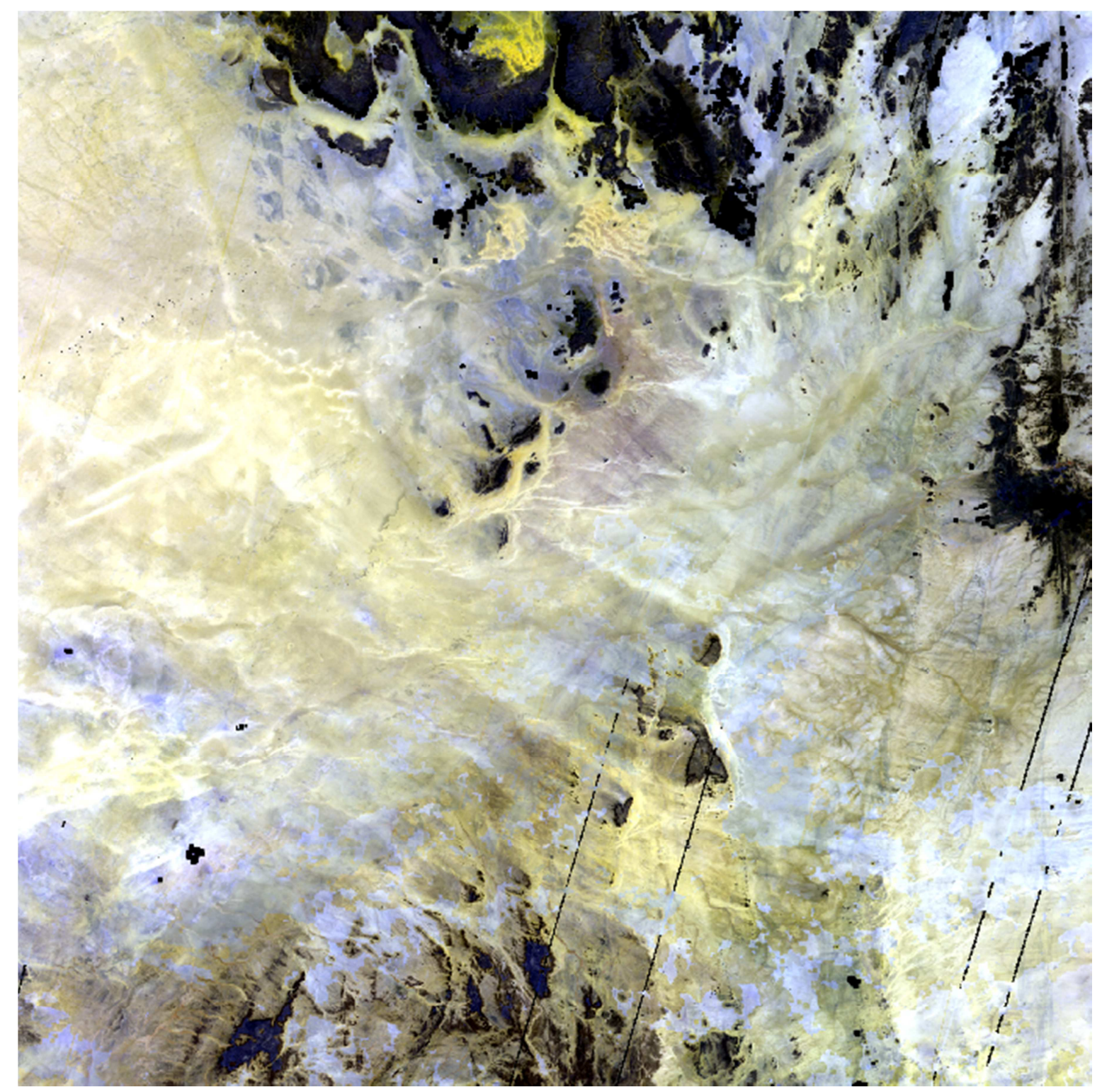

Figure 6-8: Example of CCI-LC PROBA-V SR 7-day composite, at 300m spatial resolution and tile h36v13ESACCI-LC-L3-SR-VEGETATION-300m-P7D-h36v13-20150319-v2.0.nc

Figure 6-9 shows the CCI-LC global seven-week seasonal surface reflectance composite from all PROBA-V SR 7-day composites from 2014-07-16 to2014-09-02, at 300m spatial resolution. 


\begin{tabular}{|c|c|c|c|c|}
\hline \multirow{2}{*}{ CeSa } & Ref & \multicolumn{2}{|c|}{ CCI LC PUG v2 } \\
\cline { 2 - 4 } & Issue & Page & Date & Iand couer \\
\cline { 2 - 5 } & 2.0 & 67 & $2017-03-31$ & lai \\
\hline
\end{tabular}

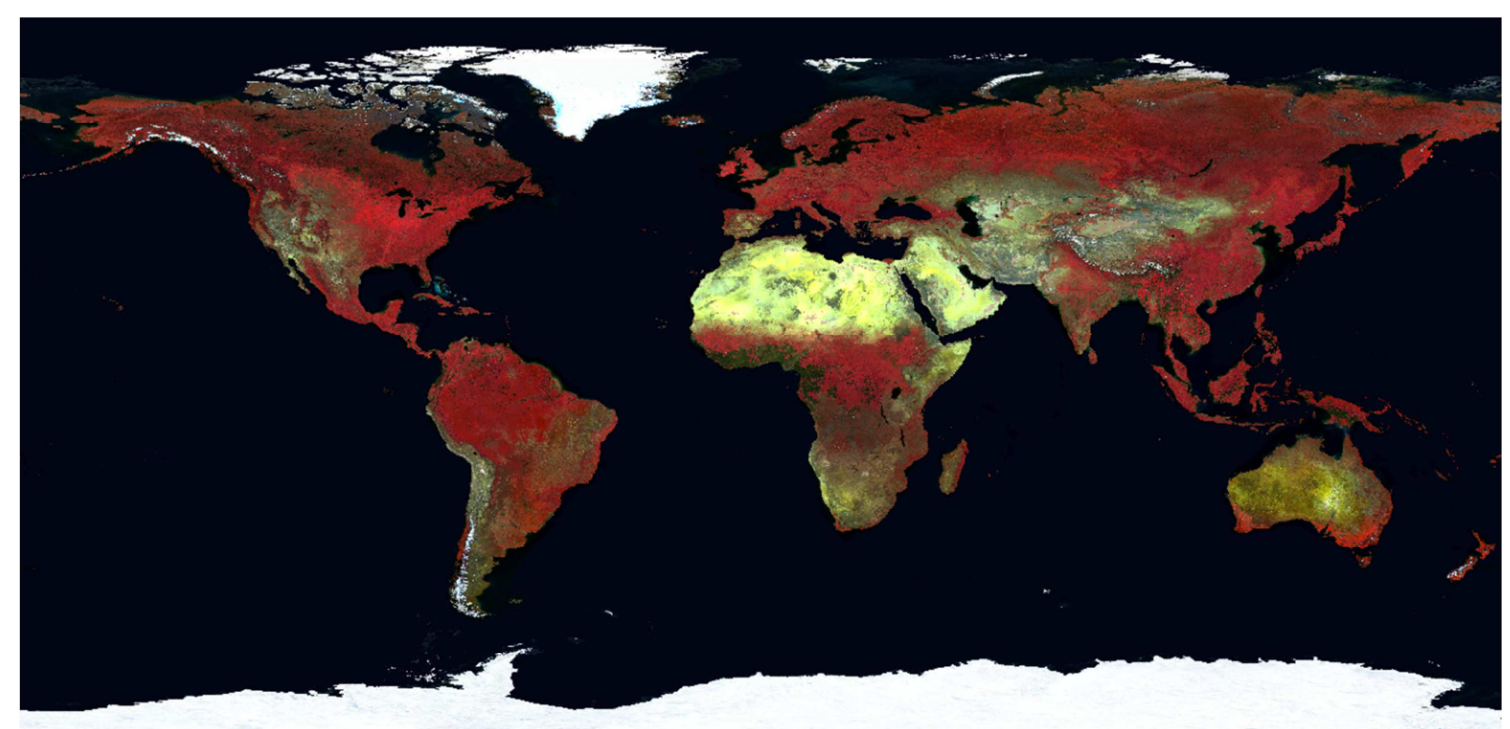

Figure 6-9: The CCI-LC Global Surface reflectance AVHRR composite from all SR 7-day composites from 2014-0716 to2014-09-02, at 300m spatial resolution (ESACCI-LC-L3-SR-Vegetation-300m-P7D-h00-71v00-3520140716-201400902-v2.1.nc)

\subsection{Products format}

\section{- Naming convention}

The file name convention of the global SR composite time series delivered by the CCI-LC project is the following:

File name $=\langle i d>-v<v e r s i o n>. n c$

$$
\begin{aligned}
& \text { where }\langle\text { id }\rangle=\langle\text { type }\rangle-\langle\text { tile }\rangle-\langle\text { start time }> \\
& \text { where }\langle\text { type }\rangle=\langle\text { project }\rangle[-<\text { level }\rangle]-\langle\text { code }\rangle-\langle\text { sensor }\rangle-<\text { spatres }\rangle-<\text { tempres }>
\end{aligned}
$$

The dash "-" is the separator between name components. The filename convention obeys NetCDF CF by using the postfix ".nc". The different name components are defined in Table 6-5.

Table 6-5: Components that make the name of the SR products delivered by the CCI-LC project.

\begin{tabular}{|l|l|l|}
\hline \multicolumn{1}{|c|}{ FIELD } & \multicolumn{1}{c|}{ SIGNIFICATION } & \multicolumn{1}{c|}{ VALUE } \\
\hline project & Project Acronym & ESACCI-LC (constant) \\
\hline level & Processing level & L3 (constant) \\
\hline code & Product code identifier for CCI-LC products & SR (constant) \\
\hline sensor & Mission, platform and sensor identifier & MERIS, PROBA-V, AVHRR \\
\hline spatres & Spatial resolution & 300m or 1000m \\
\hline tempres & Compositing period & P7D (constant) \\
\hline tile & Tile of the Plate Carrée grid (see Figure 6-1) & Tile name in format hXXVYY where XX is the \\
\hline
\end{tabular}




\begin{tabular}{|c|c|c|c|c|}
\hline \multirow{2}{*}{ CeSa } & Ref & \multicolumn{3}{|c|}{ CCI LC PUG v2 } \\
\cline { 2 - 5 } & Issue & Page & Date & Iand couer \\
\cline { 2 - 5 } & 2.0 & 68 & $2017-03-31$ & cci \\
\hline
\end{tabular}

\begin{tabular}{|c|c|c|}
\hline FIELD & SIGNIFICATION & VALUE \\
\hline & & $\begin{array}{l}\text { column and } \mathrm{YY} \text { is the row } \\
\text { e.g. " h71v27" - tile in column } 71 \text { and row } 27 \text { of } \\
\text { the Plate Carrée grid (see Figure 6-1) }\end{array}$ \\
\hline $\begin{array}{l}\text { start } \\
\text { time }\end{array}$ & $\begin{array}{l}\text { Start time of the interval mentioned in the field } \\
\text { "period" }\end{array}$ & $\begin{array}{l}\text { "yyyyMMdd" where: } \\
\text { "yyy" is the start year of the composite } \\
\text { "MM" is the start month of the composite } \\
\text { "dd" is the start day of the composite }\end{array}$ \\
\hline version & $\begin{array}{l}\text { Incremental that follows the successive } \\
\text { revisions of the CCI-LC Processing lines }\end{array}$ & $\begin{array}{l}\text { Version of product, preferably major.minor, } \\
\text { optionally with processing centre } \\
\text { [a-zA-Z0-9._] }\end{array}$ \\
\hline
\end{tabular}

An example file name of the first 7-day MERIS FR SR composite for the year 2008 located at the tile h40v13 would be: "ESACCI-LC-L3-SR-MERIS-300m-P7D-h40v13-20080326-v1.0.nc"

\section{- Processing Level}

Level 3 (i.e. "data or retrieved environmental variables which have been derived from level 1 or 2 products and which have been spatially and/or temporally resampled" [RD.14])

\section{- Units}

Top of Canopy Reflectance values (no unit, provided as a fraction) coded in 16-bits

\section{- Spatial Extent}

All the terrestrial zones of the earth between the parallels $90^{\circ} \mathrm{N}$ and $60^{\circ} \mathrm{S}$. The SR products are provided in tiles as defined in Section 6.1.

\section{- Spatial resolution}

$300 \mathrm{~m}$ or $1000 \mathrm{~m}$

\section{- Temporal resolution}

7 day

\section{- Product layers}

The CCI-LC global 7-day SR products description is based on the structure of the NetCDF files. The global attributes of the composites are described in the Appendix 2.

\section{- Projection}

The projection is a Plate Carrée with a geographic Lat/Long representation based on the WGS84 ellipsoid (see Section 3.1.3 for a complete description).

\section{- Format}

All the SR time series are delivered in NetCDF-4 format using the "classic model" of NetCDF with compression. The file specification follows CF conventions [RD.16]. 


\begin{tabular}{|c|c|c|c|c|}
\hline \multirow{2}{*}{ CeSa } & Ref & \multicolumn{2}{|c|}{ CCI LC PUG v2 } \\
\cline { 2 - 5 } & Issue & Page & Date & land couer \\
& 2.0 & 69 & $2017-03-31$ & lai \\
\hline
\end{tabular}

\section{- Metadata}

The metadata for the SR products is provided as global attributes in the NetCDF file. It follows the CCI guidelines [RD.17].

\section{- Estimated size}

The size of a global 7-day 300-m MERIS FR/RR SR composite is estimated at $\sim 70 \mathrm{~GB} / \sim 8 \mathrm{~GB}$ (compressed) and the size of the one tile is estimated at $\sim 0.3 \mathrm{~GB} / \sim 0.02 \mathrm{~GB}$ (compressed).

The size of a global 7-day 1000-m AVHRR SR composite is estimated at $\sim 4$ GB (compressed) and the size of the one tile is estimated at $\sim 3 \mathrm{MB}$ (compressed).

The size of a global 7-day 300-m PROBA-V SR composite is estimated at $\sim 40$ GB (compressed) and the size of the one tile is estimated at $\sim 90 \mathrm{MB}$ (compressed). 


\begin{tabular}{|c|c|c|c|c|}
\hline \multirow{2}{*}{ CeSa } & Ref & & CCI LC PUG v2 & Date \\
\cline { 2 - 5 } & Issue & Page & $2017-03-31$ & land couer \\
\cline { 2 - 5 } & 2.0 & 70 & cci \\
\hline
\end{tabular}

\section{SOFTWARE TOOLS}

A set of tools to browse and view the content of the CCI-LC products are available.

\subsection{Software tools for viewing and using the CCI-LC SR 7-day composite products}

\subsubsection{BEAM}

Since the CCI-LC SR 7-day products are in NetCDF format, these products can be opened with all NetCDF compatible software packages. We particularly recommend using the BEAM toolbox, which is specifically developed by ESA for the exploitation of EO data products. BEAM, for example, features the interpretation of flag-codings, provides image interpretation information, handles missing data gracefully and allows band arithmetic using a fast expression language.

BEAM is the Basic European Remote Sensing Satellite (ERS) \& Envisat (Advanced) Along Track Scanning Radiometer ((A)ATSR) and MERIS Toolbox and is a collection of executable tools and an Application Programming Interface (API) which have been developed to facilitate the use, viewing and processing of data of various sensors. Furthermore, BEAM is open source and freely available from http://earth.esa.int/beam.

Regarding the CCI-LC products, BEAM could for example be used to:

- view the images and metadata;

- create regional subsets;

- investigate the products by creating statistics, histograms, and scatter plots;

- perform image analysis (e.g. clustering);

- validate data by comparison with in-situ or any other kind of reference data.

The components of the BEAM software are the following ones:

- VISAT - an intuitive desktop application to be used for visualization, analysis and processing of remote sensing raster data. Figure 7-1 gives an impression of how VISAT looks and feels like;

- a set of scientific tools running either from the command line or invoked by VISAT, also entirely written in Java;

- a rich Java API for the development of new remote sensing applications and BEAM extension plug-ins. 


\begin{tabular}{|c|c|c|c|c|}
\hline \multirow{2}{*}{ e ESa } & Ref & \multicolumn{2}{|c|}{ CCI LC PUG v2 } & Date \\
\cline { 2 - 5 } & Issue & Page & $2017-03-31$ & land couer \\
& 2.0 & 71 & cci \\
\hline
\end{tabular}

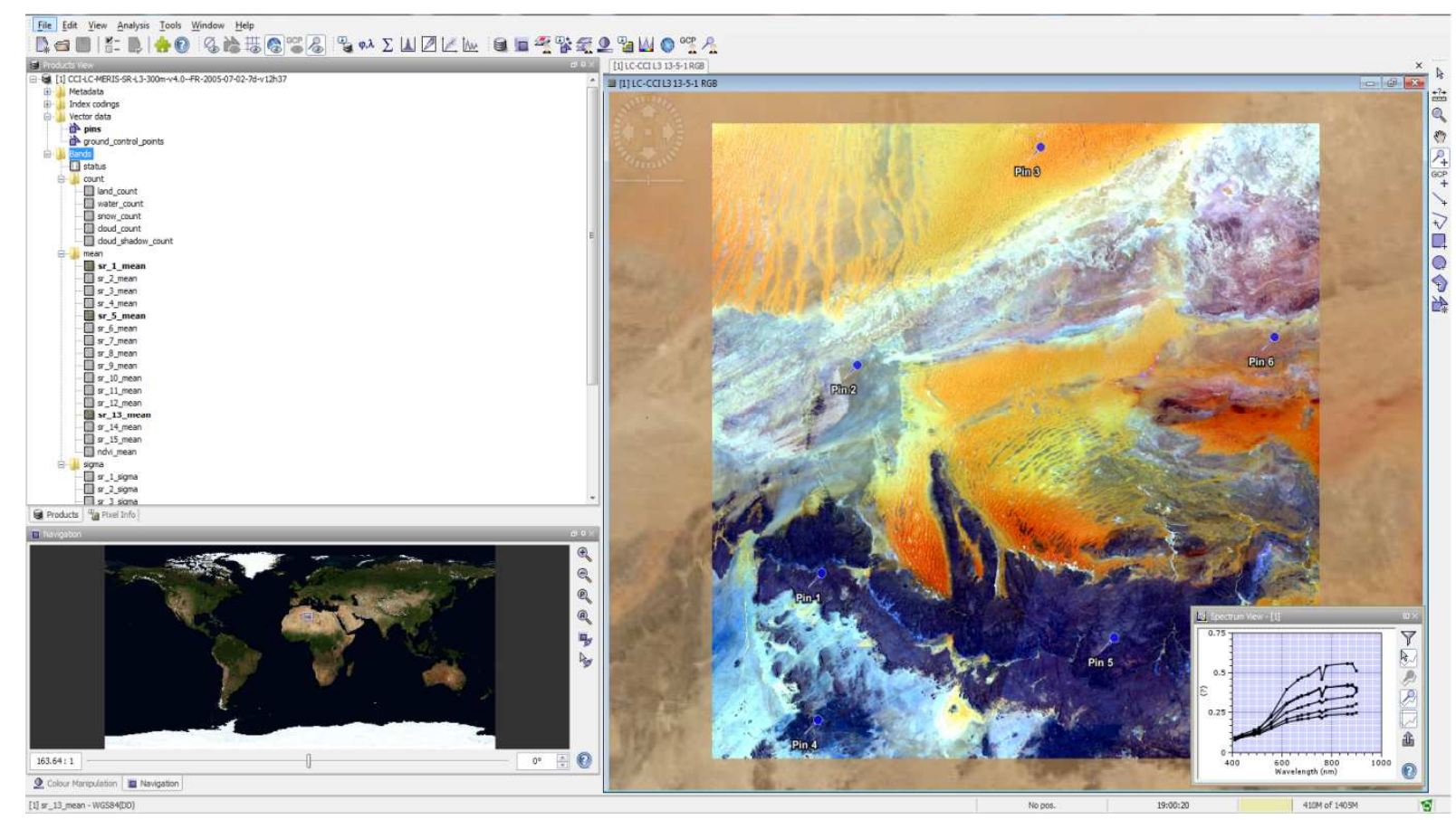

Figure 7-1: Screenshot of VISAT.

\subsubsection{Panoply}

The Panoply data viewer provided by for free (available at http://www.giss.nasa.gov/tools/panoply/) can also be used. It is illustrated at Figure 7-2.

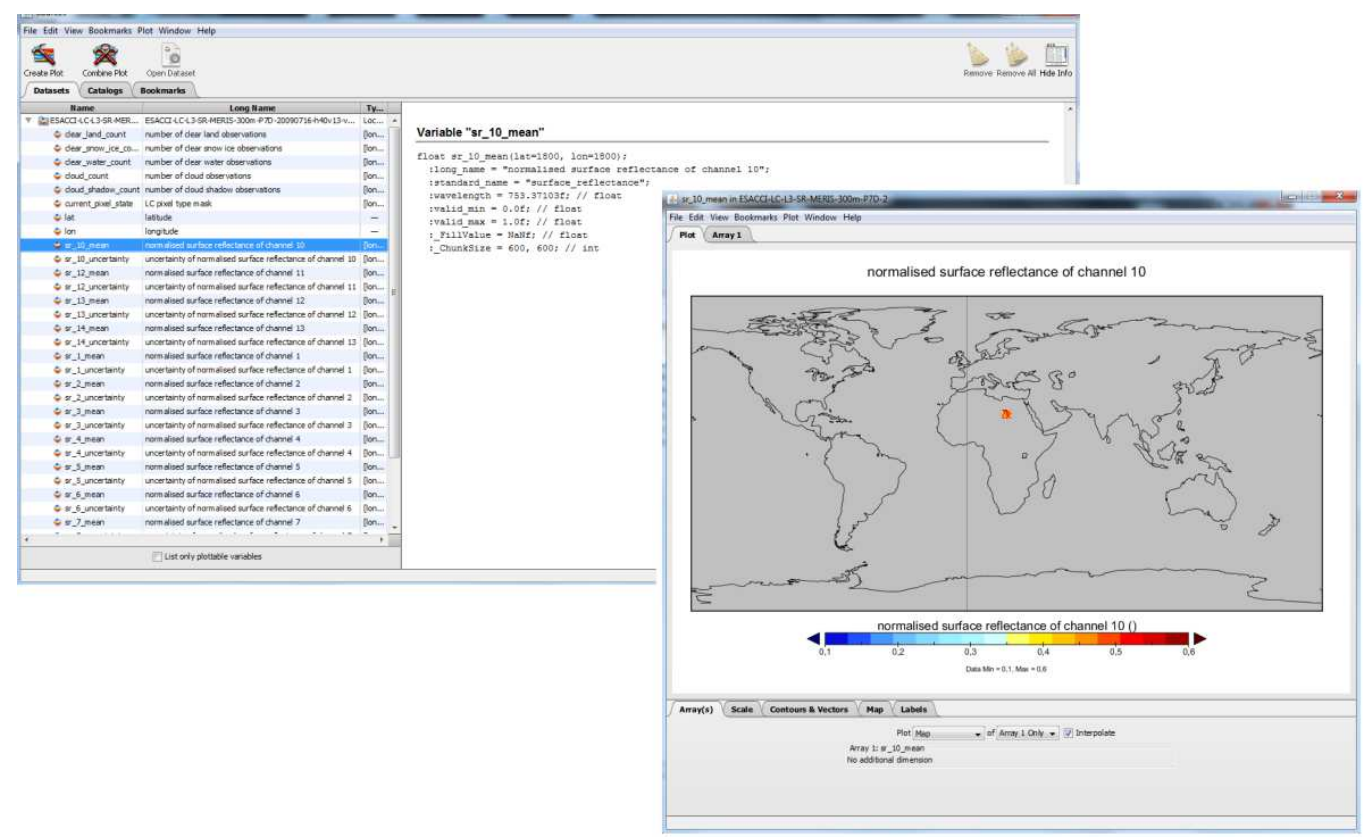

Figure 7-2: Screenshot of Panoply. 


\begin{tabular}{|c|c|c|c|c|}
\hline \multirow{2}{*}{ CeSa } & Ref & \multicolumn{2}{|c|}{ CCI LC PUG v2 } \\
\cline { 2 - 5 } & Issue & Page & Date & land couer \\
& 2.0 & 72 & $2017-03-31$ & lai \\
\hline
\end{tabular}

\subsection{Software tools for the CCI-LC maps and seasonality products}

The CCI-LC map and seasonality product are delivered both in the NetCDF and GeoTiff formats.

The GeoTiff format is supported by many softwares such as ArcGIS, Erdas and ENVI. These softwares can be used simply to visualize the data or to cross LC information with other spatial sources (vector or raster layers), extract temporal series on the seasonality products, compute statistics, etc.

Several Open Source softwares also support the GeoTiff format, such as the Geospatial Data Abstraction Library (GDAL [RD.18]) and the Geographic Resources Analysis Support System (GRASS GIS [RD.19]).

GDAL is a library for reading and writing raster geospatial data formats. It is built with a variety of useful command-line utilities for data translation and processing. This software allows easy access to the metadata and statistics of the files via the gdalinfo command. Regional subsets can also be created with the gdal_translate function.

GRASS GIS is a free Geographic Information System (GIS) software used for geospatial data management and analysis, image processing, graphics/maps production, spatial modelling, and visualization.

\subsection{CCI-LC user tool}

The LC map and seasonality products are delivered at spatial resolution of $300 \mathrm{~m}$ and $1 \mathrm{~km}$, respectively. All products are delivered in a Plate Carrée projection as global files. However, climate models may need products associated with a coarser spatial resolution, over specific areas (e.g. for regional climate models) and/or in another projection. In order to face the variety of requirements, the CCI-LC project has developed a tool that allows users to adjust these three parameters of the LC products in a way which is suitable to their model.

The climate users of the CCI-LC project have established a minimum list of possibilities in terms of spatial resolution and projection that the tool shall - and does - offer. They are presented in Table 7-1.

Table 7-1: Minimum set of projections and spatial resolutions that need to be included in the re-projection, aggregation and subset tool developed by the CCI-LC project.

\begin{tabular}{|l|l|}
\hline \multicolumn{1}{|c|}{ PARAMETER THAT CAN BE ADJUSTED } & \multicolumn{1}{c|}{ POSSIBILITIES OFFERED BY THE TOOL } \\
\hline \multirow{2}{*}{ Regional subset ID } & Predefined regional subset \\
\cline { 2 - 2 } & Free specification of regional subset (4 corner coordinates) \\
\hline \multirow{3}{*}{ Spatial resolution } & Original resolution \\
\cline { 2 - 2 } & 0.25 degree \\
\cline { 2 - 2 } & 0.5 degree \\
\cline { 2 - 2 } & 1 degree \\
\cline { 2 - 2 } & 1.875 degree \\
\hline
\end{tabular}




\begin{tabular}{|c|c|c|c|c|}
\hline \multirow{2}{*}{ Cesa } & Ref & \multicolumn{3}{|c|}{ CCI LC PUG v2 } \\
\cline { 2 - 5 } & Issue & Page & Date & Iand couer \\
\cline { 2 - 5 } & 2.0 & 73 & $2017-03-31$ & cci \\
\hline
\end{tabular}

\begin{tabular}{|l|l|}
\hline \multicolumn{1}{|c|}{ PARAMETER THAT CAN BE ADJUSTED } & \multicolumn{1}{c|}{ POSSIBILITIES OFFERED BY THE TOOL } \\
\hline Projection & Original projection (Plate-Carrée) \\
\cline { 2 - 2 } & Gaussian grid \\
\hline Conversion of CCI-LC classes to PFT & CCl-LC standard cross table \\
\cline { 2 - 2 } & $\begin{array}{l}\text { User defined cross table } \\
\text { Additional classification map }\end{array}$ \\
\hline
\end{tabular}

In case of re-projection and aggregation of the CCI-LC products the applied resampling algorithms are different depending on the type of product and on the included bands and are described in the following.

\section{- Re-sampling algorithm for the CCI-LC Map products}

The aggregated CCI-LC map product includes following bands: the fractional area of each CCI-LC class, the majority classes and the fractional area of each PFT as well as the accuracy. The majority class $\mathrm{n}$ is defined as the CCI-LC class which has the rank $\mathrm{n}$ of sorted list of CCI-LC class by fractional area in the target cell (see also Figure 7-3). The number of majority classes is a parameter which can be defined by user. The rules for the resampling are specified in consultation with the users. So each original pixel contributes to the target cell according to its area percentage but the value of a pixel will only consider if the flag -processed flag- has the status processed and the flag -current_pixel_state- has the status clear land, water or snow and ice. Then the accuracy is calculated by the median of the values of the band -algorithmic_confidence_level-.
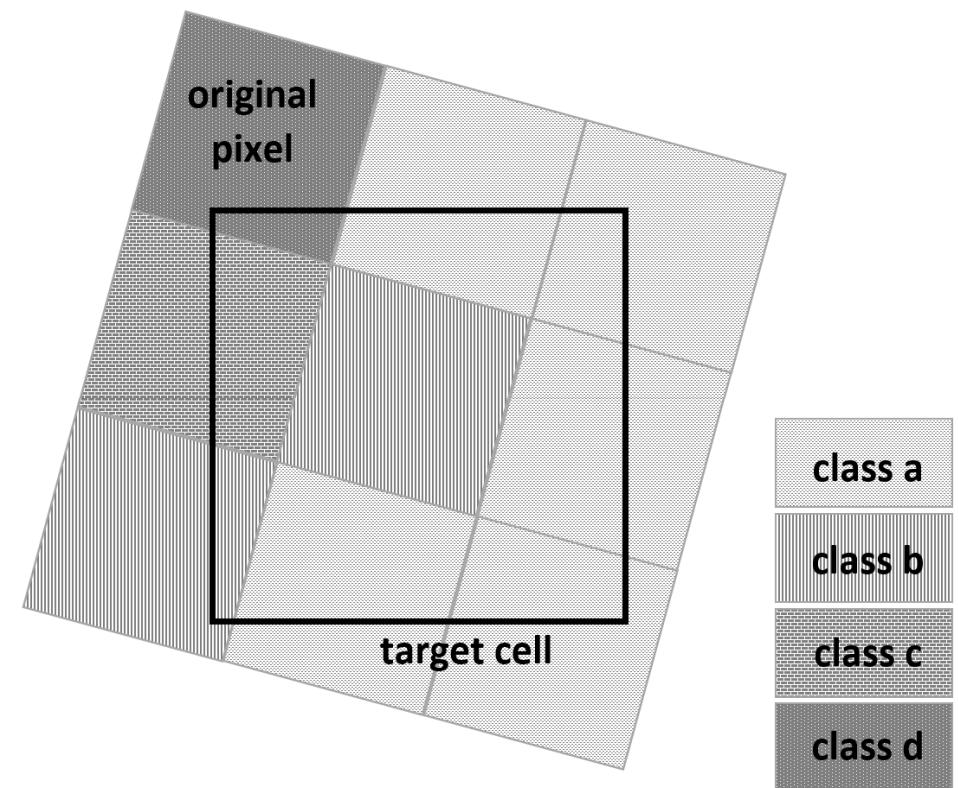

\begin{tabular}{|c|c|c|}
\hline & Area & $\begin{array}{c}\text { Majority } \\
\text { class }\end{array}$ \\
\hline class a & $\underset{8 / 16}{\sim}$ & 1 \\
\hline class b & $\underset{5 / 16}{\sim}$ & 2 \\
\hline class C & $\underset{2 / 16}{\sim}$ & 3 \\
\hline class d & $\underset{1 / 16}{\sim}$ & 4 \\
\hline
\end{tabular}

Figure 7-3: Visualization of the pixel aggregation from the spatial resolution of original LC-CCI Map product into the user defined spatial resolution of the aggregated LC-CCI Map product. 


\begin{tabular}{|c|c|c|c|c|}
\hline \multirow{2}{*}{ CeSa } & Ref & \multicolumn{3}{|c|}{ CCI LC PUG v2 } \\
\cline { 2 - 5 } & Issue & Page & Date & Iand couer \\
\cline { 2 - 5 } & 2.0 & 74 & $2017-03-31$ & Iai \\
\hline
\end{tabular}

\section{- Re-sampling algorithm for the CCI LS seasonality product}

In case of the aggregation of the NDVI CCI LS seasonality product, the mean of NDVI and the sum over all valid NDVI observations are included in the aggregated product. The rules for the resampling are also specified in consultation with the users. As well as for the CCI-LC map products, each original pixel contributes to the target cell according to its area percentage but the value of a pixel will only consider if the flag -current_pixel_state- has a dedicated status w.r.t. the type of seasonality product.

\section{- LCCS to PFT conversion}

Furthermore, it is very important that the modellers can use the aggregation tool to apply the conversion from the LC legend to their user-specific PFT list in order to deliver an appropriate PFT product. The conversion of CCI-LC classes to PFT is based on a look-up table, which has been confirmed by the climate modellers and is shown in Table 7-2. The users have the possibility to define their own look-up tables. Additionally, the user can also apply the conversion of the LCCS classes to PFT including additional information, like world map of Köppen-Geiger climate classification (v3.10 and see Figure 7-4, [RD.20]).

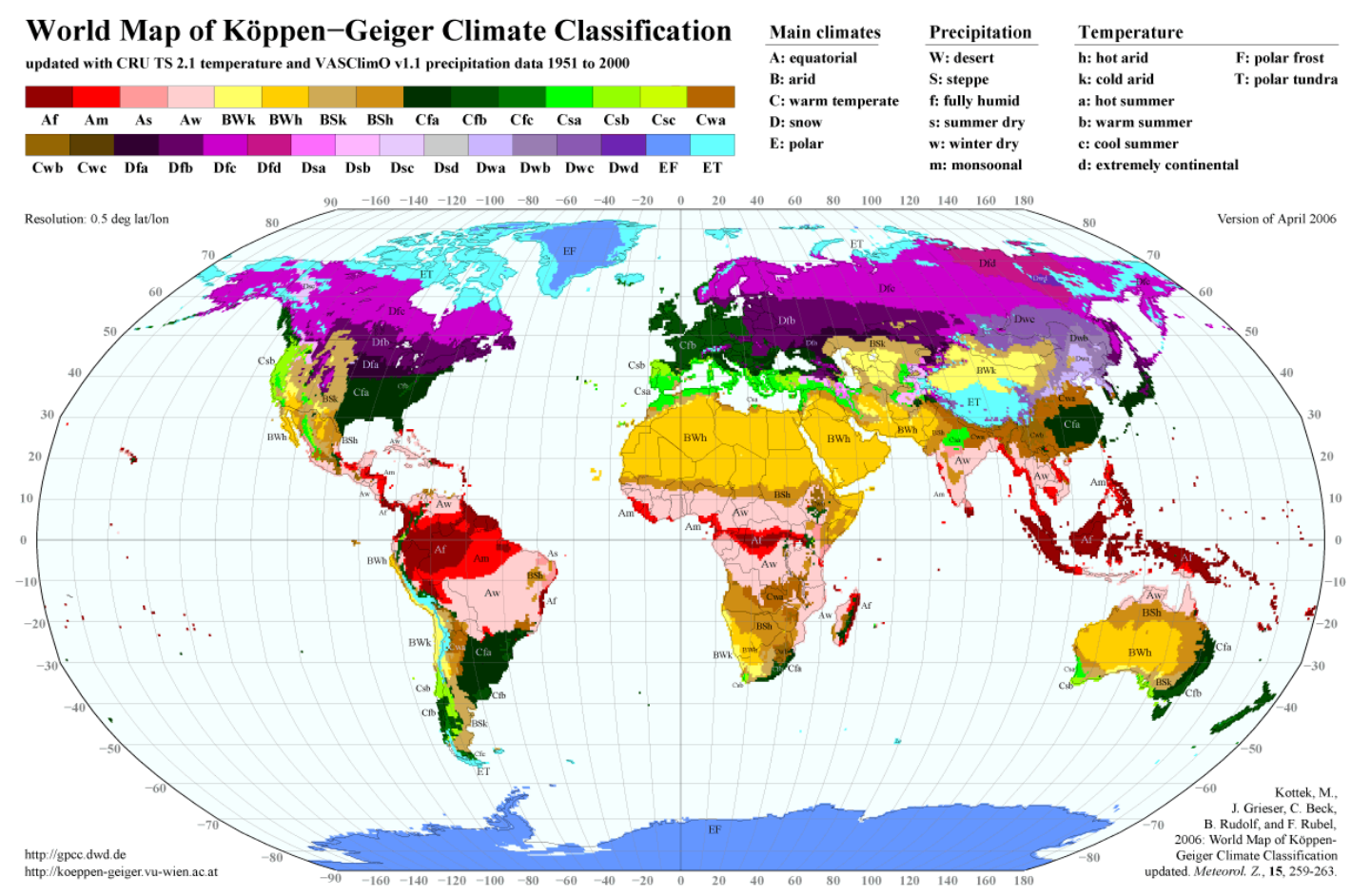

Figure 7-4: Köppen-Geiger climate classification [RD.20]. 


\begin{tabular}{|c|c|c|c|c|}
\hline \multirow{2}{*}{ CeSa } & Ref & & CCI LC PUG v2 & Date \\
\cline { 2 - 5 } & Issue & Page & $2017-03-31$ & land couer \\
\cline { 2 - 5 } & 2.0 & 75 & cci \\
\hline
\end{tabular}

Table 7-2: Look-up table - conversion of CCI-LC classes to PFT. 


\begin{tabular}{|c|c|c|c|c|}
\hline \multirow{2}{*}{ CeSa } & Ref & \multicolumn{2}{|c|}{ CCI LC PUG v2 } \\
\cline { 2 - 5 } & Issue & Page & Date & land couer \\
\cline { 2 - 5 } & 2.0 & 76 & $2017-03-31$ & cci \\
\hline
\end{tabular}

\section{- Examples}

Figure 7-5 gives an example of the global land cover map aggregated at a cell size of $9.8 \mathrm{~km}$ and the pixel value represents the majority class 1 w.r.t. the LC class, according to Table 3-1.

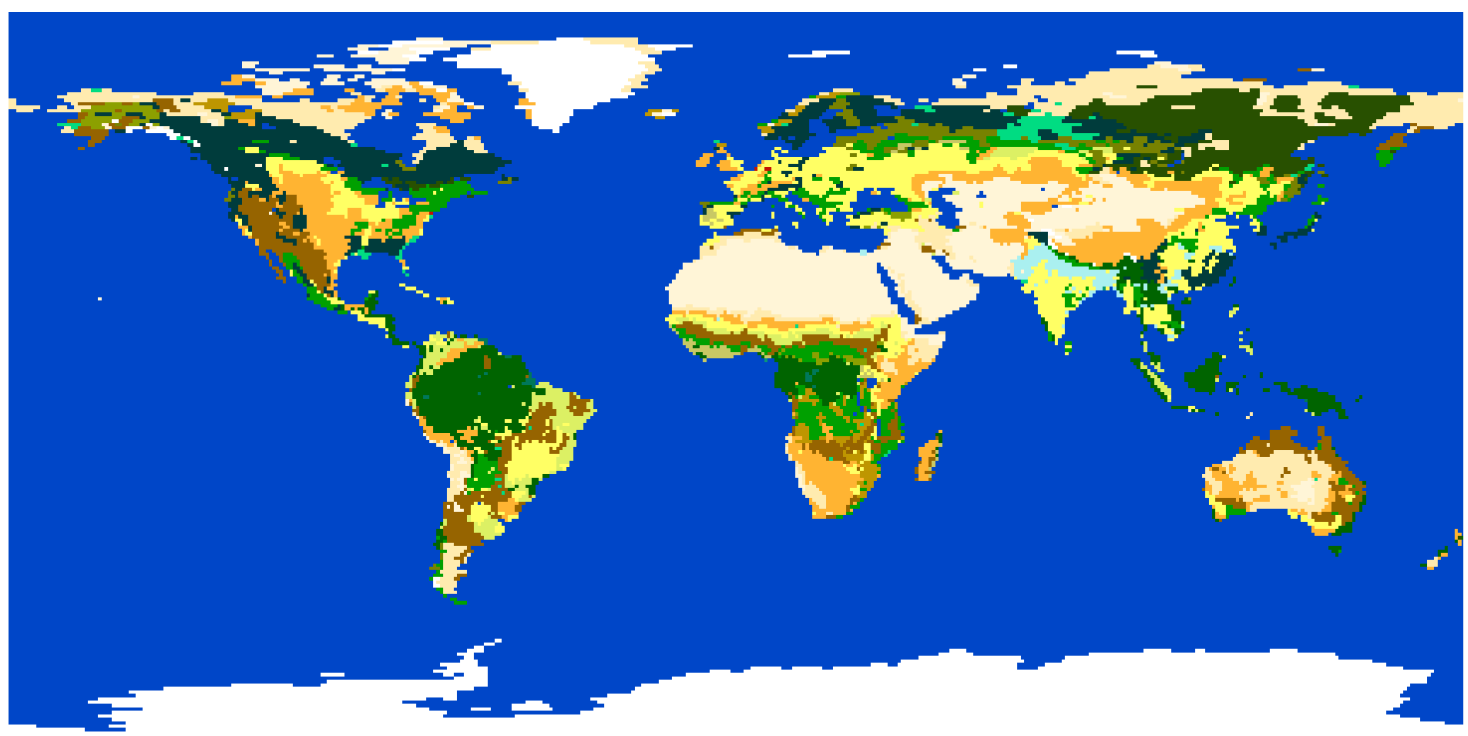

Figure 7-5: Example of the aggregated global land cover map V1 obtained with the user tool. Its pixel size is 9.8 $\mathrm{km}$, the majority class is 1 and the pixel value represents the LC class according to Table 7-2.

Figure 7-6 shows an example of the global land cover map aggregated at a cell size of $9.8 \mathrm{~km}$ and the pixel value represents the area of the LC class 130 - grassland. Figure 7-7 gives an example of the global land cover map aggregated at a cell size of $9.8 \mathrm{~km}$ and the pixel value represents the area of the PFT - natural grass. 


\begin{tabular}{|c|c|c|c|c|}
\hline \multirow{2}{*}{ CeSa } & Ref & \multicolumn{2}{|c|}{ CCI LC PUG v2 } \\
\cline { 2 - 5 } & Issue & Page & Date & land couer \\
\cline { 2 - 5 } & 2.0 & 77 & $2017-03-31$ & cci \\
\hline
\end{tabular}

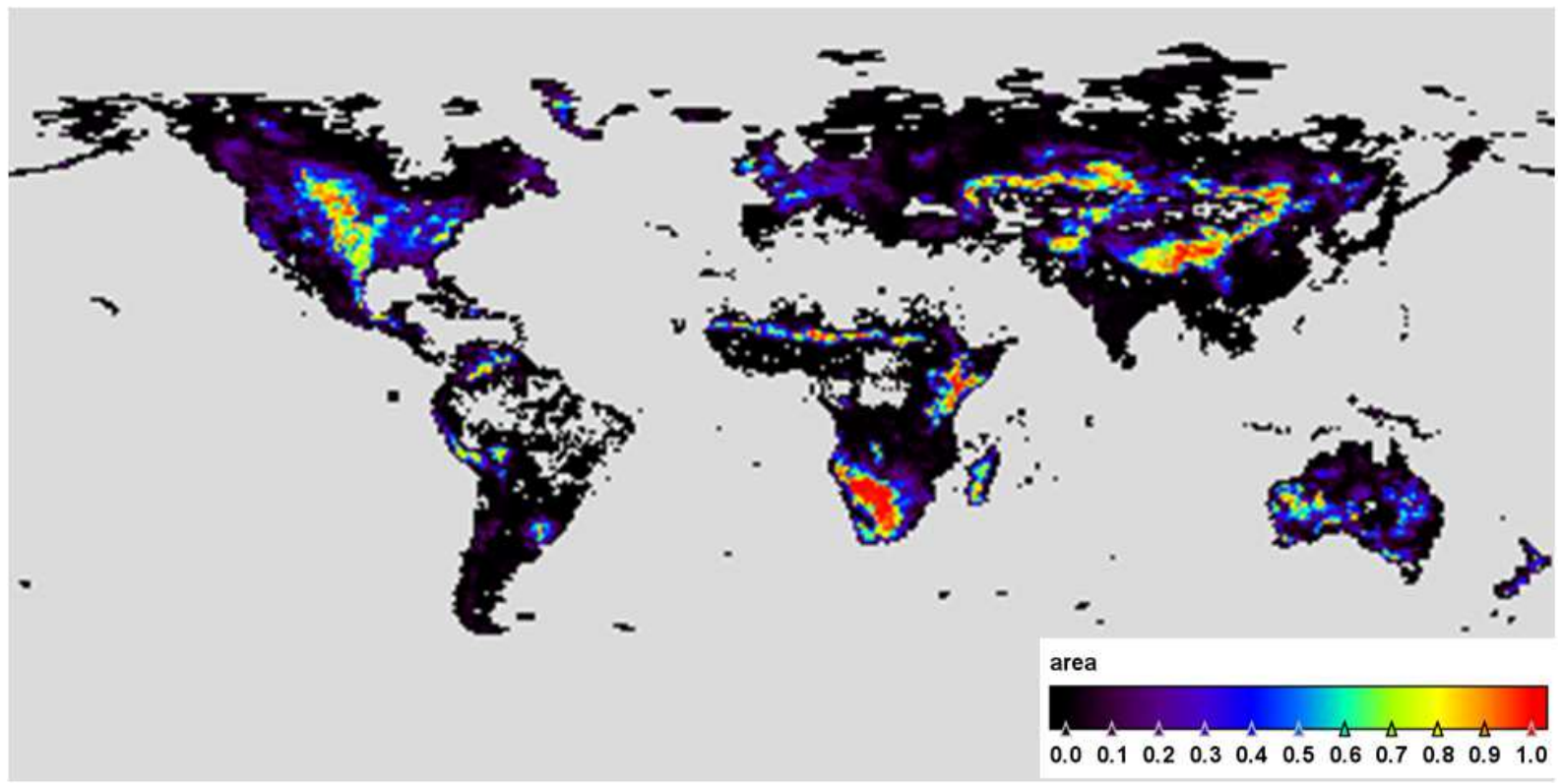

Figure 7-6: Example of an aggregated CCI Global Land Cover Map V1 obtained with the aggregation tool. Its pixel size is $9.8 \mathrm{~km}$, area of CCI-LC class - 130 - grassland.

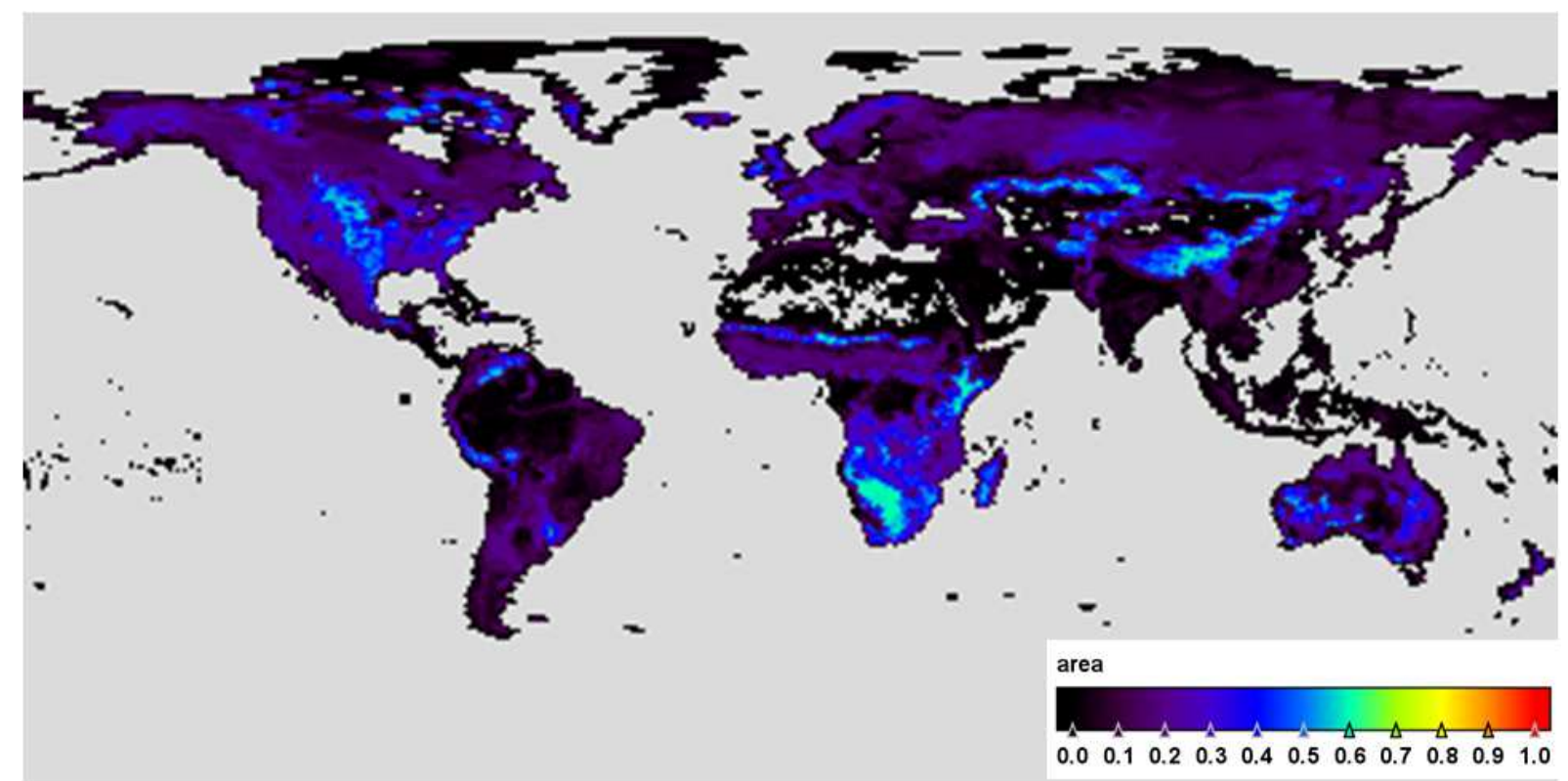

Figure 7-7: Example of an aggregated CCI Global Land Cover Map V1 obtained with the aggregation tool. Its pixel size is $9.8 \mathrm{~km}$, area of CCI-LC PFT - natural grass.

The instruction manual of the aggregation tool can be found in the Appendix 4 of this document. 


\begin{tabular}{|c|c|c|c|c|}
\hline \multirow{2}{*}{ CeSa } & Ref & \multicolumn{2}{|c|}{ CCI LC PUG v2 } \\
\cline { 2 - 5 } & Issue & Page & Date & land couer \\
& 2.0 & 78 & $2017-03-31$ & lai \\
\hline
\end{tabular}

\subsection{Software tools for CCI-LC dataset visualization}

Considering the heavy download related to the full CCI-LC products dataset, a web interface was developed to mainly visualize and interact with data. It is accessible at the following address: http://maps.elie.ucl.ac.be/CCI/viewer/index.html. Figure 7-8 illustrates the home page of the visualization interface

It includes two main compartments: the map environment (right) and the information panel (left). The information panel includes the description of the LC-Map legend (1) and the functionality to download pdf documents describing the products: this actual product user guide, summary user guides for the CCI-LC Maps and seasonality products and the CCI-LC Maps legend (2).

The "+ O -" button (3) can be used to adapt the zoom, such as the mouse wheel and to set the visualization extent to global. By default, the base layer displayed in the map environment corresponds to the CCI-LC map of year 2015 but it can be changed by selecting one of the products available in (4): a 10-year global MERIS surface reflectance product composite, the annual CCI-LC maps from 1992 to 2015 and the water body product.

The base layer is interactive (5). A left click, anywhere on the layer, highlights the LC-Map label of the selected pixel in the legend description of the left panel. A right click activates the display of the CCI LS NDVI seasonality profiles reference behaviour.

Finally, the download data button (6) redirects the user to a new web page where the products are available for download:

- The CCI-LC maps and their corresponding quality flags (see Section 3.1.3);

- The SAR WB layer from the WB product v3.0 (see Table 4-2) and v4.0 (see Table 5-2);

- The NDVI and water seasonality products can be extracted according to LAT/LONG coordinates or simply downloaded;

- The user tool. 


\begin{tabular}{|c|c|c|c|c|}
\hline \multirow{2}{*}{ CeSa } & Ref & \multicolumn{3}{|c|}{ CCI LC PUG v2 } \\
\cline { 2 - 5 } & Issue & Page & Date & Iand couer \\
\cline { 2 - 5 } & 2.0 & 79 & $2017-03-31$ & cci \\
\hline
\end{tabular}

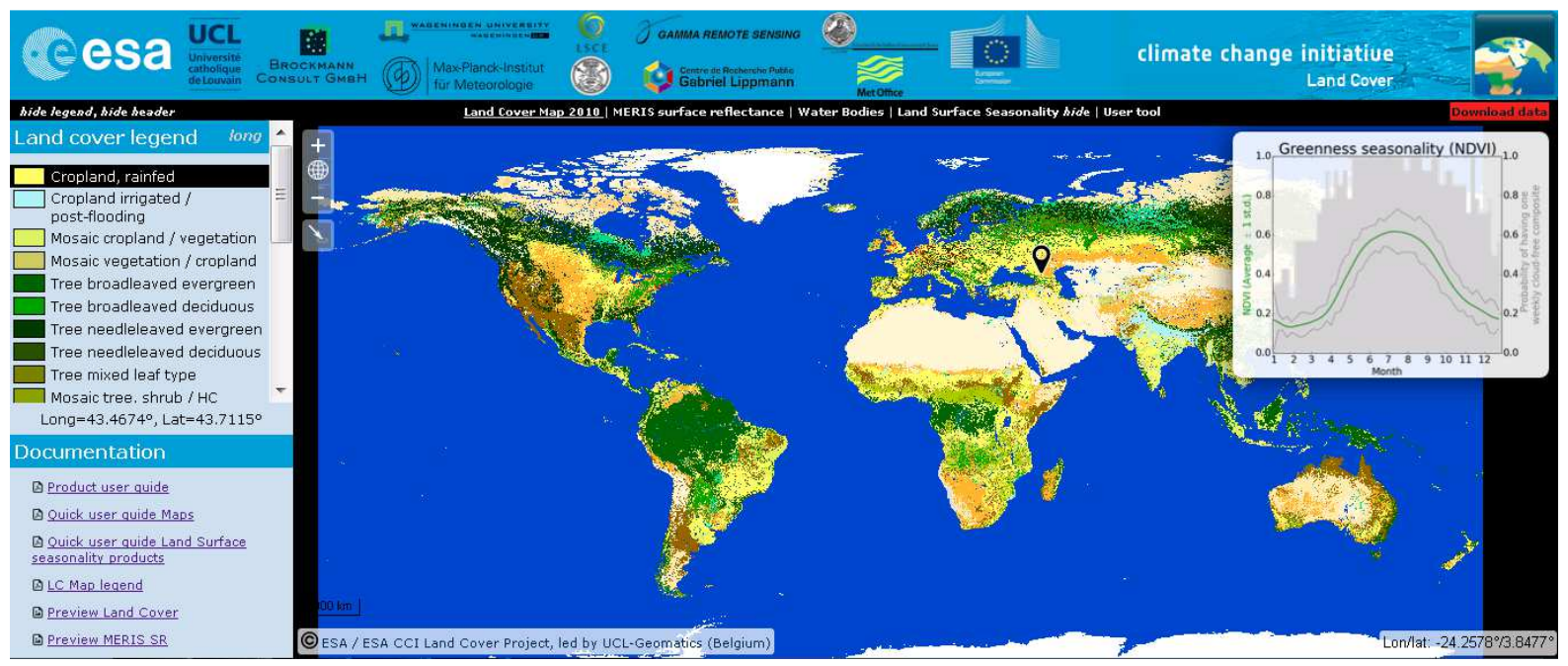

Figure 7-8: Main page of the CCI-LC products visualization tool, with the following functionalities: top-left) LCMaps legend description; bottom-left) download of documents describing the CCI-LC products; top-left) tools box to control the zooms (+ and -), to set the view to the global extent (O) and to reach particular coordinates; top) products available for visualization; centre) visualization panel. A right click on the map activates the apparition of the LS seasonality profiles (NDVI) and highlights the LC-Map label on the left panel; top right) redirection to data download web page. Please note that a right click also shows additional profiles of the dynamics of land cover regarding the snow and burned areas occurrence. 


\begin{tabular}{|c|c|c|c|c|}
\hline \multirow{2}{*}{ CeSa } & Ref & \multicolumn{2}{|c|}{ CCI LC PUG v2 } \\
\cline { 2 - 4 } & Issue & Page & Date & 2017-03-31 \\
\cline { 2 - 5 } & 2.0 & 80 & Iand couer \\
cci
\end{tabular}

\section{DATA ACCESS AND POLICY}

The CCI-LC products are made available through the viewer presented in Section 7.4:

CCI-LC visualization interface (http://maps.elie.ucl.ac.be/CCI/viewer/index.html)

For the time being, the data delivered in the CCI-LC database are the following ones:

- MERIS FR and RR time series version 1.0;

- AVHRR time series version 1.0;

- Annual LC maps from 1992 to 2015 (v2);

$\circ \quad$ Legend (csv)

○ Symbology for ENVI (.dsr), for ArcGis (.lyr) and for QGis (.qml)

- NDVI seasonality products v2.0;

- $\quad$ WB product v3.0 $(300 \mathrm{~m})$ and $\mathrm{v} 4.0(150 \mathrm{~m})$;

- $\quad$ The User Tool v3.12.

This CCI-LC database has been processed by the CCI-LC consortium led by UCL-Geomatics (Belgium). They are made available to the public by ESA and the consortium. You may use one or several CCI-LC products land cover map for educational and/or scientific purposes, without any fee on the condition that you credit the ESA Climate Change Initiative and in particular its Land Cover project as the source of the CCI-LC database:

Copyright notice: @ ESA Climate Change Initiative - Land Cover project 2017

Should you write any scientific publication on the results of research activities that use one or several CCI-LC products as input, you shall acknowledge the ESA CCI Land Cover project in the text of the publication and provide the project with an electronic copy of the publication (contact@esalandcover-cci.org).

If you wish to use one or several CCI-LC products in advertising or in any commercial promotion, you shall acknowledge the ESA CCI Land Cover project and you must submit the layout to the project for approval beforehand (contact@esa-landcover-cci.org). 


\begin{tabular}{|c|c|c|c|c|}
\hline \multirow{2}{*}{ CeSa } & Ref & \multicolumn{2}{|c|}{ CCI LC PUG v2 } \\
\cline { 2 - 5 } & Issue & Page & Date & 2017-03-31 \\
\cline { 2 - 5 } & 2.0 & 81 & Iand couer \\
cci
\end{tabular}

\section{APPENDIX 1 - CCI-LC LEGEND}

\subsection{Hierarchical global and regional legends}

\begin{tabular}{|c|c|c|c|c|}
\hline \multicolumn{2}{|c|}{ LABEL } & \multicolumn{2}{|c|}{ VALUE } & \multirow{2}{*}{ COLOR } \\
\hline GLOBAL & REGIONAL & GLOBAL & REGIONAL & \\
\hline No Data & & 0 & & \\
\hline \multirow[t]{3}{*}{ Cropland, rainfed } & & 10 & & \\
\hline & $\begin{array}{l}\text { Cropland, rainfed, herbaceous } \\
\text { cover }\end{array}$ & & 11 & \\
\hline & $\begin{array}{l}\text { Cropland, rainfed, tree or shrub } \\
\text { cover }\end{array}$ & & 12 & \\
\hline $\begin{array}{l}\text { Cropland, irrigated or post- } \\
\text { flooding }\end{array}$ & & 20 & & \\
\hline $\begin{array}{l}\text { Mosaic cropland (>50\%) / } \\
\text { natural vegetation (tree, shrub, } \\
\text { herbaceous cover) }(<50 \%)\end{array}$ & & 30 & & \\
\hline $\begin{array}{l}\text { Mosaic natural vegetation } \\
\text { (tree, shrub, herbaceous cover) } \\
(>50 \%) / \text { cropland }(<50 \%)\end{array}$ & & 40 & & \\
\hline $\begin{array}{l}\text { Tree cover, broadleaved, } \\
\text { evergreen, closed to open } \\
(>15 \%)\end{array}$ & & 50 & & \\
\hline \multirow{3}{*}{$\begin{array}{l}\text { Tree cover, broadleaved, } \\
\text { deciduous, closed to open } \\
(>15 \%)\end{array}$} & & 60 & & \\
\hline & $\begin{array}{l}\text { Tree cover, broadleaved, } \\
\text { deciduous, closed (>40\%) }\end{array}$ & & 61 & \\
\hline & $\begin{array}{l}\text { Tree cover, broadleaved, } \\
\text { deciduous, open (15-40\%) }\end{array}$ & & 62 & \\
\hline \multirow{3}{*}{$\begin{array}{l}\text { Tree cover, needleleaved, } \\
\text { evergreen, closed to open } \\
(>15 \%)\end{array}$} & & 70 & & \\
\hline & $\begin{array}{l}\text { Tree cover, needleleaved, } \\
\text { evergreen, closed (>40\%) }\end{array}$ & & 71 & \\
\hline & $\begin{array}{l}\text { Tree cover, needleleaved, } \\
\text { evergreen, open (15-40\%) }\end{array}$ & & 72 & \\
\hline \multirow{3}{*}{$\begin{array}{l}\text { Tree cover, needleleaved, } \\
\text { deciduous, closed to open } \\
(>15 \%)\end{array}$} & & 80 & & \\
\hline & $\begin{array}{l}\text { Tree cover, needleleaved, } \\
\text { deciduous, closed (>40\%) }\end{array}$ & & 81 & \\
\hline & $\begin{array}{l}\text { Tree cover, needleleaved, } \\
\text { deciduous, open (15-40\%) }\end{array}$ & & 82 & \\
\hline $\begin{array}{l}\text { Tree cover, mixed leaf type } \\
\text { (broadleaved and } \\
\text { needleleaved) }\end{array}$ & & 90 & & \\
\hline $\begin{array}{l}\text { Mosaic tree and shrub (>50\%) / } \\
\text { herbaceous cover }(<50 \%)\end{array}$ & & 100 & & \\
\hline Mosaic herbaceous cover & & 110 & & \\
\hline
\end{tabular}




\begin{tabular}{|c|c|c|c|c|}
\hline \multirow{2}{*}{ CeSa } & Ref & \multicolumn{3}{|c|}{ CCI LC PUG v2 } \\
\cline { 2 - 5 } & Issue & Page & Date & Iand couer \\
\cline { 2 - 5 } & 2.0 & 82 & $2017-03-31$ & cci \\
\hline
\end{tabular}

\begin{tabular}{|c|c|c|c|}
\hline$(>50 \%) /$ tree and shrub $(<50 \%)$ & & & \\
\hline \multirow[t]{3}{*}{ Shrubland } & & 120 & \\
\hline & Evergreen shrubland & & 121 \\
\hline & Deciduous shrubland & & 122 \\
\hline Grassland & & 130 & \\
\hline Lichens and mosses & & 140 & \\
\hline \multirow{4}{*}{$\begin{array}{l}\text { Sparse vegetation (tree, shrub, } \\
\text { herbaceous cover) }(<15 \%)\end{array}$} & & 150 & \\
\hline & Sparse tree $(<15 \%)$ & & 151 \\
\hline & Sparse shrub $(<15 \%)$ & & 152 \\
\hline & $\begin{array}{l}\text { Sparse herbaceous cover } \\
(<15 \%)\end{array}$ & & 153 \\
\hline $\begin{array}{l}\text { Tree cover, flooded, fresh or } \\
\text { brakish water }\end{array}$ & & 160 & \\
\hline $\begin{array}{l}\text { Tree cover, flooded, saline } \\
\text { water }\end{array}$ & & 170 & \\
\hline $\begin{array}{l}\text { Shrub or herbaceous cover, } \\
\text { flooded, fresh/saline/brakish } \\
\text { water }\end{array}$ & & 180 & \\
\hline Urban areas & & 190 & \\
\hline \multirow[t]{3}{*}{ Bare areas } & & 200 & \\
\hline & Consolidated bare areas & 201 & \\
\hline & Unconsolidated bare areas & 202 & \\
\hline Water bodies & & 210 & \\
\hline Permanent snow and ice & & 220 & \\
\hline
\end{tabular}

\subsection{LCCS coding of the CCI-LC legend}

\begin{tabular}{|c|c|c|c|c|}
\hline VALUE & $\begin{array}{l}\text { LCCS } \\
\text { ENTRY }\end{array}$ & LCCS LABEL & LCCCODE & LCCLEVEL \\
\hline 10 & \multirow{6}{*}{ 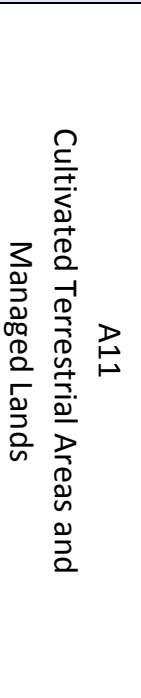 } & $\begin{array}{l}\text { Rainfed shrub crops // Rainfed tree crops } \\
\text { // Rainfed herbaceous crops }\end{array}$ & $\begin{array}{l}11494 / / 11490 \\
/ / 11498\end{array}$ & $\begin{array}{l}\text { A2XXXXXXD1 // } \\
\text { A1XXXXXXD1// } \\
\text { A3XXXXXXD1 }\end{array}$ \\
\hline 11 & & Rainfed herbaceous crops & 11498 & A3XXXXXXD1 \\
\hline 12 & & Rainfed shrub crops // Rainfed tree crops & $11490 / / 11494$ & $\begin{array}{l}\text { A1XXXXXXD1 // } \\
\text { A2XXXXXXD1 }\end{array}$ \\
\hline 20 & & $\begin{array}{l}\text { Irrigated tree crops // Irrigated shrub } \\
\text { crops // Irrigated herbaceous crops // } \\
\text { Post- flooding cultivation of herbaceous } \\
\text { crops }\end{array}$ & $\begin{array}{l}11491 / / 11495 \\
/ / 11500 / / \\
11499\end{array}$ & $\begin{array}{l}\text { A1XXXXXXD3 // } \\
\text { A2XXXXXXD3 // } \\
\text { A3XXXXXXD3 // } \\
\text { A3XXXXXXD2 }\end{array}$ \\
\hline 30 & & $\begin{array}{l}\text { Cultivated and managed terrestrial areas } \\
\text { / Natural and semi-natural primarily } \\
\text { terrestrial vegetation }\end{array}$ & $0003 / 0004$ & A11 / A12 \\
\hline 40 & & $\begin{array}{l}\text { Natural and semi-natural primarily } \\
\text { terrestrial vegetation / Cultivated and } \\
\text { managed terrestrial areas }\end{array}$ & $0004 / 0003$ & A12 / A11 \\
\hline
\end{tabular}




\begin{tabular}{|c|c|c|c|l|}
\hline \multirow{2}{*}{ CeSa } & Ref & \multicolumn{3}{|c|}{ CCI LC PUG v2 } \\
\cline { 2 - 5 } & Issue & Page & Date & Iand couer \\
\cline { 2 - 5 } & 2.0 & 83 & $2017-03-31$ & cci \\
\hline
\end{tabular}

\begin{tabular}{|c|c|c|c|c|}
\hline 50 & \multirow{11}{*}{ 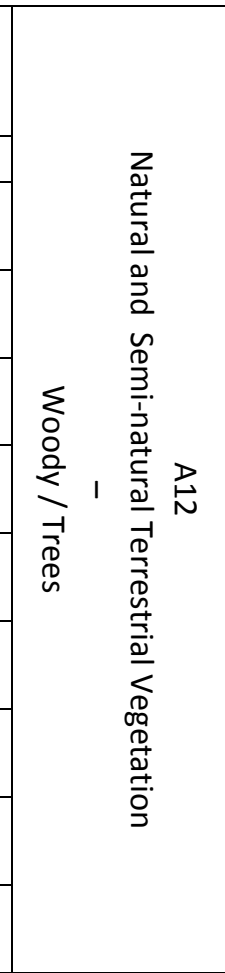 } & $\begin{array}{l}\text { Broadleaved evergreen closed to open trees } \\
\text { // Broadleaved semi-deciduous closed to } \\
\text { open trees }\end{array}$ & \begin{tabular}{l|l}
$21496 / /$ \\
$21497-15048$
\end{tabular} & $\begin{array}{l}\text { A3A20B2XXD1E1 // } \\
\text { A3A20B2XXD1E2-E4 }\end{array}$ \\
\hline 60 & & Broadleaved deciduous closed to open trees & 21497 & A3A20B2XXD1E2 \\
\hline 61 & & $\begin{array}{l}\text { Broadleaved deciduous closed (100-40\%) } \\
\text { trees }\end{array}$ & $\begin{array}{l}21497- \\
121340\end{array}$ & A3A20B2XXD1E2-A21 \\
\hline 62 & & $\begin{array}{l}\text { Broadleaved deciduous open (40-(20-10)\%) } \\
\text { trees }\end{array}$ & $20132-3012$ & A3A11B2XXD1E2-A13 \\
\hline 70 & & $\begin{array}{l}\text { Needleleaved evergreen closed to open } \\
\text { trees }\end{array}$ & 21499 & A3A20B2XXD2E1 \\
\hline 71 & & $\begin{array}{l}\text { Needleleaved evergreen closed (100-40\%) } \\
\text { trees }\end{array}$ & $\begin{array}{l}21499- \\
121340\end{array}$ & A3A20B2XXD2E1-A21 \\
\hline 72 & & $\begin{array}{l}\text { Needleleaved evergreen open }(40-(20-10) \%) \\
\text { trees }\end{array}$ & 20134-3012 & A3A11B2XXD2E1-A13 \\
\hline 80 & & $\begin{array}{l}\text { Needleleaved deciduous closed to open } \\
\text { trees }\end{array}$ & 21500 & A3A20B2XXD2E2 \\
\hline 81 & & $\begin{array}{l}\text { Needleleaved deciduous closed (100-40\%) } \\
\text { trees }\end{array}$ & $\begin{array}{l}21500- \\
121340\end{array}$ & A3A20B2XXD2E2-A21 \\
\hline 82 & & $\begin{array}{l}\text { Needleleaved deciduous open (40-(20- } \\
\text { 10)\%) trees }\end{array}$ & $20135-3012$ & A3A11B2XXD2E2-A13 \\
\hline 90 & & $\begin{array}{l}\text { Broadleaved closed to open trees / } \\
\text { Needleleaved closed to open trees }\end{array}$ & $\begin{array}{ll}21495 / \\
21498\end{array}$ & $\begin{array}{l}\text { A3A20B2XXD1/ } \\
\text { A3A20B2XXD2 }\end{array}$ \\
\hline 100 & \multirow{2}{*}{ 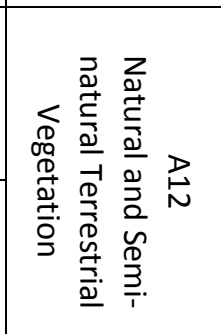 } & $\begin{array}{l}\text { Closed to open trees / Closed to open } \\
\text { shrubland (thicket) // Herbaceous closed to } \\
\text { open vegetation }\end{array}$ & $\begin{array}{l}21445 / / \\
21449 / \\
21453\end{array}$ & A3A20 // A4A20 / A2A20 \\
\hline 110 & & $\begin{array}{l}\text { Herbaceous closed to open vegetation // } \\
\text { Closed to open trees / Closed to open } \\
\text { shrubland (thicket) }\end{array}$ & $\begin{array}{l}21453 / \\
21445 / / \\
21449\end{array}$ & A2A20 / A3A20 // A4A20 \\
\hline 120 & \multirow{3}{*}{ 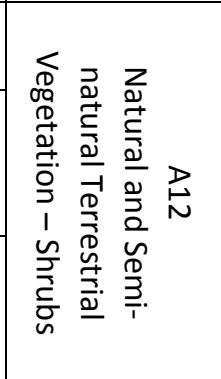 } & $\begin{array}{l}\text { Broadleaved closed to open shrubland } \\
\text { (thicket) }\end{array}$ & 21449 & A4A20 \\
\hline 121 & & $\begin{array}{l}\text { Broadleaved Evergreen Closed to Open } \\
\text { Thicket // Needleleaved Evergreen Closed to } \\
\text { Open Thicket }\end{array}$ & $\begin{array}{l}21517 / / \\
21520\end{array}$ & $\begin{array}{l}\text { A4A20B3XXD1E1 // } \\
\text { A4A20B3XXD2E1 }\end{array}$ \\
\hline 122 & & $\begin{array}{l}\text { Broadleaved Deciduous Closed to Open } \\
\text { Thicket // Needleleaved Deciduous Closed to } \\
\text { Open Thicket }\end{array}$ & $\begin{array}{l}21518 / / \\
21521\end{array}$ & $\begin{array}{l}\text { A4A20B3XXD1E2 // } \\
\text { A4A20B3XXD2E2 }\end{array}$ \\
\hline 130 & \multirow{2}{*}{ 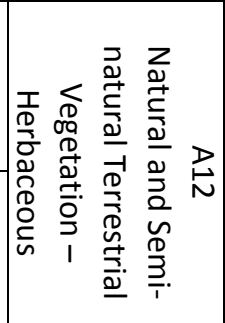 } & Herbaceous closed to very open vegetation & 21453 & A2A20 \\
\hline 140 & & Closed to open lichens/mosses & 21465 & A7A20 \\
\hline
\end{tabular}




\begin{tabular}{|c|c|c|c|c|}
\hline \multirow{2}{*}{ Cesa } & Ref & \multicolumn{3}{|c|}{ CCI LC PUG v2 } \\
\cline { 2 - 5 } & Issue & Page & Date & Iand couer \\
\cline { 2 - 5 } & 2.0 & 84 & $2017-03-31$ & Ici \\
\hline
\end{tabular}

\begin{tabular}{|c|c|c|c|c|}
\hline 150 & \multirow{4}{*}{ 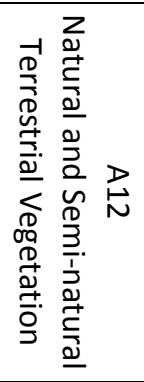 } & $\begin{array}{l}\text { Sparse trees // Herbaceous sparse vegetation // } \\
\text { Sparse shrubs }\end{array}$ & $\begin{array}{l}20052 / / \\
20055 / / \\
20058\end{array}$ & $\begin{array}{l}\text { A3A14 // A4A14 // } \\
\text { A2A14 }\end{array}$ \\
\hline 151 & & Sparse Trees & 20052 & A3A14 \\
\hline 152 & & Sparse Shrubs & 20055 & A4A14 \\
\hline 153 & & Herbaceous Sparse Vegetation & 20058 & A2A14 \\
\hline 160 & \multirow{3}{*}{ 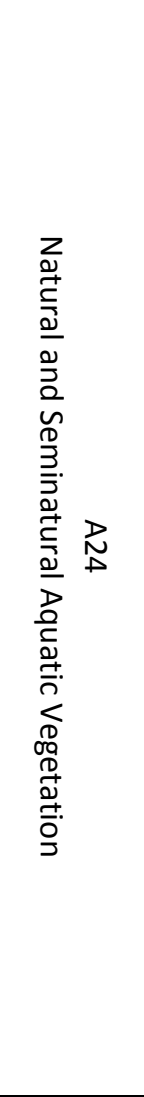 } & $\begin{array}{l}\text { Closed to open (100-40\%) broadleaved trees on } \\
\text { temporarily flooded land, water quality: fresh water } \\
\text { // Closed to open (100- } 40 \%) \text { broadleaved trees on } \\
\text { permanently flooded land, water quality: fresh water }\end{array}$ & $\begin{array}{l}\text { 41638-R1 } \\
\text { // 41724- } \\
\mathrm{R} 1\end{array}$ & $\begin{array}{l}\text { A3A20B2C1D1-R1 // } \\
\text { A3A20B2C2D1-R1 }\end{array}$ \\
\hline 170 & & $\begin{array}{l}\text { Closed to open (100-40\%) broadleaved trees on } \\
\text { permanently flooded land (with daily variations), } \\
\text { water quality: saline water // Closed to open (100- } \\
40 \% \text { ) broadleaved trees on permanently flooded } \\
\text { land (with daily variations), water quality: brackish } \\
\text { water // Closed to open (100-40\%) semi-deciduous } \\
\text { shrubland on permanently flooded land (with daily } \\
\text { variations), water quality: saline water // Closed to } \\
\text { open (100-40\%) semi-deciduous shrubland on } \\
\text { permanently flooded land (with daily variations), } \\
\text { water quality: brackish water }\end{array}$ & $\begin{array}{l}41638- \\
4891-\mathrm{R} 2 / / \\
41638- \\
4891-\mathrm{R} 3\end{array}$ & $\begin{array}{l}\text { A3A20B2C1D1-C5-R2 } \\
\text { // A3A20B2C1D1-C5- } \\
\text { R3 }\end{array}$ \\
\hline 180 & & $\begin{array}{l}\text { Closed to open shrubs on } \\
\text { permanently flooded land // Closed to open } \\
\text { herbaceous vegetation on } \\
\text { permanently flooded land // Closed to open shrubs } \\
\text { on temporarily flooded land // Closed to open } \\
\text { herbaceous vegetation on temporarily } \\
\text { flooded land // Closed to open shrubs on } \\
\text { waterlogged soil // Closed to open herbaceous } \\
\text { vegetation on waterlogged soil } \\
\text { Water quality: fresh, brackish or saline water }\end{array}$ & $\begin{array}{l}41897 / / \\
41983 / / \\
42069 / / \\
42347 / / \\
42348 / / \\
42349\end{array}$ & $\begin{array}{l}\text { A4A20B3C1 // } \\
\text { A4A20B3C2 // } \\
\text { A4A20B3C3 // } \\
\text { A2A20B4C1 // } \\
\text { A2A20B4C2 // } \\
\text { A2A20B4C3 }\end{array}$ \\
\hline 190 & 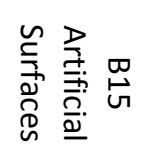 & Artificial surfaces and associated areas & 0010 & B15 \\
\hline 200 & \multirow{3}{*}{ 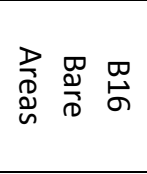 } & Bare areas & 0011 & B16 \\
\hline 201 & & Consolidated Material(s) & 6001 & A1 \\
\hline 202 & & Unconsolidated Material(s) & 6004 & A2 \\
\hline 210 & \multirow{2}{*}{ 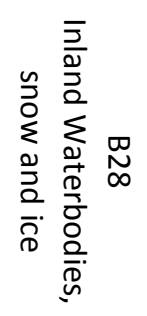 } & Natural water bodies // Artificial water bodies & $\begin{array}{l}7002 / / \\
8002\end{array}$ & A1B1 // A1B1 \\
\hline 220 & & $\begin{array}{l}\text { Artificial perennial snow // Artificial perennial ice // } \\
\text { Perennial snow // Perennial ice }\end{array}$ & $\begin{array}{l}7005 / / \\
7008 / / \\
8006 / / \\
8009\end{array}$ & $\begin{array}{l}\text { A2B1 // A3B1 // A2B1 } \\
\text { // A3B1 }\end{array}$ \\
\hline
\end{tabular}




\begin{tabular}{|c|c|c|c|c|}
\hline \multirow{2}{*}{ Cesa } & Ref & \multicolumn{2}{|c|}{ CCI LC PUG v2 } \\
\cline { 2 - 4 } & Issue & Page & Date & Iand couer \\
\cline { 2 - 5 } & 2.0 & 85 & $2017-03-31$ & cci \\
\hline
\end{tabular}

\section{APPENDIX 2 - NETCDF ATTRIBUTES}

\section{- Surface reflectance product}

The CCI-LC global 7-day SR products description is based on the structure of the NetCDF files. The global attributes of the composites are described in Table 10-1.

Table 10-1: Global attributes of the global 7-day SR products delivered by the CCI-LC project, according to the structure of the NetCDF files.

\begin{tabular}{|c|c|c|c|}
\hline Attribute Name & Format & Value & Description \\
\hline title & & $\begin{array}{l}\text { ESACCI-LC-L3-SR-MERIS-300m-P7D- } \\
\text { h40v13-20080326-v1.0 }\end{array}$ & $\begin{array}{l}\text { Product identifier } \\
\text { (see "naming } \\
\text { convention" see } \\
6.2 \text { ) }\end{array}$ \\
\hline summary & & $\begin{array}{l}\text { This dataset contains a tile of a Level-3 } \\
\text { 7-day global surface reflectance } \\
\text { composite from satellite observations } \\
\text { placed onto a regular grid. }\end{array}$ & \\
\hline project & & $\begin{array}{l}\text { Climate Change Initiative - European } \\
\text { Space Agency }\end{array}$ & \\
\hline references & & http://www.esa-landcover-cci.org/ & $\begin{array}{l}\text { References that } \\
\text { describe the data } \\
\text { or methods used to } \\
\text { produce it. }\end{array}$ \\
\hline institution & & Brockmann Consult GmbH & $\begin{array}{l}\text { Where the data has } \\
\text { been produced }\end{array}$ \\
\hline contact & & info@brockmann-consult.de & \\
\hline source & & e.g. MERIS FR L1b & $\begin{array}{l}\text { Method of } \\
\text { production of the } \\
\text { original data }\end{array}$ \\
\hline history & & $\begin{array}{l}\text { e.g. MERIS FR/RR: } \\
\text { amorgos- } 4.0 \\
\text { Ic-sdr- } 2.0 \\
\text { Ic-sr- } 2.0\end{array}$ & $\begin{array}{l}\text { List of applications } \\
\text { that have modified } \\
\text { the original data, } \\
\text { with time stamp, } \\
\text { processor and } \\
\text { parameters }\end{array}$ \\
\hline comment & & & $\begin{array}{l}\text { Miscellaneous } \\
\text { information about } \\
\text { the data or method } \\
\text { used to produce it }\end{array}$ \\
\hline Conventions & & CF-1.6 & $\begin{array}{l}\text { Name of the } \\
\text { conventions } \\
\text { followed }\end{array}$ \\
\hline $\begin{array}{l}\text { standard_name_ } \\
\text { vocabulary }\end{array}$ & & $\begin{array}{l}\text { NetCDF Climate and Forecast (CF) } \\
\text { Standard Names version } 18\end{array}$ & \\
\hline
\end{tabular}




\begin{tabular}{|c|c|c|c|l|}
\hline \multirow{2}{*}{ CeSa } & Ref & \multicolumn{3}{|c|}{ CCI LC PUG v2 } \\
\cline { 2 - 5 } & Issue & Page & Date & Iand couer \\
\cline { 2 - 5 } & 2.0 & 86 & $2017-03-31$ & cci \\
\hline
\end{tabular}

\begin{tabular}{|c|c|c|c|}
\hline Attribute Name & Format & Value & Description \\
\hline keywords & & satellite,observation, reflectance & \\
\hline $\begin{array}{l}\text { keywords } \\
\text { vocabulary }\end{array}$ & & $\begin{array}{l}\text { NASA Global Change Master Directory } \\
\text { (GCMD) Science Keywords }\end{array}$ & \\
\hline license & & $\begin{array}{l}\text { ESA CCI Data Policy: free and open } \\
\text { access }\end{array}$ & \\
\hline naming_authority & & org.esa-cci & \\
\hline cdm_data_type & & grid & \\
\hline platform & & e.g "ENVISAT" & \\
\hline sensor & & e.g "MERIS" & \\
\hline type & & $s r-300 m-7 d$ & Product type \\
\hline id & & $\begin{array}{l}\text { e.g "ESACCI-LC-L3-SR-MERIS-300m- } \\
\text { P7D-h40v13-20080326-v1.0" }\end{array}$ & \\
\hline tracking_id & & $\begin{array}{l}\text { e.g "2521cb70-348f-4676-9d7c- } \\
\text { c0311a8118ac" }\end{array}$ & \\
\hline tile & hXXvYY & e.g. "h71v27" & $\begin{array}{l}\text { Example for the tile } \\
\text { in row } 27 \text { and } \\
\text { column } 71 \text { of the } \\
\text { Plate Carrée grid } \\
\text { (see Figure 6-1) }\end{array}$ \\
\hline product_version & major.minor & e.g " 1.0" & $\begin{array}{l}\text { Product revision } \\
\text { (see here above) }\end{array}$ \\
\hline date_created & $\begin{array}{l}\text { yyyy-MM- } \\
\text { dd'T'HH:mm:ss'Z' }\end{array}$ & e.g " 20130424T124732Z" & $\begin{array}{l}\text { Creation time of } \\
\text { product }\end{array}$ \\
\hline creator_name & & Brockmann Consult & \\
\hline creator_url & & http://www.brockmann-consult.de/ & \\
\hline creator_email & & info@brockmann-consult.de & \\
\hline time_coverage_start & $\begin{array}{l}\text { yyyy-MM- } \\
\text { dd'T'HH:mm:ss'Z' }\end{array}$ & e.g" 20080326T000000Z" & $\begin{array}{l}\text { Start of } \\
\text { aggregation period } \\
\text { e.g. 2009-01- } \\
\text { 01T00:00:00Z }\end{array}$ \\
\hline time_coverage_end & $\begin{array}{l}\text { yyyy-MM- } \\
\text { dd'T'HH:mm:ss'Z' }\end{array}$ & e.g" 20080402T000000Z" & $\begin{array}{l}\text { End of aggregation } \\
\text { period } \\
\text { e.g. 2009-01- } \\
\text { 11T00:00:00Z }\end{array}$ \\
\hline time_coverage_duration & $0 \ldots 1382400$ & P7D & aggregation period \\
\hline time_coverage_resolution & & P7D & \\
\hline geospatial_lat_min & $-90.0 \ldots 90.0$ & & $\begin{array}{l}\text { South border of the } \\
\text { bounding box }\end{array}$ \\
\hline geospatial_lat_max & $-90.0 \ldots 90.0$ & & $\begin{array}{l}\text { North border of the } \\
\text { bounding box }\end{array}$ \\
\hline geospatial_lon_min & $-180.0 \ldots 180.0$ & & $\begin{array}{l}\text { West border of the } \\
\text { bounding box }\end{array}$ \\
\hline geospatial_lon_max & $-180.0 \ldots 180.0$ & & $\begin{array}{l}\text { East border of the } \\
\text { bounding box }\end{array}$ \\
\hline spatial_resolution & & 300 & $\begin{array}{l}\text { Resolution of the } \\
\text { product in meters }\end{array}$ \\
\hline geospatial_lat_units & & degrees_north & \\
\hline geospatial_lat_ & & e.g " 0.002778 " & \\
\hline
\end{tabular}




\begin{tabular}{|c|c|c|c|c|}
\hline \multirow{2}{*}{ CeSa } & Ref & \multicolumn{3}{|c|}{ CCI LC PUG v2 } \\
\cline { 2 - 5 } & Issue & Page & Date & Iand couer \\
\cline { 2 - 5 } & 2.0 & 87 & $2017-03-31$ & cci \\
\hline
\end{tabular}

\begin{tabular}{|l|l|l|l|}
\hline \multicolumn{1}{|c|}{ Attribute Name } & \multicolumn{1}{c|}{ Format } & \multicolumn{1}{c|}{ Value } & \multicolumn{1}{c|}{ Description } \\
\hline resolution & & & \\
\hline geospatial_lon_units & & degrees_east & \\
\hline $\begin{array}{l}\text { geospatial_lon_ } \\
\text { resolution }\end{array}$ & & e.g "0.002778 " & \\
\hline TileSize & & $600: 600$ & \\
\hline
\end{tabular}

The global 7-day SR NetCDF file for a tile has two dimensions that define the spatial raster, as described in Table 10-2.

Table 10-2: Information related to the spatial dimension of the global SR products delivered by the CCI-LC project

\begin{tabular}{|l|l|l|}
\hline \multicolumn{1}{|c|}{ Dimension } & \multicolumn{1}{|c|}{ Value } & \multicolumn{1}{c|}{ Description } \\
\hline lat & 1800 & Dimension that distinguishes different lines \\
\hline lon & 1800 & Dimension that distinguishes different columns \\
\hline
\end{tabular}

The variables and variables' attributes of the global 7-day SR NetCDF file are presented in Table $10-3$.

Table 10-3: Variables and variables' attributes of the global 7-day SR products delivered by the CCI-LC project, according to the structure of the NetCDF files.

\begin{tabular}{|c|c|c|c|c|}
\hline Variable & Attribute & Format & Value & Description \\
\hline \multirow[t]{3}{*}{ crs } & & int & 0 & $\begin{array}{l}\text { Coordinate } \\
\text { reference system } \\
\text { attribute container }\end{array}$ \\
\hline & wkt & & $\begin{array}{l}\text { GEOGCS["WGS84(DD)" } \\
\text { DATUM["WGS84", } \\
\text { SPHEROID["WGS84", 6378137.0, } \\
\text { 298.257223563]], } \\
\text { PRIMEM["Greenwich", 0.0], } \\
\text { UNIT["degree", } \\
\text { 0.017453292519943295], } \\
\text { AXIS["Geodetic longitude", EAST], } \\
\text { AXIS["Geodetic latitude", NORTH]] }\end{array}$ & \\
\hline & $\mathrm{i} 2 \mathrm{~m}$ & & $\begin{array}{l}0.002777777777777778,0.0,0.0,- \\
0.002777777777777778,20.0,25.0\end{array}$ & \\
\hline \multirow[t]{5}{*}{ Ion } & & $\begin{array}{l}\text { float } \\
\text { (lon) }\end{array}$ & $-180.0 . .180 .0$ & $\begin{array}{l}\text { Longitude } \\
\text { coordinate of pixel } \\
\text { column }\end{array}$ \\
\hline & standard_name & & longitude & \\
\hline & long_name & & longitude coordinate & \\
\hline & units & & degrees east & \\
\hline & valid_min & & -180.0 & \\
\hline
\end{tabular}




\begin{tabular}{|c|c|c|c|c|}
\hline \multirow{2}{*}{ CeSa } & Ref & \multicolumn{3}{|c|}{ CCI LC PUG v2 } \\
\cline { 2 - 5 } & Issue & Page & Date & Iand couer \\
\cline { 2 - 5 } & 2.0 & 88 & $2017-03-31$ & cci \\
\hline
\end{tabular}

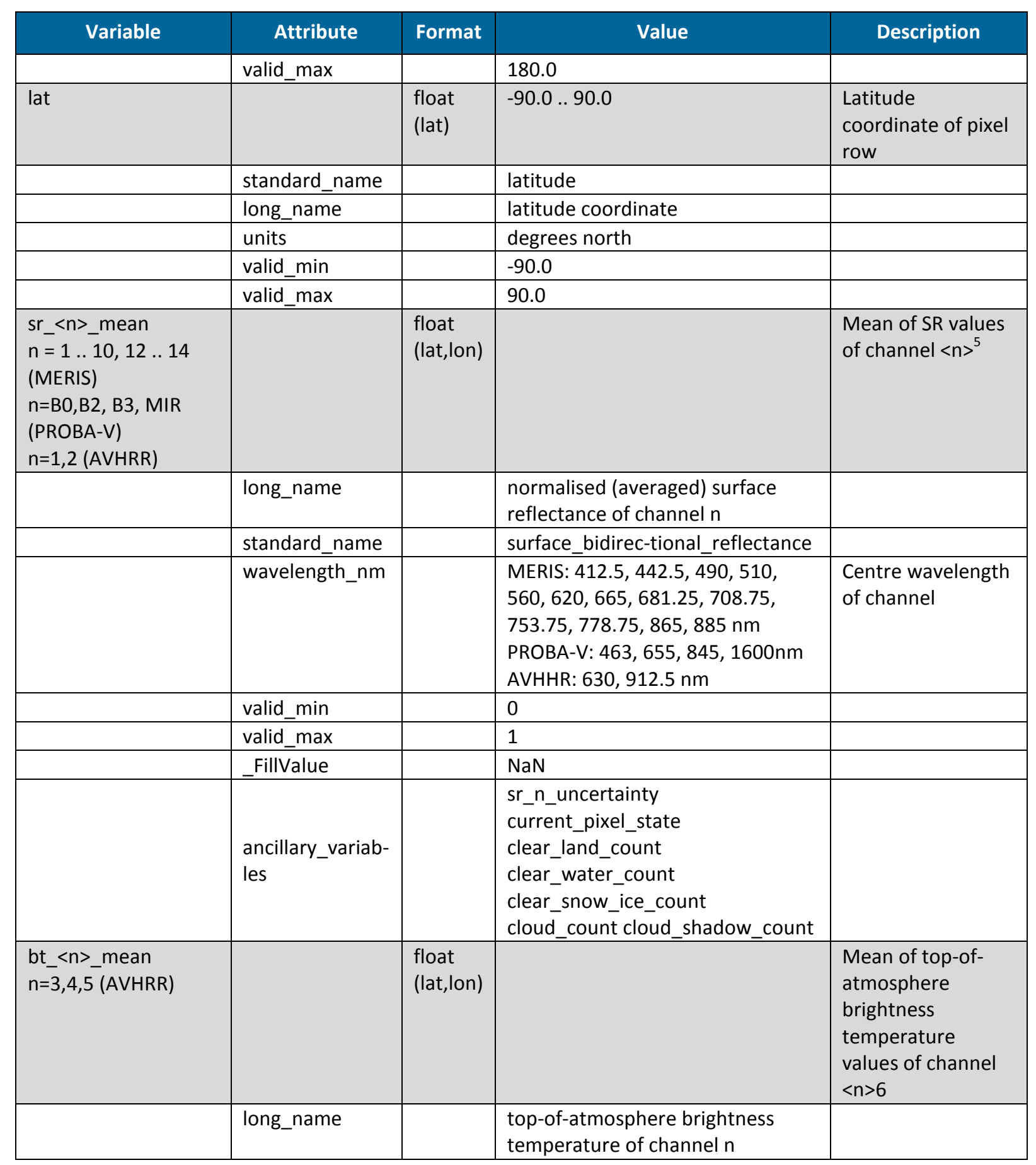

${ }^{5}$ valid for current pixel_state 1 or 3

${ }^{6}$ valid for current pixel_state 1 or 3 


\begin{tabular}{|c|c|c|c|c|}
\hline \multirow{2}{*}{ CeSa } & Ref & \multicolumn{3}{|c|}{ CCI LC PUG v2 } \\
\cline { 2 - 5 } & Issue & Page & Date & 2017-03-31 \\
\cline { 2 - 5 } & 2.0 & 89 & Iand couer \\
\hline
\end{tabular}

\begin{tabular}{|c|c|c|c|c|}
\hline Variable & Attribute & Format & Value & Description \\
\hline & standard_name & & toa_brightness_temperature & \\
\hline & wavelength_nm & & AVHHR: $3740,11000,11000 \mathrm{~nm}$ & $\begin{array}{l}\text { Centre wavelength } \\
\text { of channel }\end{array}$ \\
\hline & valid_min & & 0 & \\
\hline & valid_max & & 400 & \\
\hline & FillValue & & $\mathrm{NaN}$ & \\
\hline & $\begin{array}{l}\text { ancillary_variab- } \\
\text { les }\end{array}$ & & $\begin{array}{l}\text { current_pixel_state } \\
\text { clear_land_count } \\
\text { clear_water_count } \\
\text { clear_snow_ice_count } \\
\text { cloud_count cloud_shadow_count }\end{array}$ & \\
\hline \multirow[t]{7}{*}{$\begin{array}{l}\text { sr_<n>_uncertainity } \\
n=1 . .10,12 . .14 \\
\text { (MERIS) } \\
n=B 0, B 2, B 3, \text { MIR } \\
\text { (PROBA-V) } \\
n=1,2 \text { (AVHRR) }\end{array}$} & & $\begin{array}{l}\text { float } \\
\text { (lat,lon) }\end{array}$ & & $\begin{array}{l}\text { uncertainity of } \\
\text { normalized surface } \\
\text { reflectance values } \\
\text { of channel }\langle\mathrm{n}\rangle^{7}\end{array}$ \\
\hline & long_name & & $\begin{array}{l}\text { uncertainity of normalized surface } \\
\text { reflectance values of channel } n\end{array}$ & \\
\hline & standard_name & & $\begin{array}{l}\text { surface_bidirec-tional_reflectance } \\
\text { standard_error }\end{array}$ & \\
\hline & wavelength_nm & & see above & $\begin{array}{l}\text { Centre wavelength } \\
\text { of channel }\end{array}$ \\
\hline & valid_min & & 0.0 & \\
\hline & valid_max & & 0.5 & \\
\hline & _FillValue & & $\mathrm{NaN}$ & \\
\hline \multirow[t]{7}{*}{$\begin{array}{l}\text { vegetation } \\
\text { index_mean }\end{array}$} & & $\begin{array}{l}\text { float } \\
\text { (lat,lon) }\end{array}$ & & $\begin{array}{l}\text { Mean of } \\
\text { vegetation index, } \\
\text { e.g. NDVI }\end{array}$ \\
\hline & long_name & & mean of vegetation index & \\
\hline & standard_name & & $\begin{array}{l}\text { normalized_difference_ } \\
\text { vegetation_index }\end{array}$ & \\
\hline & valid_min & & -1 & \\
\hline & valid_max & & +1 & \\
\hline & FillValue & & $\mathrm{NaN}$ & \\
\hline & $\begin{array}{l}\text { ancillary_variab- } \\
\text { les }\end{array}$ & & $\begin{array}{l}\text { current_pixel_state } \\
\text { clear_land_count } \\
\text { clear_water_count } \\
\text { clear_snow_ice_count } \\
\text { cloud_count cloud_shadow_count }\end{array}$ & \\
\hline
\end{tabular}

${ }^{7}$ The uncertainity values of the SR values are to less due to a calculation failure regarding the error propagation of the uncertainty of the SDR values. 


\begin{tabular}{|c|c|c|c|c|}
\hline \multirow{2}{*}{ Cesa } & Ref & \multicolumn{3}{|c|}{ CCI LC PUG v2 } \\
\cline { 2 - 5 } & Issue & Page & Date & Iand couer \\
\cline { 2 - 5 } & 2.0 & 90 & $2017-03-31$ & Ici \\
\hline
\end{tabular}

\begin{tabular}{|c|c|c|c|c|}
\hline Variable & Attribute & Format & Value & Description \\
\hline \multirow[t]{6}{*}{$\begin{array}{l}\text { clear_land_ } \\
\text { count }\end{array}$} & & $\begin{array}{l}\text { short } \\
\text { (lat,lon) }\end{array}$ & & $\begin{array}{l}\text { Number of } \\
\text { contributing } \\
\text { observations over } \\
\text { clear sky land in } \\
\text { aggregation period }\end{array}$ \\
\hline & long_name & & $\begin{array}{l}\text { Number of contributing of } \\
\text { observations over clear sky land }\end{array}$ & \\
\hline & standard_name & & $\begin{array}{l}\text { surface_bidirectional_ } \\
\text { reflectance } \\
\text { number_of_observations }\end{array}$ & \\
\hline & valid_min & & 0 & \\
\hline & valid_max & & 150 & \\
\hline & FillValue & & -1 & \\
\hline \multirow[t]{6}{*}{$\begin{array}{l}\text { clear_water_ } \\
\text { count }\end{array}$} & & $\begin{array}{l}\text { short } \\
\text { (lat,lon) }\end{array}$ & & $\begin{array}{l}\text { Number of } \\
\text { observations with } \\
\text { water coverage in } \\
\text { aggregation period }\end{array}$ \\
\hline & long_name & & $\begin{array}{l}\text { number of clear_water } \\
\text { observations }\end{array}$ & \\
\hline & standard_name & & $\begin{array}{l}\text { surface_bidirectional_ } \\
\text { reflectance } \\
\text { number_of_observations }\end{array}$ & \\
\hline & valid_min & & 0 & \\
\hline & valid_max & & 150 & \\
\hline & _FillValue & & -1 & \\
\hline \multirow[t]{6}{*}{$\begin{array}{l}\text { clear_snow_ } \\
\text { ice_count }\end{array}$} & & $\begin{array}{l}\text { short } \\
\text { (lat,lon) }\end{array}$ & & $\begin{array}{l}\text { Number of } \\
\text { contributing } \\
\text { observations with } \\
\text { snow and ice } \\
\text { coverage in } \\
\text { aggregation period }\end{array}$ \\
\hline & long_name & & $\begin{array}{l}\text { number of clear_snow_ice } \\
\text { observations }\end{array}$ & \\
\hline & standard_name & & $\begin{array}{l}\text { surface_bidirectional_ } \\
\text { reflectance } \\
\text { number_of_observations }\end{array}$ & \\
\hline & valid_min & & 0 & \\
\hline & valid_max & & 150 & \\
\hline & _FillValue & & -1 & \\
\hline \multirow[t]{4}{*}{ cloud_count } & & $\begin{array}{l}\text { short } \\
\text { (lat,lon) }\end{array}$ & & $\begin{array}{l}\text { Number of } \\
\text { observations with } \\
\text { cloud coverage in } \\
\text { aggregation period }\end{array}$ \\
\hline & long_name & & number of cloud observations & \\
\hline & standard_name & & $\begin{array}{l}\text { surface_bidirectional_ } \\
\text { reflectance } \\
\text { number_of_observations }\end{array}$ & \\
\hline & valid_min & & 0 & \\
\hline
\end{tabular}




\begin{tabular}{|c|c|c|c|c|}
\hline \multirow{2}{*}{ Cesa } & Ref & \multicolumn{3}{|c|}{ CCI LC PUG v2 } \\
\cline { 2 - 5 } & Issue & Page & Date & 2017-03-31 \\
\cline { 2 - 5 } & 2.0 & 91 & Iand couer \\
\hline
\end{tabular}

\begin{tabular}{|c|c|c|c|c|}
\hline Variable & Attribute & Format & Value & Description \\
\hline & valid_max & & 150 & \\
\hline & FillValue & & -1 & \\
\hline \multirow[t]{6}{*}{ cloud_shadow_count } & & $\begin{array}{l}\text { short } \\
\text { (lat,lon) }\end{array}$ & & $\begin{array}{l}\text { Number of } \\
\text { observations with } \\
\text { cloud shadow } \\
\text { coverage in } \\
\text { aggregation period }\end{array}$ \\
\hline & long_name & & $\begin{array}{l}\text { number of cloud_shadow } \\
\text { observations }\end{array}$ & \\
\hline & standard_name & & $\begin{array}{l}\text { surface_bidirectional_ } \\
\text { reflectance } \\
\text { number_of_observations }\end{array}$ & \\
\hline & valid_min & & 0 & \\
\hline & valid_max & & 150 & \\
\hline & FillValue & & -1 & \\
\hline \multirow[t]{8}{*}{ current_pixel_state } & & $\begin{array}{l}\text { byte } \\
\text { (lat,lon) }\end{array}$ & & $\begin{array}{l}\text { Status of surface } \\
\text { associated with the } \\
\text { surface reflectance } \\
\text { in the aggregation } \\
\text { period: } \\
\text { "invalid" = } 0 \\
\text { "clear_land " = } 1 \\
\text { "clear_water" = } 2 \\
\text { "clear_snow_ice" = } \\
3 \\
\text { "cloud" = } 4 \\
\text { "cloud_shadow"=5 }\end{array}$ \\
\hline & long_name & & LC pixel type mask & \\
\hline & standard_name & & $\begin{array}{l}\text { surface_bidirectional_ } \\
\text { reflectance status_flag }\end{array}$ & \\
\hline & flag_values & & $0 \ldots 5$ & \\
\hline & flag_meanings & & $\begin{array}{l}\text { invalid clear_land clear_water } \\
\text { clear_snow_ice cloud } \\
\text { cloud_shadow }\end{array}$ & \\
\hline & valid_min & & 0 & \\
\hline & valid_max & & 5 & \\
\hline & _FillValue & & -1 & \\
\hline
\end{tabular}

- Land cover products

The CCI-LC global land cover products description is based on the structure of the NetCDF files. The global attributes of the land cover maps are described in Table 10-4.

Table 10-4 : Global attributes of the global LC maps delivered by the CCI-LC project, according to the structure of the NetCDF files

\begin{tabular}{|l|l|l|l|}
\hline \multicolumn{1}{|c|}{ Attribute Name } & \multicolumn{1}{|c|}{ Format } & \multicolumn{1}{|c|}{ Value } & \multicolumn{1}{c|}{ Description } \\
\hline title & & $\begin{array}{l}\text { ESACCI-LC-L4-LCCS-Map-300m-P1Y-2010- } \\
\text { v1.0.nc/tif }\end{array}$ & $\begin{array}{l}\text { Product identifier (see } \\
\text { "naming convention" }\end{array}$ \\
\hline
\end{tabular}

(C) UCL-Geomatics 2017

This document is the property of the LAND COVER CCI partnership, no part of it shall be reproduced or transmitted without the express prior written authorization of UCL-Geomatics (Belgium). 


\begin{tabular}{|c|c|c|c|c|}
\hline \multirow{2}{*}{ CeSa } & Ref & \multicolumn{3}{|c|}{ CCI LC PUG v2 } \\
\cline { 2 - 5 } & Issue & Page & Date & Iand couer \\
\cline { 2 - 5 } & 2.0 & 92 & $2017-03-31$ & cci \\
\hline
\end{tabular}

\begin{tabular}{|c|c|c|c|}
\hline Attribute Name & Format & Value & Description \\
\hline & & & above) \\
\hline summary & & $\begin{array}{l}\text { This dataset contains a global land cover } \\
\text { map obtained from surface reflectance } \\
\text { composites, placed onto a regular grid. }\end{array}$ & \\
\hline project & & $\begin{array}{l}\text { Climate Change Initiative - European } \\
\text { Space Agency }\end{array}$ & \\
\hline references & & http://www.esa-landcover-cci.org/ & $\begin{array}{l}\text { References that } \\
\text { describe the data or } \\
\text { methods used to } \\
\text { produce it. }\end{array}$ \\
\hline institution & & UCL & $\begin{array}{l}\text { Where the data has } \\
\text { been produced }\end{array}$ \\
\hline contact & & Pierre.Defourny@uclouvain.be & \\
\hline source & & MERIS FR L1B, MERIS RR L1B, & $\begin{array}{l}\text { Source of the original } \\
\text { data }\end{array}$ \\
\hline history & & $\begin{array}{l}\text { Ic-mosaic-1.1 } \\
\text { Ic-compositing-1.0 } \\
\text { Ic-stratification-1.0 } \\
\text { Ic-classification-1.0 } \\
\text { Ic-labeling-1.0 }\end{array}$ & $\begin{array}{l}\text { List of applications } \\
\text { that have modified } \\
\text { the surface } \\
\text { reflectance } \\
\text { composites, with time } \\
\text { stamp, processor and } \\
\text { parameters }\end{array}$ \\
\hline comment & & & $\begin{array}{l}\text { Miscellaneous } \\
\text { information about the } \\
\text { data or method used } \\
\text { to produce it }\end{array}$ \\
\hline Conventions & & CF-1.6 & $\begin{array}{l}\text { Name of the } \\
\text { conventions followed }\end{array}$ \\
\hline type & & LCMap-300m & Product type \\
\hline date_created & $\begin{array}{l}\text { yyyy-MM- } \\
\text { dd'T'HH:mm:ss'Z' }\end{array}$ & e.g " 20130424T124732Z" & $\begin{array}{l}\text { Creation time of } \\
\text { product }\end{array}$ \\
\hline creator_name & & UCL-Geomatics & \\
\hline creator_url & & http://www.uclouvain.be/elie.html & \\
\hline creator_email & & Pierre.Defourny@uclouvain.be & \\
\hline epoch & YYYY & $\begin{array}{l}{[Y Y Y Y] \text { where the two "YYYY" are the year }} \\
\text { of the product }\end{array}$ & Year of the product, \\
\hline geospatial_lat_min & $-90.0 \ldots 90.0$ & & $\begin{array}{l}\text { South border of the } \\
\text { bounding box }\end{array}$ \\
\hline geospatial_lat_max & $-90.0 \ldots 90.0$ & & $\begin{array}{l}\text { North border of the } \\
\text { bounding box }\end{array}$ \\
\hline geospatial_lon_min & $-180.0 \ldots 180.0$ & & $\begin{array}{l}\text { West border of the } \\
\text { bounding box }\end{array}$ \\
\hline geospatial_lon_max & $-180.0 \ldots 180.0$ & & $\begin{array}{l}\text { East border of the } \\
\text { bounding box }\end{array}$ \\
\hline geospatial_lat_min & $-90.0 \ldots 90.0$ & & $\begin{array}{l}\text { South border of the } \\
\text { bounding box }\end{array}$ \\
\hline geospatial_lat_units & & degrees_north & \\
\hline geospatial_lat_ & & e.g " 0.002778 " & \\
\hline
\end{tabular}




\begin{tabular}{|c|c|c|c|c|}
\hline \multirow{2}{*}{ CeSa } & Ref & \multicolumn{3}{|c|}{ CCI LC PUG v2 } \\
\cline { 2 - 5 } & Issue & Page & Date & Iand couer \\
\cline { 2 - 5 } & 2.0 & 93 & $2017-03-31$ & cci \\
\hline
\end{tabular}

\begin{tabular}{|l|l|l|l|}
\hline \multicolumn{1}{|c|}{ Attribute Name } & \multicolumn{1}{|c|}{ Format } & \multicolumn{1}{c|}{ Value } & Description \\
\hline resolution & & & \\
\hline geospatial_lon_units & & degrees_east & \\
\hline
\end{tabular}

The variables and variables' attributes of the global 7-day SR NetCDF file are presented in Table $10-5$.

Table 10-5: Variables and variables' attributes of the global LC maps delivered by the CCI-LC project, according to the structure of the NetCDF files

\begin{tabular}{|c|c|c|c|c|}
\hline Variable & Attribute & Format & Value & Description \\
\hline \multirow[t]{8}{*}{ crs } & & int & & $\begin{array}{l}\text { Coordinate } \\
\text { reference } \\
\text { system } \\
\text { attribute } \\
\text { container }\end{array}$ \\
\hline & grid_mapping_name & & Plate Carrée & \\
\hline & semi_major_axis & & 6378137.0 & \\
\hline & inverse flattening & & 298.257223563 & \\
\hline & false_easting & & 0.0 & \\
\hline & false_northing & & 0.0 & \\
\hline & longitude_of_central_meridian & & 0.0 & \\
\hline & $\begin{array}{l}\text { scale_factor_at_central_meridia } \\
\mathrm{n}\end{array}$ & & 1.0 & \\
\hline \multirow[t]{4}{*}{ time } & & double(time) & & $\begin{array}{l}\text { Start time } \\
\text { of the multi- } \\
\text { year period }\end{array}$ \\
\hline & standard_name & & time & \\
\hline & long_name & & multi-year period & \\
\hline & units & & year & \\
\hline \multirow[t]{6}{*}{ Ion } & & double (Ion) & -180.0 .. 180.0 & $\begin{array}{l}\text { Longitude } \\
\text { coordinate } \\
\text { of image } \\
\text { column }\end{array}$ \\
\hline & standard_name & & longitude & \\
\hline & long_name & & $\begin{array}{l}\text { WGS84 longitude } \\
\text { coordinate }\end{array}$ & \\
\hline & units & & degrees east & \\
\hline & valid_min & & -180.0 & \\
\hline & valid_max & & 180.0 & \\
\hline \multirow[t]{3}{*}{ lat } & & double (lat) & $-90.0 . .90 .0$ & $\begin{array}{l}\text { Latitude } \\
\text { coordinate } \\
\text { of image } \\
\text { row }\end{array}$ \\
\hline & standard_name & & latitude & \\
\hline & long_name & & $\begin{array}{l}\text { WGS84 latitude } \\
\text { coordinate }\end{array}$ & \\
\hline
\end{tabular}




\begin{tabular}{|c|c|c|c|c|}
\hline \multirow{2}{*}{ CeSa } & Ref & \multicolumn{3}{|c|}{ CCI LC PUG v2 } \\
\cline { 2 - 5 } & Issue & Page & Date & 2017-03-31 \\
\cline { 2 - 5 } & 2.0 & 94 & Iand couer \\
\hline
\end{tabular}

\begin{tabular}{|c|c|c|c|c|}
\hline Variable & Attribute & Format & Value & Description \\
\hline & units & & degrees north & \\
\hline & valid_min & & -90.0 & \\
\hline & valid_max & & 90.0 & \\
\hline \multirow[t]{7}{*}{ Ic_classif_Icss } & & byte (lat,lon) & & $\begin{array}{l}\text { LC } \\
\text { classificatio } \\
\mathrm{n} \text { in LCCS }\end{array}$ \\
\hline & standard_name & & land cover & \\
\hline & long_name & & LC class defined in LCCS & \\
\hline & vocabulary & & UN-LCCS 2005 & \\
\hline & valid_min & & 1 & \\
\hline & valid_max & & 240 & \\
\hline & _FillValue & & $0 \mathrm{~b}$ & \\
\hline \multirow[t]{6}{*}{$\begin{array}{l}\text { Ic_quality_flag_ } \\
1\end{array}$} & & byte (lat,lon) & & $\begin{array}{l}\text { LC map } \\
\text { quality flag } \\
\text { 1: pixel } \\
\text { processed } \\
\text { or not } \\
\end{array}$ \\
\hline & standard_name & & land_cover status_flag & \\
\hline & long_name & & $\begin{array}{l}\text { LC map processed area } \\
\text { flag }\end{array}$ & \\
\hline & valid_min & & 0 & \\
\hline & valid_max & & 1 & \\
\hline & FillValue & & $-1 b$ & \\
\hline \multirow[t]{6}{*}{$\begin{array}{l}\text { Ic_quality_flag } \\
2\end{array}$} & & byte (lat,lon) & & $\begin{array}{l}\text { LC map } \\
\text { quality flag } \\
\text { 2: pixel } \\
\text { status }\end{array}$ \\
\hline & standard_name & & land_cover status_flag & \\
\hline & long_name & & LC map area type mask & \\
\hline & valid_min & & 0 & \\
\hline & valid_max & & 6 & \\
\hline & _FillValue & & $-1 b$ & \\
\hline \multirow[t]{8}{*}{$\begin{array}{l}\text { Ic_quality_flag_ } \\
3\end{array}$} & & $\begin{array}{l}\text { short(lat,long } \\
\text { ) }\end{array}$ & & $\begin{array}{l}\text { LC map } \\
\text { quality flag } \\
\text { 3: number } \\
\text { of valid } \\
\text { observation } \\
\mathrm{s}\end{array}$ \\
\hline & standard_name & & $\begin{array}{l}\text { land_cover } \\
\text { number_of_observation } \\
\mathrm{s}\end{array}$ & \\
\hline & long_name & & $\begin{array}{l}\text { number of valid } \\
\text { observations }\end{array}$ & \\
\hline & valid_min & & 0 & \\
\hline & valid_max & & 32767 & \\
\hline & FillValue & & $-1 s$ & \\
\hline & _FillValue & & $-1 b$ & \\
\hline & scale_factor & & $0.01 \mathrm{f}$ & \\
\hline
\end{tabular}




\begin{tabular}{|c|c|c|c|c|}
\hline \multirow{2}{*}{ CeSa } & Ref & \multicolumn{3}{|c|}{ CCI LC PUG v2 } \\
\cline { 2 - 5 } & Issue & Page & Date & Iand couer \\
\cline { 2 - 5 } & 2.0 & 95 & $2017-03-31$ & cci \\
\hline
\end{tabular}

\begin{tabular}{|c|c|c|c|c|}
\hline Variable & Attribute & Format & Value & Description \\
\hline \multirow[t]{6}{*}{ Ic_quality_flag_ } & & byte(lat,long) & & $\begin{array}{l}\text { LC map } \\
\text { quality flag } \\
4: \text { LC map } \\
\text { confidence } \\
\text { level }\end{array}$ \\
\hline & standard_name & & $\begin{array}{l}\text { land_cover } \\
\text { confidence_level }\end{array}$ & \\
\hline & long_name & & $\begin{array}{l}\text { LC map confidence level } \\
\text { based on product } \\
\text { validation }\end{array}$ & \\
\hline & valid_min & & 0 & \\
\hline & valid_max & & 100 & \\
\hline & FillValue & & $-1 b$ & \\
\hline \multirow[t]{6}{*}{$\begin{array}{l}\text { Ic_quality_flag_ } \\
5\end{array}$} & & byte(lat,long) & & $\begin{array}{l}\text { LC map } \\
\text { quality flag } \\
5: \text { change } \\
\text { confidence } \\
\text { level }\end{array}$ \\
\hline & standard_name & & $\begin{array}{l}\text { change } \\
\text { confidence_level }\end{array}$ & \\
\hline & long_name & & $\begin{array}{l}\text { Change confidence level } \\
\text { based on change } \\
\text { detection module }\end{array}$ & \\
\hline & valid_min & & 0 & \\
\hline & valid_max & & 100 & \\
\hline & FillValue & & $-1 b$ & \\
\hline
\end{tabular}




\begin{tabular}{|c|c|c|c|c|}
\hline \multirow{2}{*}{ CeSa } & Ref & \multicolumn{2}{|c|}{ CCI LC PUG v2 } \\
\cline { 2 - 5 } & Issue & Page & Date & 2017-03-31 \\
\cline { 2 - 5 } & 2.0 & 96 & Iand couer \\
cci
\end{tabular}

\section{APPENDIX 3 - METADATA}

\section{- NDVI seasonality product}

The following attributes are included in all 4 series of products (AggOcc, Std, NYearObs and Status). Fields named "Files", "Data set", "Description", "Scaling factor" and "Valid values range" vary according to the layer of interest. It follows the CCI guidelines [RD.17].

The following metadata concerning the NDVI status layer is proposed as an example.

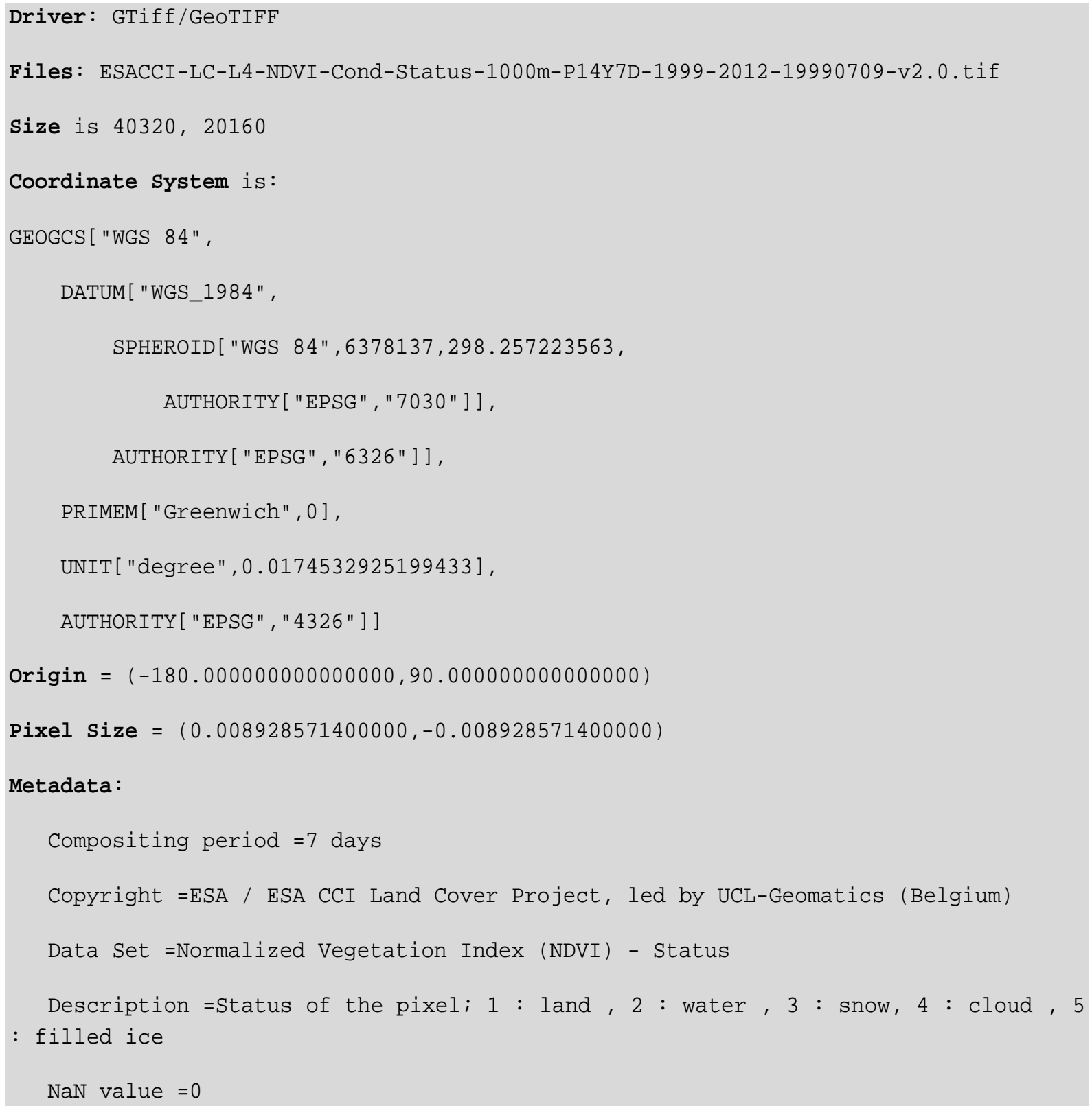




\begin{tabular}{|c|c|c|c|c|}
\hline \multirow{2}{*}{ CeSa } & Ref & \multicolumn{2}{|c|}{ CCI LC PUG v2 } & Date \\
\cline { 2 - 5 } & Issue & Page & $2017-03-31$ & $\begin{array}{l}\text { land couer } \\
\text { cci }\end{array}$ \\
\cline { 2 - 5 } & 2.0 & 97 &
\end{tabular}

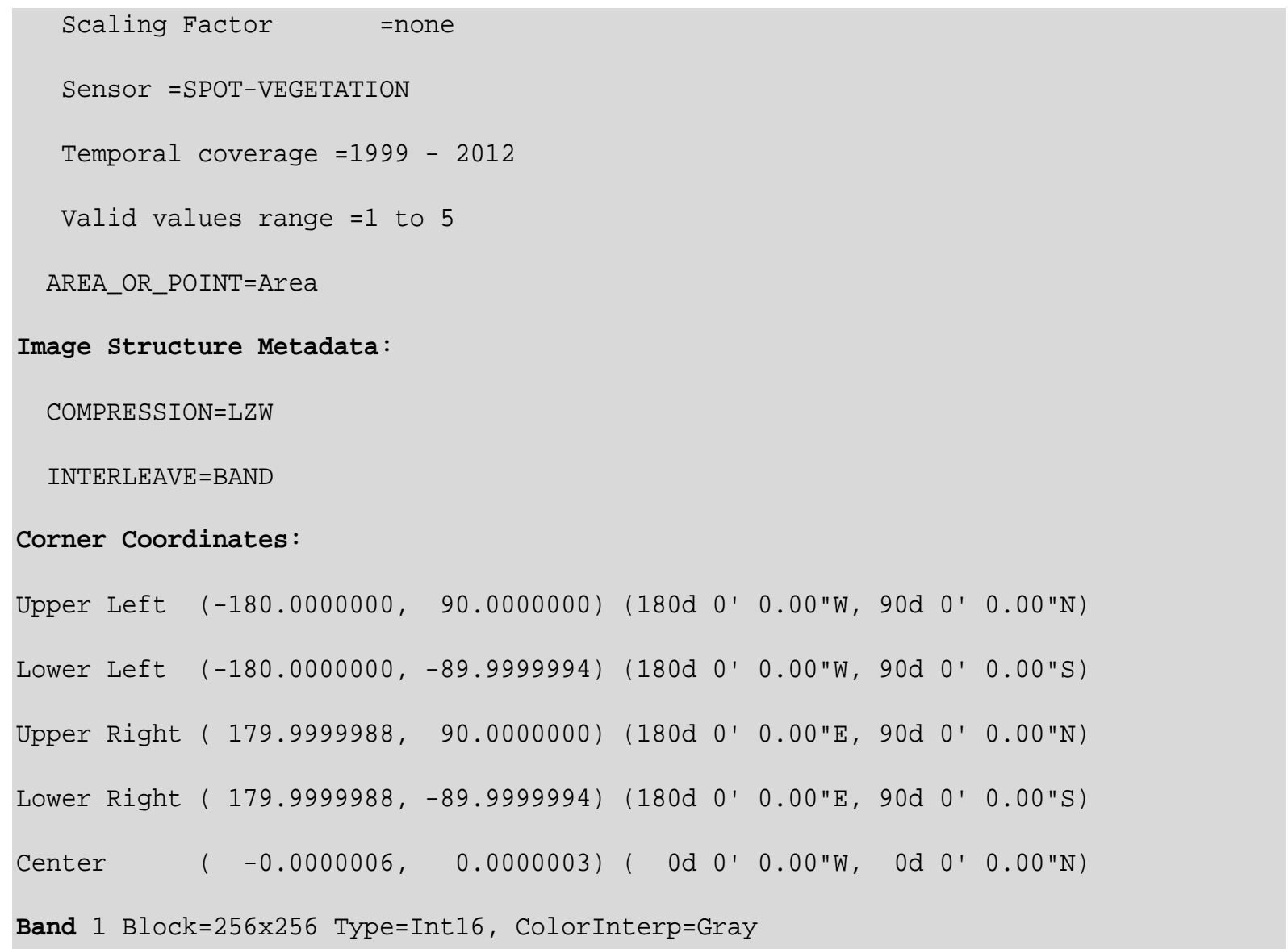

\section{- Open water body product}

The following attributes are included in the layers of the product. It follows the CCI guidelines [RD.17].

The metadata of the WB-Map layer v3.0 is proposed as an example.

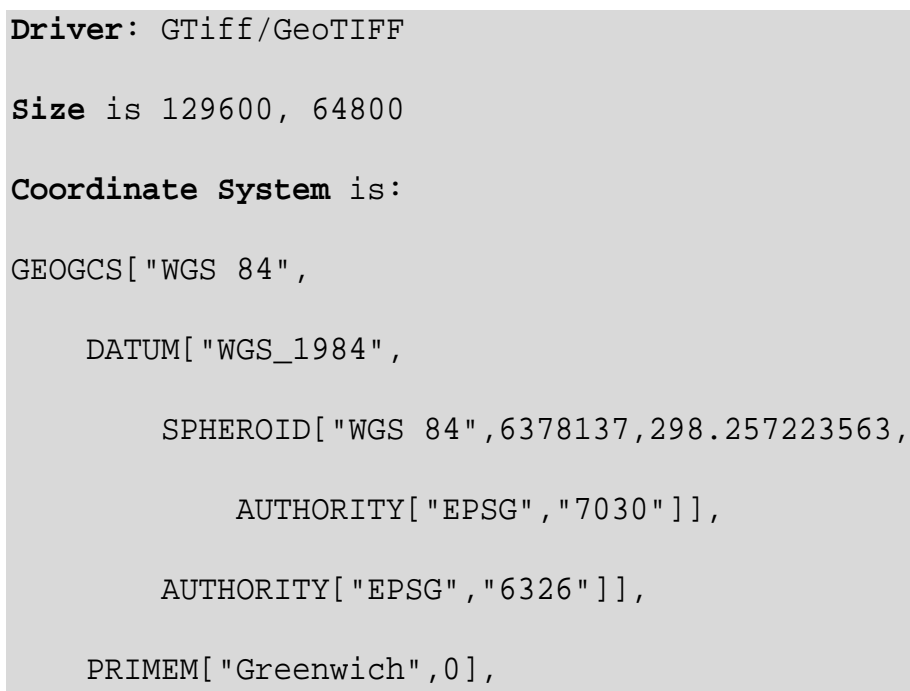




\begin{tabular}{|c|c|c|c|c|}
\hline \multirow{2}{*}{ e ESa } & Ref & \multicolumn{2}{|c|}{ CCI LC PUG v2 } & Date \\
\cline { 2 - 5 } & Issue & Page & $2017-03-31$ & land couer \\
& 2.0 & 98 & cci \\
\hline
\end{tabular}

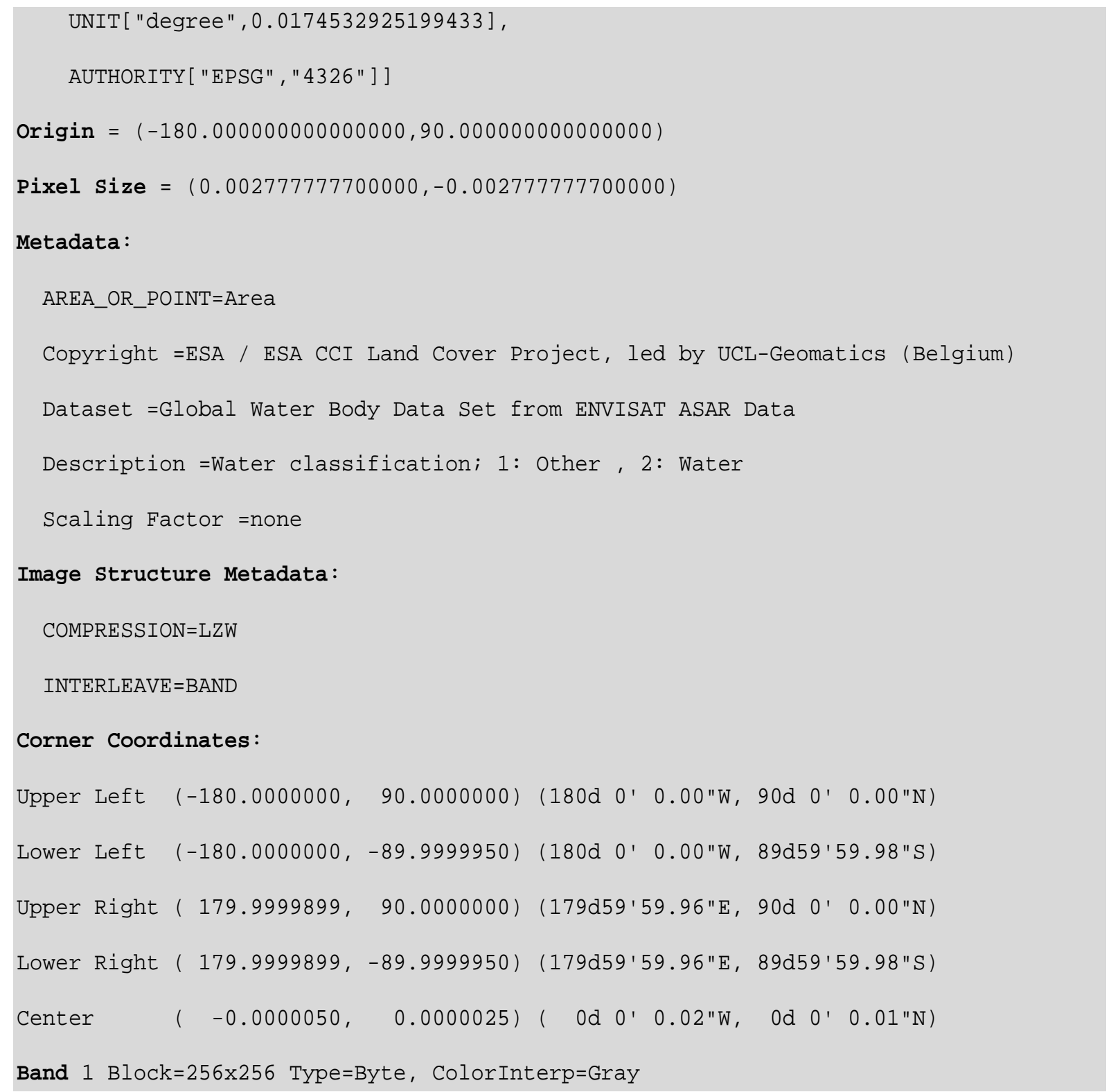




\begin{tabular}{|c|c|c|c|c|}
\hline \multirow{2}{*}{ CeSa } & Ref & \multicolumn{2}{|c|}{ CCI LC PUG v2 } \\
\cline { 2 - 4 } & Issue & Page & Date & 2017-03-31 \\
\cline { 2 - 5 } & 2.0 & 99 & Iand couer \\
cci
\end{tabular}

\section{APPENDIX 4 - INSTRUCTION MANUAL OF THE AGGREGATION TOOL}

\section{CCI-LC User Tools}

Version: 3.11

Release: 2017/01/11

Summary

This set of tools (conversion tool, aggregation tool, subset tool) prepares data for model computation.

General Note

The target files are always written in NetCDF-4 (enhanced model) file format.

If the NetCDF-4 Classic file format is needed the standard nccopy tool can be used for conversion.

When the REGULAR_GAUSSIAN_GRID is chosen as target grid and a regional subset which crosses the prime meridian is also defined the aggregation or the subsetting process will not work. This affects the predefined regions WESTERN_EUROPE_AND_MEDITERRANEAN and AFRICA.

Installation

As a prerequisite the CCI-LC User Tools require an installed Java SE 64Bit JRE version 7 or higher on the system. It can be obtained from the web page at http://www.oracle.com/technetwork/java/javase/downloads/index.html.

1) Unzip the zip-file in a directory of your choice.

2) Inside the unzipped directory you can find a folder which is named 'bin'.

Inside you can find the windows and unix start scripts for the CCI-LC tools.

Execution

All provided scripts are available in windows (*.bat) and unix (*.sh) versions.

The scripts need to be invoked from the command line. Navigate to the bin directory of the folder where you have unpacked the tools to. Write the command as described as follows.

Conversion Tool Usage (converts Tiff to NetCDF-4 files)

convert(.sh/.bat) - PtargetDir=<dirPath $><$ pathToMapTifFile|pathToConditionTifFile $>$

In case of a CCI-LC Map file the corresponding flag files must be in the same directory as the Map file. They are automatically detected and added to the output NetCDF-4 file.

For an alternative map the corresponding QF1 and QF2 files, as well as the qualityflag3 and qualityflag4 files of the original Map must be in the same directory.

If a condition product shall be converted the AggMean tif file must be provided as source. All the associated variables (AggMean, Std, Status and NYearObs) are considered and integrated into the output NetCDF-4 file if they reside in the same folder as the source tif file. transmitted without the express prior written authorization of UCL-Geomatics (Belgium). 


\begin{tabular}{|c|c|c|c|c|}
\hline \multirow{2}{*}{ CeSa } & Ref & \multicolumn{3}{|c|}{ CCI LC PUG v2 } \\
\cline { 2 - 5 } & Issue & Page & Date & Iand couer \\
\cline { 2 - 5 } & 2.0 & 100 & $2017-03-31$ & cci \\
\hline
\end{tabular}

Parameter Description:

-PtargetDir=<dirPath>

Specifies the directory where the target will be written. If this parameter is omitted the directory of the source file is used. The target is written as NetCDF-4 file.

If already a file with the same name/path exists, it will be overwritten.

(see "Output File Naming Convention" )

Aggregation Tool Usage

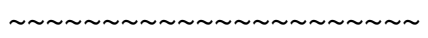

CCI-LC Condition Products

aggregate-cond(.sh/.bat) - PgridName $=<$ name $>-$ PnumRows $=<$ integer $>$

-PtargetDir $=<$ dirPath $><$ sourceFilePath $>$

Parameter Description:

- PgridName $=<$ name $>$

Specifies the target grid of the resulting product. This is a mandatory parameter.

Valid parameters are: GEOGRAPHIC_LAT_LON and REGULAR_GAUSSIAN_GRID.

-PnumRows=<integer>

Specifies the number of rows for the specified grid.

Default ist 2160 rows. A grid with the default number of rows leads to a resolution of

$\sim 9.8 \mathrm{~km} /$ pixel in the target product.

For a REGULAR_GAUSSIAN_GRID only the following values are valid:

$32,48,80,128,160,200,256,320,400,512,640$

-PpredefinedRegion $=\langle$ regionName $>$

Specifies one of the available predefined regions. This is an optional value.

If a predefined region is given it has precedence over the user defined region (north, east, ...)

Valid Values are: NORTH_AMERICA, CENTRAL_AMERICA, SOUTH_AMERICA, WESTERN_EUROPE_AND_MEDITERRANEAN, ASIA, AFRICA, SOUTH_EAST_ASIA, AUSTRALIA_AND_NEW_ZEALAND, GREENLAND

- Pnorth $=<$ degree $>$

Specifies north bound of the regional subset. This is an optional value

-Peast $=<$ degree $>$

Specifies east bound of the regional subset. This is an optional value

-Psouth $=<$ degree $>$

Specifies south bound of the regional subset. This is an optional value

-Pwest $=<$ degree $>$

Specifies west bound of the regional subset. This is an optional value

-PtargetDir=<dirPath $>$

Specifies the directory where the target will be written. If this parameter is omitted the directory

of the source file is used. It is written as NetCDF-4 file.

If already a file with the same name/path exists, it will be overwritten.

(see "Output File Naming Convention" )

<sourceFilePath>

Is the path to the source NetCDF-4 file.

CCI-LC WB Products

aggregate- $\mathrm{wb}(. \mathrm{sh} /$.bat $)-$ PoutputWbClasses $=<$ boolean $>$-PnumMajorityClasses $=<$ integer $>$

- PgridName $=\langle$ name $>-$ PnumRows $=\langle$ integer $>-$ PtargetDir $=\langle$ dirPath $\rangle\langle$ sourceFilePath $\rangle$

Parameter Description:

-PoutputWbClasses=<boolean $>$ 


\begin{tabular}{|c|c|c|c|c|}
\hline \multirow{2}{*}{ CeSa } & Ref & \multicolumn{2}{|c|}{ CCI LC PUG v2 } & Date \\
\cline { 2 - 5 } & Issue & Page & $2017-03-31$ & $\begin{array}{l}\text { land couer } \\
\text { cci }\end{array}$ \\
\cline { 2 - 5 } & 2.0 & 101 &
\end{tabular}

Whether or not to add the WB class areas to the output. The default is true

-PnumMajorityClasses $=$ <integer $>$

The number of majority classes generated and added to the output. The default is 2 .

- PgridName $=<$ name $>$

Specifies the target grid of the resulting product. This is a mandatory parameter.

Valid parameters are: GEOGRAPHIC_LAT_LON and REGULAR_GAUSSIAN_GRID.

-PnumRows $=<$ integer $>$

Specifies the number of rows for the specified grid.

Default ist 2160 rows. A grid with the default number of rows leads to a resolution of

$\sim 9.8 \mathrm{~km} /$ pixel in the target product.

For a REGULAR_GAUSSIAN_GRID only the following values are valid:

$32,48,80,128,160,200,256,320,400,512,640$

-PpredefinedRegion $=<$ regionName $>$

Specifies one of the available predefined regions. This is an optional value.

If a predefined region is given it has precedence over the user defined region (north, east, ...)

Valid Values are: NORTH_AMERICA, CENTRAL_AMERICA, SOUTH_AMERICA, WESTERN_EUROPE_AND_MEDITERRANEAN, ASIA, AFRICA, SOUTH_EAST_ASIA, AUSTRALIA_AND_NEW_ZEALAND, GREENLAND

-Pnorth $=<$ degree $>$

Specifies north bound of the regional subset. This is an optional value

-Peast $=$ <degree>

Specifies east bound of the regional subset. This is an optional value

-Psouth $=$ <degree>

Specifies south bound of the regional subset. This is an optional value

-Pwest=<degree>

Specifies west bound of the regional subset. This is an optional value

-PtargetDir $=<$ dirPath $>$

Specifies the directory where the target will be written. If this parameter is omitted the directory

of the source file is used. It is written as NetCDF-4 file.

If already a file with the same name/path exists, it will be overwritten.

(see "Output File Naming Convention" )

<sourceFilePath>

Is the path to the source NetCDF-4 file.

CCI-LC Map Products

aggregate-map(.sh/.bat) - PgridName $=<$ name $>-$ PnumRows $=<$ integer $>$

-PoutputLCCSClasses $=<$ boolean $>$-PnumMajorityClasses $=<$ integer $>$

-PoutputPFTClasses $=\langle$ boolean $>$-PuserPFTConversionTable $=\langle$ filePath $\rangle$

-PadditionalUserMap $=<$ filePath $>$-PoutputUserMapClasses $=<$ boolean $>$

-PadditionalUserMapPFTConversionTable $=\langle$ filePath $\rangle$

-PoutputAccuracy $=\langle$ boolean $>$

-PtargetDir $=<$ dirPath $><$ sourceFilePath $>$

Parameter Description:

For a description of the common aggregation parameters please have a look into the above section for the CCI-LC Condition Products. In addition for the aggregation of the CCI-LC Map Products the following parameters exist:

-PoutputLCCSClasses $=<$ boolean $>$

Specifies whether the LCCS classes shall be added to the output. This parameter can be omitted. The default is true.

-PnumMajorityClasses $=<$ integer $>$

Specifies the number of majority classes in the output. This parameter can be

omitted, in this case the default (5) is used. A value of 1 will produce an output with 


\begin{tabular}{|c|c|c|c|c|}
\hline \multirow{2}{*}{ CeSa } & Ref & \multicolumn{2}{|c|}{ CCI LC PUG v2 } & Date \\
\cline { 2 - 5 } & Issue & Page & $2017-03-31$ & $\begin{array}{l}\text { land couer } \\
\text { cci }\end{array}$ \\
\cline { 2 - 5 } & 2.0 & 102 &
\end{tabular}

just the majority class.

-PoutputPFTClasses $=<$ boolean $>$

Specifies if a conversion to PFT classes shall be performed and the result added to the output. This parameter can be omitted. The default is true.

-PuserPFTConversionTable $=\langle$ filePath $\rangle$

Specifies the path to a user defined PFT conversion table. If not given the default

CCI-LC conversion table will be used. For a description of the file format see further down.

-PadditionalUserMap $=<$ filePath $>$

A map containing additional classes which can be used to refine the conversion from

LCCS to PFT classes.

-PoutputUserMapClasses $=<$ boolean $>$

Whether or not to add the classes of the user map to the output.

This option is only applicable if the additional user map is given too.

-PadditionalUserMapPFTConversionTable $=\langle$ filePath $\rangle$

The conversion table from LCCS to PFTs considering the additional user map.

This option is only applicable if the additional user map is given too.

-PoutputAccuracy=<boolean>

Specifies the computation of the accuracy shall be performed and the result added to the

output. This parameter can be omitted. The default is true.

<sourceFilePath>

Is the path to the source NetCDF-4 file.

A real example might look like the following:

aggregate-map $($. sh/.bat) -PgridName=REGULAR_GAUSSIAN_GRID - PnumRows=320

-PoutputLCCSClasses=false - PnumMajorityClasses $=3$

-PpredefinedRegion=AUSTRALIA_AND_NEW_ZEALAND

2010-v2.nc"

-PtargetDir="/data/CCI-LC/output/" "/data/CCI-LC/ESACCI-LC-L4-LCCS-Map-300m-P5Y-

The PFT (Plant Functional Type) conversion table

The table, also known as Cross Walking Table, describes the conversion of the LCCS classes to PFTs.

The file can start with an optional comment. If the comment is used the first line must start with '\#' in

order to indicate the comment. Multiple lines are not supported. The comment ('pft_table_comment') is included as an attribute into the NetCDF output file.

The actual PFT table starts with a table header. Each column of the header defines one PFT except the first. The first column is for the LCCS class indices.

The subsequent data rows, one for each LCCS class, define the conversion from corresponding class to the PFTs. Each cell specifies the percentage of the PFT, floating point values can be used. Zero percentage can be omitted. Columns are separated with the pipe ('|') symbol and the column header names are used as band names.

Example:

\# An optional comment describing the conversion table

LCCS Class|Tree Broadleaf Evergreen|...|Managed Grass|Bare soil|Water|Snow/Ice|No data

$0\|\ldots\||\|| \mid 100$

10||$. .|100||| \mid$

$11\|. .|100|\| \mid$

$12\|. .|50|\| \mid$

$20\|. . .100|\||$

$30|5| . . .60||||$

$40|5| \ldots|25| 40|| \mid$

...

220||$\ldots|||| 100 \mid$ 


\begin{tabular}{|c|c|c|c|c|}
\hline \multirow{2}{*}{ e ESa } & Ref & \multicolumn{2}{|c|}{ CCI LC PUG v2 } \\
\cline { 2 - 5 } & Issue & Page & Date & land couer \\
\cline { 2 - 5 } & 2.0 & 103 & $2017-03-31$ & cci \\
\hline
\end{tabular}

Subset Tool Usage

subset(.sh/.bat) - PpredefinedRegion=<regionName $>$-PtargetDir $=<$ dirPath $\rangle\langle$ sourceFilePath $\rangle$

or

subset(.sh/.bat) - Pnorth $=\langle$ degree $>-$ Peast $=\langle$ degree $>-$ Psouth $=\langle$ degree $>$

- Pwest $=<$ degree $>$-PtargetDir $=<$ dirPath $><$ sourceFilePath $>$

-PpredefinedRegion=<regionName $>$

Specifies one of the available predefined regions.

Valid Values are: NORTH_AMERICA, CENTRAL_AMERICA, SOUTH_AMERICA, WESTERN_EUROPE_AND_MEDITERRANEAN, ASIA, AFRICA, SOUTH_EAST_ASIA, AUSTRALIA_AND_NEW_ZEALAND, GREENLAND

-Pnorth $=<$ degree $>$

Specifies north bound of the regional subset.

-Peast $=<$ degree $>$

Specifies east bound of the regional subset. If the grid of the source product is REGULAR_GAUSSIAN_GRID

coordinates the values must be between 0 and 360 .

-Psouth $=<$ degree $>$

Specifies south bound of the regional subset.

-Pwest $=<$ degree $>$

Specifies west bound of the regional subset. If the grid of the source product is REGULAR_GAUSSIAN_GRID

coordinates the values must be between 0 and 360 .

-PtargetDir=<dirPath>

Specifies the directory where the target will be written. It is written as NetCDF-4 file.

If already a file with the same name/path exists, it will be overwritten.

(see "Output File Naming Convention" )

<sourceFilePath>

The source file to create a regional subset from.

In order to create a regional subset of a map, condition or aggregated product the subset tool can be used. As parameter either one of the predefined regions can be selected or the outer bounds of the desired region can be specified. The target file is written into the directory of the source file.

Classes Remapping Tool Usage

remap(.sh/.bat) - PuserPFTConversionTable $=\langle$ filePath $\rangle$

-PadditionalUserMap $=<$ filePath $>$

-PadditionalUserMapPFTConversionTable $=\langle$ filePath $>$

<sourceFilePath>

-PuserPFTConversionTable $=<$ filePath $>$

Specifies the path to a user defined PFT conversion table. If not given the default

CCI-LC conversion table will be used. For a description of the file format see further down.

-PadditionalUserMap $=<$ filePath $>$

A map containing additional classes which can be used to refine the conversion from

LCCS to PFT classes.

-PadditionalUserMapPFTConversionTable $=<$ filePath $\rangle$

The conversion table from LCCS to PFTs considering the additional user map. 


\begin{tabular}{|c|c|c|c|c|}
\hline \multirow{2}{*}{ e ESa } & Ref & \multicolumn{2}{|c|}{ CCI LC PUG v2 } \\
\cline { 2 - 5 } & Issue & Page & Date & land couer \\
\cline { 2 - 5 } & 2.0 & 104 & $2017-03-31$ & cci \\
\hline
\end{tabular}

This option is only applicable if the additional user map is given too. <sourceFilePath>

The source file to create a regional subset from.

This tool splits up the information found in the band "lccs_class" into the PFTs given via look-up table files.

The basis for the look-up table is the csv file provided as userPFTConversionTable.

If additionally the additionalUserMapPFTConversionTable csv file is specified, it is used to improve the conversion to PFTs by using the also the additionalUserMap. Usage'.

For an example of the userPFTConversionTable please have a look at the section 'Aggregation Tool

The additionalUserMapPFTConversionTable has a similar structure.

\# Koeppen-Geiger Map

LCCS_Class|Köppen_Geiger_Class|PFT_1|PFT_2|_PFT3|...|No_data

$10|11||||||||| 14|86|||||$

$10|12||||||||| 11|89||| \mid$

$10|13||||||||| 10|90|||||$

$10|14||||||||| 4|96||| \mid$

$10|21||||||||| 6|94||| \mid$

$10|22||||||||| 20|80||| \mid$

$10|26||||||||| 13|87||| \mid$

$20|11||||||||| 15|85||| \mid$

$20|12||||||||| 21|79||| \mid$

$20|26||||||||| 2|98||| \mid$

The first column is again the LCCS class, the second the class in the additional user map.

If one LCCS class, user class combination is missing the algorithm falls back to the

userPFTConversionTable, if given or to the defaults of the CCI-LC conversion table

Output File Naming Convention

Conversion Tool Output:

Map Product: $\quad$ ESACCI-LC-L4-LCCS-Map- $\{$ sRes $\}$ m-P $\{$ tRes $\}$ Y-\{epoch $\}-v\{$ versNr $\} . n c$

Condition Product: $\quad$ ESACCI-LC-L4-\{condition $\}$-Cond- $\{$ sRes $\}$ m-P $\{$ tRes $\} D-\{$ startY $\}\{$ MonthDay $\}-$ $\mathrm{v}\{$ versNr\}.nc

Split Points:

Map Product: $\quad$ ESACCI-LC-L4-LCCS-Map-\{sRes $\}$ m-P $\{$ tRes $\}$ Y-\{epoch $\}-v\{$ versNr $\} . n c$

$\hat{\mid---S p l i t ~ P o s i t i o n ~}$

Condition Pr.: ESACCI-LC-L4-\{condition $\}$-Cond- $\{$ sRes $\}$ m-P $\{$ tRes $\}$ D- $\{$ startY $\}\{$ MonthDay $\}-v\{$ versNr $\} . n c$

--- Split Position

Examples Map Result:

Aggregation: 


\begin{tabular}{|c|c|c|c|c|}
\hline \multirow{2}{*}{ CeSa } & Ref & \multicolumn{3}{|c|}{ CCI LC PUG v2 } \\
\cline { 2 - 5 } & Issue & Page & Date & Iand couer \\
\cline { 2 - 5 } & 2.0 & 105 & $2017-03-31$ & cci \\
\hline
\end{tabular}

Input: ESACCI-LC-L4-LCCS-Map-300m-P5Y-2006-v2.nc

Output: ESACCI-LC-L4-LCCS-Map-300m-P5Y-aggregated-0.083333Deg-2006-v2.nc

Subset:

Input: ESACCI-LC-L4-LCCS-Map-300m-P5Y-aggregated-0.083333Deg-2006-v2.nc

Output: ESACCI-LC-L4-LCCS-Map-300m-P5Y-aggregated-0.083333Deg-EUROPE-2006-v2.nc Output: ESACCI-LC-L4-LCCS-Map-300m-P5Y-aggregated-0.083333Deg-ASIA-2006-v2.nc

Output: ESACCI-LC-L4-LCCS-Map-300m-P5Y-aggregated-0.083333Deg-USER_REGION-2006-v2.nc

Examples Condition Result:

Subset:

Input: ESACCI-LC-L4-NDVI-Cond-300m-P9Y7D-20010101-v2.nc

Output: ESACCI-LC-L4-NDVI-Cond-300m-P9Y7D-EUROPE-20010101-v2.nc

Output: ESACCI-LC-L4-NDVI-Cond-300m-P9Y7D-ASIA-20010101-v2.nc

Output: ESACCI-LC-L4-NDVI-Cond-300m-P9Y7D-USER_REGION-20010101-v2.nc 